\title{
LA MAQUINARIA FISCAL DEL PAPADO AVIÑONÉS EN LA CORONA DE ARAGÓN: LA COLECTORÍA DE BERENGUER RIBALTA $(1400-1402)$
}

\author{
THE FISCAL MACHINERY OF THE PAPACY OF AVIGNON \\ IN THE CROWN OF ARAGON: \\ THE COLLECTORATE OF BERENGUER RIBALTA (1400-1402)
}

\author{
JORDI MORELLÓ BAGET \\ Institución Milá y Fontanals \\ CSIC, Barcelona
}

\begin{abstract}
Resumen: Este artículo contiene el análisis de un registro de colectoría del Archivo Vaticano, a partir del cual es posible contabilizar todos los ingresos y gastos efectuados a lo largo de dos ejercicios contables por Berenguer Ribalta, prior del convento de Santa Ana de Barcelona, a raíz de su nombramiento como colector de la Corona de Aragón en septiembre de 1400. Por lo que respecta a los ingresos, las décimas ocupan un lugar principal, situándose bastante o muy por encima de otras tasas apostólicas (anatas, procuraciones, vacantes, expolios...), aunque todo ello quedaría distorsionado por la importante entrada que registra el obispado de Lleida, cuyas rentas revertieron íntegramente a favor de la Cámara Apostólica. Al margen de los gastos más ordinarios, es posible reconstruir los flujos de transferencia de dinero entre Barcelona y Aviñón a través de diversos cambistas, no sólo italianos, y sus respectivos socios barceloneses. La recaudación, sumando ambos ejercicios, se eleva a más de 31 mil lb.b., de las cuales casi 27 mil fueron transferidas a Aviñón, dejando el resto para gastos de gestión. Los resultados obtenidos de esta colectoría parecen ratificar la tesis según la cual la Corona de Aragón constituyó, después de Francia, el principal sostén financiero del papado aviñonés.
\end{abstract}

Palabras clave: Papado; Finanzas; Colectorías; Corona de Aragón; Iglesia, obispados.

\begin{abstract}
This article offers an analysis of one collectorate record of the Vatican Archive, from which it is possible to count all the incomes and the expenses made along two exercises by Berenguer Ribalta, prior of the convent of Santa Anna of Barcelona, since his nomination as taxman of the Crown of Aragon in September of 1400 . In relation to the incomes, the tenths represent the main entry: they are quite or very above other apostolic taxes (annates, procurations, fruits during vacancies, spoils...), although all this would be distorted by the important entry corresponding to the bishopric of Lleida, which rents totally reverted in favour of the Apostolic Chamber. In the chapter of the expenses, it is possible to rebuild the flows of money transfers between Barcelona and Avignon through several bankers, not only Italians, and their respective partners from the Catalan capital. The collection from both exercises amounts to 31 thousand pounds (in money from Barcelona), of which almost 27 thousand were transferred to Avignon, leaving the rest for expenses of management. The results obtained from this collectorate seem to ratify the thesis according to which the Crown of Aragon constituted, behind France, the main financial support of the papacy of Avignon.
\end{abstract}

Keywords: Papacy; Finances; Collectorates; Crown of Aragon; Church; Bishoprics. 


\section{SUMARIO}

1. Preámbulo.- 2. Las cuentas de la colectoría de la Corona de Aragón (1400-1402): 2.1. La organización de la colectoría administrada por B. Ribalta. 2.2. Los ingresos. 2.3. Los pagos. 3. Conclusiones.

\section{PREÁMBULO}

La Iglesia, y en particular el papado, impulsó el desarrollo precoz de un estado de las finanzas (como gustan decir los historiadores franceses), un estado sustentado más que nada en l'impôt, que adquirió un carácter regular antes incluso de que se regularizaran ciertos impuestos en algunas monarquías de la época ${ }^{1}$. Como es sabido, fueron los papas de Aviñón quienes más contribuyeron a la construcción de ese Estado financiero ${ }^{2}$. En Aviñón se produjo la transformación de la Iglesia en una monarquía pontificia (Y. Renouard) y en esta transformación debió desempeñar un papel de primer orden la fiscalidad, a imagen y semejanza de lo que sucedió en el ámbito de las monarquías coetáneas.

Ciertamente, la fiscalidad pontificia se abrió camino en circunstancias bastante similares a las que empujaron a las monarquías seculares a desarrollar sus respectivos sistemas fiscales: igual que éstas, que a partir de cierto momento ya no pudieron vivir de las rentas de sus bienes patrimoniales, tampoco el papado pudo sustentarse con los réditos obtenidos de sus dominios, sobre todo a partir del traslado de la sede pontificia a Aviñón (1309). Ello se tradujo en la búsqueda de nuevas fuentes de ingresos, con lo que se puso en pie - en relativamente pocos años- una potente maquinaria fiscal basada en el sistema beneficial eclesiástico. Fue durante el período aviñonés, y especialmente durante el pontificado de Juan XXII (1316-1334), cuando más avances se hicieron de cara al afianzamiento de esa fiscalidad y a su extensión a toda la Cristiandad. Durante aquel pontificado, se llevó a cabo la ampliación del sistema de reserva de beneficios, que suponía la intervención directa del papado en la provisión y nombramiento de los cargos eclesiásticos, a cambio de sustanciosas contraprestaciones económicas. Aunque ciertos impuestos no fueron creados por dicho pontífice, fue a instancias suyas que se generalizó

${ }^{1}$ Así se expresaba J. VERGER, Le transfert de modèles, d'organisation de l'Église à l'Etat à la fin du Moyen Age, en J-Ph. GENET; B. VINCENT, Etat et Eglise dans la genèse dè l'Etat Moderne, Madrid, 1986, p. 7.

${ }^{2}$ A este respecto, habría que aludir al congreso celebrado en Aviñón en 1988 con el título: $A u x$ origines de l'Etat Moderne: Le fonctionnement administratif de la papauté d'Avignon, cuyas actas fueron publicadas en 1990, con prólogo de Jean Favier y aportaciones de distintos autores, entre los cuales destacaría los de Jean-Daniel Morerod sobre las décimas en Francia y Fausto Piọla Casẹlli sobre la evolución de la contabilidad de la Cámara Apostólica en la época de referencia. Recientemente, cabe considerar una serie de aportaciones centradas en las reformas contables de la Cámara Apostólica de la primera mitad del s.XIV, todas ellas recogidas en la revista "Mélanges de l'Ecole française de Rome: Moyen Age", $118 / 2$ (2006), con introducción de V. THEIS; E. ANHEIM, La comptabilité des dépenses de la papauté au XIV siècle. Structure documentaire et usages de l'ecrit, pp. 165-168. 
el cobro de los mismos. Debemos destacar con énfasis la originalidad del sistema beneficial, un hecho diferencial de la administración pontificia que no tiene parangón posible con las administraciones de los soberanos seculares; en palabras de Jean Favier: c'est le poids des affaires beneficiales, sans équivalent dans les principautés temporelles, qui nourrit pour l'essentiel l'activité administrative et juridique de la papauté.

El traslado a Aviñón se manifestó en una férrea centralización eclesiástica -fenómeno, éste sí, paralelo a lo que sucedía en los estados seculares-, que implicó una importante renovación de las estructuras administrativas y burocráticas. Bajo el impulso de Juan XXII se reorganizó la Cámara Apostólica, organismo central de las finanzas pontificias, cuya dirección correspondía al camerarius [camarlengo] —-verdadero ministro de finanzas del papado (Mollat) - , asistido por un tesorero y un nutrido grupo de clérigos contables. Los gastos experimentaron en esta época un espectacular aumento, no sólo para el sustento de la diplomacia y la administración pontificias, sino también para sufragar la política edilicia (por ejemplo, la construcción del palacio de Aviñón, reformado a instancias de Benedicto XII y Clemente VI) y las necesidades militares, como la defensa de los estados pontificios. El desarrollo de la Cámara era consecuencia tanto del incremento de los gastos como de la aparición de nuevas fuentes de ingresos para hacerles frente. Además, los papas aviñoneses se rodearon de un grupo de mercaderesbanqueros, sobre todo florentinos, que colaboraban con la Cámara en operaciones de crédito y transferencia de capitales.

Desde Aviñón, se organizó un eficaz sistema de recaudación por toda la Cristiandad a través de una amplia red de colectores, convertidos en funcionarios permanentes desde la época de Clemente VI (1342-52). Éstos eran nombrados por el papa o por su camarero para un tiempo indeterminado. La Colectoría era la institución encargada de percibir una serie de derechos eclesiásticos debidos a la Cámara Apostólica ${ }^{3}$ así como también el nombre que recibía el territorio asignado a un colector para el desempeño de sus funciones, al cual estaban supeditados una serie de subcolectores (generalmente, una subcolectoría se correspondía con el territorio de una diócesis; en cambio, la colectoría podía abarcar dos o más reinos, una o más provincias eclesiásticas, provincias de un reino y diócesis de otro...). La importancia de las colectorías pontificias fue en aumento a lo largo del siglo XIV y su máximo desarrollo se daría en la segunda mitad de esta centuria.

En el organigrama del Archivo Vaticano, la Collectoria constituye una de las tres grandes series generadas por la Cámara Apostólica, junto a las denominadas Introitus et Exitus y Obligationes et Solutiones ${ }^{4}$. La primera serie

${ }^{3}$ No obstante, hay que advertir que no todos los ingresos de la Cámara Apostólica eran cobrados por los colectores; algunos, como los servicios comunes o las visitas ad limina, eran entregados directamente por los deudores respectivos; véase la clasificación sobre tasas cobradas en la misma corte pontificia y tasas percibidas en cada territorio de la Cristiandad, en $\mathrm{G}$. MOLlat, Les papes d'Avignon (1305-1378), Paris, 1964, pp. 530-39.

${ }^{4}$ Véase, entre otros, F. PIOLA CASELLI, L'espansione delle fonti finanziarie della Chiesa nel XIV secolo, "Archivio della Società Romana di Storia Patria", 110 (1987), pp. 63-98. 
documental está formada básicamente por los manuales redactados por un colector en los que se daba cuenta detallada de los ingresos y gastos efectuados durante su misión en una determinada circunscripción. Acabada la misión, y después de la necesaria rendición de cuentas, estos manuales pasaban a poder de la Cámara Apostólica. De hecho, los colectores confeccionaban dos o más ejemplares, uno de los cuales se entregaba a la Cámara para su examen y aprobación: correspondía al tesorero revisar las cuentas de los colectores, todo ello bajo la supervisión del Camarlengo, que era quien ejercía el control de las finanzas pontificias, o de su sustituto (vicecamarlengo).

Aunque existen numerosos estudios basados en los registros contables de la Cámara Apostólica, sólo algunos están relacionados más directamente con el análisis de las colectorías ${ }^{5}$. Por lo que se refiere a la Corona de Aragón, el estudio de estas fuentes no ha suscitado hasta el momento toda la atención que, sin duda, merecen ${ }^{6}$. Para la época medieval, hay, de hecho, pocas colectorías conservadas; algunas han sido estudiadas o transcritas parcialmente. En general, los escasos estudios disponibles se circunscriben a determinadas demarcaciones territoriales situadas bajo el dominio de los reyes de Aragón. Antes que nada, debemos referirnos a las cuentas publicadas (parcialmente) por G. Mollat a principios del siglo XX sobre el colector de la diócesis de Elna a partir de un registro del Archivo Vaticano (ASV, Fondo Camerale, Colectoría, n. ${ }^{\circ} 160$ ), coincidente más o menos con el periodo que voy a analizar ${ }^{7}$. La siguiente referencia que conozco corresponde al pequeño estudio realizado por J. Rius Serra en 1942 sobre un registro perteneciente al mismo fondo archivístico (n. ${ }^{\circ} 229$ ), donde figuran las cuentas del colector de la provincia tarraconense Almaraz de Cabrespí para los años anteriores a la Peste Negra (trabajo luego completado por J. Trenchs con otros documentos

\footnotetext{
${ }^{5}$ El pionero del tema fue J.-P. Kirsch, quién editó las colectorías alemanas del siglo XIV (Die päpstlichen Kollectorien in Deutschland waebrend des XIV Jahrhunderts, Paderborn, 1894). Siguieron después otros trabajos regionales, como los de U. BERLIERE, Les collectories pontificales dạns les anciens diòceses de Cambrai, Thérouanne et, Tournai au XIV siècle, "Analecta Vaticano-Belgica", X, 1929; J. GLÉNISSON, Documenti dell'archivio vaticano relativi alla collettoria di Sicilia, 1372-1375, "Rivista di storia della Chiesa in Italia", II (1948), pp. 225262; G. DESPY, Bruges et les collectories pontificales de Scandinavie et de Pologne au XIV siècle, "Bulletin de l'Institut historique belge de Rome", XXVII (1952), pp. 95-109; W.-E. LUNT, Papal revenues in the Middle Ages, 2 vol., New-York 1934; IDEM, Accounts rendered by Papal Collectors in England, 1317-1378, Philadelphie, 1968. Por otra parte, sigue siendo de obligada consulta el clásico estudio de J. Favier (Les finances pontificales à l'èpoque du grand schisme d'Occident (1378-1409), Paris, 1966), donde se proporciona una visión bastante a fondo de la evolución financiera del papado durante la ẹtapa del Cisma, en base a la consulta de una gran cantidad de fuentes del Archivo Vaticano, incluyendo un buen número de colectorías. Vease también Ch. SAMARAN; G. MOLLAT, La fiscalité pontificale en France au XIV siècle, Paris, 1968, caps. III, IV y V. Como estudio más reciente, podemos señalar ẹl de Ch. Schuchard sobre la figura del colector y la organización de las colectorías en el ámbito germano (Die päpstlichen Kollectoren im späten Mittelalter, Tübingen, 2000).

${ }^{6}$ Para tener una visión mucho más amplia sobre la producción hiștoriográfica, al menos de la existente hasta 2001, véase J. DÍAZ IBÁN̂EZ, El pontificado y los reinos peninsulares durante la Edad Media. Balance historiográfico, "En la España Medieval", 24 (2001), pp. 465-536, espec. pp. 476-78 y 491-92; o la más reciente síntesis de M $^{\mathrm{a}} \mathrm{N}$. MUNSUUR ROSADO, Clero e Iglesia en la Baja Edad Media hispánica: estado de la cuestión, "eHumanista”, 10 (2008), pp. 133-169.

${ }^{7} \mathrm{Cf}$. G. MOLLAT, Les comptes de Jean de Rivesaltes, collecteur apostolique dans le diòcese d'Elne, "Revue d'Histoire et d'Archéologie du Roussillon", V (1904), pp. 296-312, 373-388; VI (1905), pp. 22-32, 59-61.
} 
del Archivo Vaticano) ${ }^{8}$. Por otro lado, el citado J. Trenchs, aparte del estudio realizado como tesis doctoral sobre el sistema de colecta en la época de Benedicto XII, publicó la trascripción de un manual de colectoría relativo a Cerdeña, fechado entre 1396 y $1408^{9}$. La colectoría n. ${ }^{\circ} 122$ (idem), referida al periodo 1384-1387, que precede a la que aquí voy a estudiar, fue analizada muy sucintamente por P. Bertran, quien sólo tuvo en cuenta los datos generales relativos a los obispados catalanes ${ }^{10}$. A efectos comparativos, y aunque sea para época más tardía, resulta muy interesante el estudio realizado por J.M. Carretero sobre otra fuente de la Colectoría que abarca el periodo 1529-1546, cuando ya la Corona de Aragón tributaba a la Santa Sede junto con las diócesis de Castilla y Navarra ${ }^{11}$.

Como una aportación más a este tema tan escasamente estudiado, presento el análisis de la colectoría de Berenguer Ribalta (1400-1402). A través de ella podremos observar lo que aportaba la Iglesia de la Corona catalanoaragonesa a las finanzas pontificias.

\section{LAS CUENTAS DE LA COLECTORÍA DE LA CORONA DE ARAGÓN (1400-1402)}

En este trabajo, me baso fundamentalmente en el registro de colectoría n $^{\mathrm{o}} 123$ del fondo Camerale del Archivio Segreto Vaticano (ASV) de los años 1400-1402 (este periodo coincide con el encierro del papa en el palacio de Aviñón). Dicha colectoría estuvo a cargo de Berenguer Ribalta, entonces prior del convento de Santa Ana de Barcelona (de la orden del Santo Sepulcro), quien fue nombrado colector general de las provincias de Tarragona, Zaragoza y Reino de Mallorca según carta de comisión fechada el 25 de septiembre de 1400, transmitida por parte de Francesc Climent, que

${ }^{8} \mathrm{Cf}$. J. RIUS SERRA, La colectoría de Almaraz Cabrespí con el inventario de los bienes del obispo Ferrer Colom (1334-40), "Analecta Sacra Tarraconensia", XV (1942), pp. 362-396; J. TRENCHS, Dos colectores franceses, Ponc Teixidor y Almeraz de Cabrespí, en la Corona de Aragón, en XII Congrès d'Histoire de la Couronne d'Aragon, vol. 2, Montpellier, 1985, pp. 187201 .

${ }^{9} \mathrm{Cf}$. J. TRENCHS, La Cámara Apostólica y el reino de Aragón. Las colectorías papales bajo Benedicto XII, 3 vol., tesis doctoral inédita, Univ. de Barcelona, 1971; IDEM, El manuale della "Collectoria" di Mateo Rapaz in Sardegna (1396-1408), "Medioevo. Saggi e Rassegne", 8 (1983), pp. 71-109.

${ }^{10}$ Cf. P. BERTRAN, La fiscalitat eclesiàstica en els bisbats catalans (1384-1392). Tipologies impositives $i$ diferències territorials, "Acta Historica et Archaeologica Mediaevalia", 18 (1997), pp. 281-300.

${ }^{11}$ Cf. J.M. CARRETERO, La colectoría de España en época de Carlos V: cuentas del nuncio y colector general Giovanni Poggio (1529-1546), "Cuadernos de Historia de España", LXXVIII (2003-2004), pp. 103-135; del mismo autor, Las relaciones financieras entre España e Italia del siglo XV al XVI: el modelo de la Colectoría, en A. GALÁN (coord.), Fiscalidad y sociedad en el Mediterráneo Bajomedieval. Congreso Internacional (Málaga, 17-20 de mayo 2006), en prensa. Ya R. Carande hizo una primera incursión sobre las fuentes relativas a la gestión de Giovanni Poggio: véase R. CARANDE, La gestión del nuncio Juan Poggio, colector general de la Cámara Apostólica en España, "Boletín de la Real Academia de la Historia", CLXXV (1978), pp. 495532; véase también J.'FERNÁNDEZ ALONSO, Los enviados pontificios y la Colectoría en España de 1466 a 1475, "Anthologica Annua", 2 (1954), pp. 51-122, espec. pp. 80-85. 
a la sazón ejercía como vicario general del papa, y era hombre de confianza del papa Luna ${ }^{12}$.

El volumen en cuestión, en excelente estado de conservación y caligrafía también excelente, contiene dos ejercicios financieros, el primero, comprendido entre el 25 de septiembre de 1400 y el 24 del mismo mes de 1401 (fol. 7v-44v); el segundo, entre el 25 de septiembre de 1401 y el 24 del mismo mes de 1402 (46v-83r).

El primer ejercicio va precedido por la copia de las cuentas de Guillem Carbonell, canónigo de Barcelona, quien rigió la colectoría antes de Berenguer Ribalta ${ }^{13}$, y después de la muerte de Jaume de Ribes, preceptor de Mallorca ${ }^{14}$.

Primero se anotan los ingresos, especificando para cada diócesis las entradas correspondientes a vacantes, procurationes, decima y "comunitates"; siguen luego los gastos, con un primer apartado dedicado a los gastos comunes y un segundo donde se anotan todos los cambios o transferencias de dinero realizadas a favor de la Cámara Apostólica ${ }^{15}$. En cada ejercicio se incluyen otros apartados de recepte de carácter extraordinario, con algunos apartados más específicos, como el referido a entradas de expolios (recepte de spoliis prelatorum), inserto al final de la compartimentación por diócesis de 1400-01, o bien cierto apartado del siguiente ejercicio de 1401-02, donde se anotan ingresos procedentes de las rentas del obispado de Lleida, al margen, pues, de las entradas ordinarias obtenidas en esta diócesis.

\footnotetext{
${ }^{12}$ En el preámbulo del libro se alude a la bulla sive littera potestatis seu comissionis, aunque no se inserta copia de la misma. Aún así, sabemos que el nombramiento fue realizado el 4 del mismo mes y año por parte del abad de San Juan de la Peña, actuando éste como portavoz del camarero apostólico; documento reseñado en M. ROVIRA, Catàleg dels pergamins municipals de Barcelona. Anys 1396-1440, vol. III, Barcelona, 2008, pp. 54-56 (doc. n. ${ }^{\text {9 847). }}$

Respecto a Francesc Climent (o Clemente, suponiendo que fuera aragonés), véase el estudio de M. CANELlas, La Iglesia Colegiata de Santa María de los Corporales de Daroca y su prior don Francisco Clemente, según un vade-mecum inédito de 1397, Zaragoza, 1983; o el artículo que se le dedica en Diccionari d'história eclesiàstica de Catalunya, I, Barcelona, 1998, pp. 552553. Sucesivamente, fue ocupando diversos cargos episcopales: nombrado obispo de Mallorca en 1403, más tarde lo fue de Tortosa (1407-10), de Barcelona (1410-15), arzobispo de Zaragoza (entre 1415-19) y de nuevo obispo de Barcelona (1420-29), acabando sus últimos años al frente, otra vez, de la sede zaragozana. También ejerció como tesorero de la Cámara Apostólica (a partir de 1396).

${ }^{13} \mathrm{La}$ administración de G. Carbonell se iniciaba el 14 de junio de 1400 , pero no comenzó su labor realmente hasta el 25 de juliọ, finalizando el 25 de septiembre, cuandọ pasó a ser sustituido por Berenguer Ribalta. Estas primeras cuentas ocupan tan sólo los seis primeros folios del registro, con una primera parte dedicada a los ingresos percibidos en cada diócesis y otra parte donde se anotan los gastos y asignaciones hechas por dicho recaudador. Las cifras están expresadas en florines y sueldos barceloneses. Al final se anota el correspondiente saldo, que se traspasó a las cuentas propiamente dichas de B. Ribalta.

${ }^{14}$ Jaume de Ribes fue, antẹ que colector, subcolector del reino de Mallorca, y también ejerció como nuncio apostólico el mismo año en que se hizo cargo del oficio de colector (1394). Aparece citado en numerrosas, ocasiones en el compendio documental que realizó J. BAUCELLS, El fons "Cisma d'Occident" de l'Arxiu Capitular de la catedral de Barcelona. Catàleg de còdexs $i$ pergamins, Barcelona, 1985.

${ }^{15}$ Todo manual de colectoría debía constar de los siguientes apartados: en primer lugar, y después de la bula de nombramiento del colector, los ingresos ordenados por diócesis y materias; los gastos efectuados por el colector; cantidades pendientes de cobro; cambios de moneda; y, por último, el total entregado a la Cámara; cf. J. TRENCHS, La Cámara Apostólica y sus documentos $\left(1^{a}\right.$ mitad del siglo XIV), p. 652.
} 
Como es preceptivo en todo sistema contable, al pie de cada folio se indican las sumas resultantes. Se hacen luego otras anotaciones correspondientes a la suma de los ingresos de cada diócesis. Al final del apartado de ingresos, se hace compendio de todo lo consignado y se anota la suma total (fols. 37v y 76r). También en el apartado de gastos comunes se indica al final la suma resultante. Por lo que respecta a los cambios de moneda, se van sumando diversos ítems, para luego pasar a calcular el total correspondiente. Por último, se vuelven a anotar ambas sumas de ingresos y gastos de cara al establecimiento del saldo final del ejercicio (fols. 44v y 83r). En definitiva, el esquema descrito se corresponde completamente con el tipo de registro contable utilizado por las Administraciones Públicas ${ }^{16}$.

\subsection{La organización de la colectoría administrada por B. Ribalta}

La colectoría de la Corona de Aragón abarcaba un total de 14 diócesis que nos remiten a las siguientes divisiones eclesiásticas: por una parte, la provincia de Tarragona, que, además de la diócesis de la capital, comprendía las de Girona, Vic, Barcelona, Urgell, Lleida, Tortosa y Valencia ${ }^{17}$; y, por otra parte, la provincia de Zaragoza (segregada, desde 1318, de la de Tarragona): además de la diócesis de la capital, comprendía las de Huesca, Tarazona y Albarracín-Segorbe, y, fuera de la Corona de Aragón, las de Pamplona y Calahorra.

Cabe adjuntar, por otra parte, la diócesis catalana de Elna, que pertenecía a la provincia de Narbona, y la diócesis de Mallorca, que en esta época aún no estaba adscrita oficialmente a ninguna provincia, ya que desde su misma creación (s.XIII) pasó a depender directamente de la Santa Sede. Dentro de esta colecta se incluía el clero de Menorca, pero no el de Ibiza, que tributaba en la archidiócesis de Tarragona.

En suma, dicha colectoría abarcaba una provincia entera, más de la mitad de otra, la diócesis de otra provincia y una diócesis autónoma. Tal era, pues, la jurisdicción encomendada a los colectores generales de la región, quienes, para cada diócesis, tenían que nombrar subcolectores.

Berenguer Ribalta, en su función de colector general, fue desplazándose por los territorios peninsulares de la Corona de Aragón, yendo de una sede diocesana a otra, para reclamar el cobro de los diferentes exacciones que debía percibir en nombre de la Cámara Apostólica. La ruta que siguió la tenemos visualizada en los dos mapas del Apéndice, uno para cada ejercicio. [véase también la tabla A del Anexo]

Su periplo se inicia en Gerona, en octubre de 1400, ciudad a la que volvió al cabo de un año, después de haber pasado por Tortosa, Valencia,

\footnotetext{
${ }^{16} \mathrm{Y}$ que se contrapone al sistema de la partida doble comenzada a utilizar por los mercaderes en las cuentas de sus negocios; al respecto, véase E. HERNÁNDEZ ESTEVE, Reflexiones sobre la naturaleza y los orígenes de la contabilidad por partida doble, "Pecvnia", 1 (2005), pp. 93-124.

${ }^{17}$ Dentro de la diócesis de Valencia se hacía tributar por razón de anatas de hiis que Cartaginensis episcopus habet in regno Valencie (fol. 64r).
} 
Segorbe, Zaragoza, Lérida, Huesca, Urgell, Vic y también por Palafrugell, el único lugar que se cita que no era sede de ningún obispado. Parece que en Huesca hizo un viaje de ida y vuelta desde Lérida; lo mismo cabría decir de su estancia en Palafrugell, mientras estaba en Gerona. No estuvo, por tanto, ni en Tarazona, ni tampoco en otras sedes, al menos teóricamente, ya que podría deberse más bien a la falta de consignación en el libro. De lo que sí podemos estar seguros es que no estuvo en Mallorca.

En suma, la información recogida nos da una idea, por parcial que sea, de la ruta que siguió Ribalta, ruta que finalizó en Aviñón, en noviembre de 1401, donde liquidó ciertas cantidades con el abad de San Juan de la Peña [Pedro Ademar], como vicecamarlengo de la Cámara Apostólica.

De la ruta seguida durante el segundo año de su administración estamos mejor informados. A finales de noviembre, ya había iniciado la vuelta a Cataluña, puesto que se encontraba en Perpiñán. para seguir su camino hacia Gerona, pasando luego por Vic, Lleida, Tarragona, Tortosa, Valencia, Zaragoza y de nuevo en tierras catalanas: Tarragona, Lleida, Girona y Vic. Esta vez, no habría visitado la Seu de Urgell ni tampoco Segorbe, Huesca o Tarazona. Por lo que parece, de momento no volvió a viajar a Aviñón, a tenor de la transferencia realizada a dicha ciudad a propósito de la liquidación final del ejercicio.

Una vez más, a penas nada se indica de Barcelona, pese a que muchas de las operaciones derivadas de la gestión serían hechas en dicha ciudad; por ejemplo, en una ocasión se da cuenta de cierta cantidad que le fue enviada por un subcolector a Barcelona (fol. 52v), mientras que en otra ocasión declara haber recibido otra cantidad mientras estaba en Barcelona: dum fui Barchinone (fol. 14r). Aún sin contar con referencias expresas como ésta, parece deducible que muchas de las pagas anotadas en el libro fueron realizadas en la Ciudad Condal desde el momento que aparecen escrituradas ante notarios barceloneses ${ }^{18}$. Así pues, en los desplazamientos entre una u otra localidad, debió de hacer estancias en Barcelona, probablemente en el convento de la orden a la que pertenecía el susodicho colector.

Las rutas que siguió Ribalta, aunque fueran diferentes en el primero y el segundo año, guardan cierta relación con el orden en el que aparecen anotadas en sus cuentas las diferentes diócesis, iniciándose por el norte del Principado y siguiendo, alternativamente, dirección sur y oeste: en primer lugar Elna, seguida de Urgell, Girona, Vic, Barcelona, Tarragona, Lleida, Tortosa, Valencia, Segorbe, Zaragoza, Huesca y Tarazona, dejando Mallorca en último lugar.

Así pues, el itinerario, con una estancia en Aviñón de por medio, varió durante el primero y el segundo ejercicio: si, de una parte, se repiten las visitas de algunas sedes (Girona, Vic, Tortosa, Valencia, Zaragoza y Lleida),

\footnotetext{
${ }^{18}$ Incluso uno de ellos, Pere Brives, estuvo trabajando en la casa del colector: ....solvi discreto Petro Brives, notario Barchinone, pro diversis et multis laboribus sustentis in domo mea (fol. 77r).
} 
otras, en cambio, ya no llegaron a ser visitadas: tal es el caso de Tarazona, aparte de Mallorca.

Berenguer Ribalta viajó a lomos de una mula, pero, obviamente, no iba sólo. Uno de sus acompañantes sería Francesc Gener, notario apostólico, quien aparece redactando muchas de las ápocas expedidas en los diferentes pagos consignados ${ }^{19}$. Con todo, no tuvo que desplazarse en persona a todos los lugares donde debía formalizarse el cobro; algunas cantidades son recibidas por otras personas, como el ya conocido Guillem Carbonell, en un momento dado su sustituto, como lugarteniente, en el oficio de la colectoría; otras veces, figura Joan Ribalta (su hermano?) firmando ápocas en su ausencia. El mismo Francesc Gener también actuó en más de una ocasión como procurador suyo, en cuyo caso tales recibos eran firmados por otros notarios $^{20}$. Como procurador de Berenguer Ribalta, también se cita alguna vez a Pere Regaçol, presbítero de Barcelona (luego llegaría a ser canónigo en la misma sede), actuando principalmente en las diócesis de Vic, Urgell y Lleida.

Además de B. Ribalta o de sus representantes, en el libro de cuentas vemos desfilar un sinfín de personas, la mayoría subcolectores, aunque no todos tenían encomendada la misma tarea. Podemos distinguir tres tipos de subcolectores: los que se ocupaban de recaudar los derechos propiamente dichos de la Cámara Apostólica (anatas, procuraciones y demás); los que debían percibir las décimas, administradas aparte por ser un impuesto repartido entre el papado y la monarquía; y los que tenían a su cargo la recaudación de algún subsidio, cuya gestión también iba aparte. Dichos subcolectores podían entregar las cantidades recaudadas en su circunscripción bien personalmente o a través de intermediarios. Ello no obsta para que de vez en cuando se anoten cantidades directamente percibidas de algunos contribuyentes, sin que pasaran por las manos de los subcolectores o sus agentes ${ }^{21}$.

Desempeñando el oficio de subcolector encontramos (véase tabla B del Anexo) tanto canónigos como simples presbíteros, pasando por rectores y otros cargos eclesiásticos intermedios. Casi no hay miembros de órdenes, esto es, representantes del clero regular, excepto el subcolector de anatas y procuraciones en Zaragoza, Guerau Oger, que era prior del monasterio benedictino de San Pedro el Viejo, en la misma ciudad. Generalmente, se trata

\footnotetext{
${ }^{19}$ Francesc Gener siguió ejerciendo posteriormente como notario apostólico; el mismo intervino en el inventario del difunto obispo de Barcelona Francesc de Blanes, muerto en 1410, figurando entonces como rector de la parroquia de Onda, en la diócesis de Tortosa; cf. J. HERNANDO, El ius spolii papal $i$ els llibres eclesiàstics. Els llibres en les despulles del bisbe de Barcelona Francesc de Blanes $(\uparrow 1410)$, “Acta Historica et Archaeologica Mediaevalia”, 25 (2001), p. 390.

${ }^{20}$ El más citado es Pere Brives, notario barcelonés. Toda ápoca debía ser consignada por un notario, excepto cuando se recurría a la entrega de albaranes, redactados por el propio B. Ribalta. Estọs albạranes tenían que ser restituidos al colector en el caso de que la cantidad consignada hubiera sido computada finalmente en una ápoca redactada por un notario. Si no, quedaban en manos del interesado, sirviendo igualmente como comprobante de la cantidad entregada al colector.

${ }^{21}$ Como simple botón de muestra, podemos señalar la paga realizada por Alfons de Tous de $110 \mathrm{lb}$. por la anata de la iglesia de la Selva (en la diócesis de Tarragona) que había permutado con Guillem Carbonell (fol. 58v). En aquel entonces, el subcolector de Tarragona era Joan de Morelló, prior en la sede catedralicia.
} 
de eclesiásticos adscritos a la propia diócesis en donde se debía organizar la colecta, aunque hay algunas excepciones, como Antoni Caldes, rector de Pujol, de la diócesis de Valencia, que fue subcolector en Zaragoza de la décima trienal de 1397, o Martín de Odina, prior de Pertusa, colegiata adscrita a la diócesis de Lérida, que fue subcolector de anatas y de décimas en el obispado de Huesca.

Junto con los subcolectores, aparecen registrados numerosos intermediarios en los diferentes pagos realizados. Como tales se anotan otros religiosos, además de bastantes mercaderes, en relación con los principales centros urbanos de los territorios de la Corona de Aragón: así, se mencionan sobre todo mercaderes de Barcelona (actuando un poco por todas partes), además de algunos de Tarragona, Tortosa, Valencia, Zaragoza... o Mallorca, estos otros más circunscritos a las respectivas áreas diocesanas. Algunos de estos mercaderes aparecen interviniendo con cierta frecuencia en nombre de un determinado subcolector: un ejemplo de asociación de este tipo sería la del mercader zaragozano Juan de la Foz con el ya citado subcolector Guerau Oger o del mercader barcelonés Joan de Montoriol con el subcolector de Huesca (Martín de Odina). La participación de estos mercaderes sería de inestimable ayuda de cara al buen funcionamiento de la colectoría (también, como veremos, por lo que respecta a las operaciones de transferencia de moneda), gracias a las redes de intercambio que tenían establecidas entre las distintas plazas o territorios que servían de marco de operaciones. Al menos por lo que respecta al tema que nos ocupa, se constata una estrecha colaboración entre ambos estamentos (el eclesiástico y el mercantil). Aparte, también encontramos pagas realizadas a través de otras personas laicas ${ }^{22}$, incluyendo algún portero real ${ }^{23}$.

Los pagos podían ser hechos en numerario - dinero en efectivo- o bien por medio de cambios ${ }^{24}$, procedimiento que era obligado en el caso de las transferencias realizadas entre Mallorca y Barcelona. En este caso, vemos actuar como intermediarios a Jaume Biure, draper de dicha ciudad, quien parece haber sido el operador más activo, mientras que otras veces figura Guillem de Fonollet, mercader barcelonés ${ }^{25}$, y Jaume de Pujals, mercader mallorquín. Al menos en una ocasión, también intervinieron dos mercaderes italianos que estaban operando en Barcelona: Filippo de Lorino y Enrico Escarçafiga (fol. 33v).

\footnotetext{
${ }^{22}$ Podemos destacar a Antoni Buçot, ciudadano y clavario de Barcelona, a través del cual se satisfizo una paga de la décima de la diócesis de Valencia (fol. 65v).

${ }^{23} \mathrm{La}$ intermediación de porteros reales parece lógica en todo lo que concierne a la colecta de las décimas, habida cuenta de la participación de la Corona en dicha recaudación. Pero resulta hasta cierto punto sorprendente que también intervinieran en transacciones referidas a las otras colectas; asî, por ejemplo, B. Ribalta anotó haber recibido del subcolector de la diócesis de Tarragona 50 florines por medio de Pere de Puig, portero del rey, como restas de medias procuraciones (fol. 19r).

${ }^{24}$ «recepi tam per cambium quam numerando» (fol. 30v).

${ }^{25}$ Guillem de Fenollet jugó, según Favier, un papel muy importante en la gestión de las finanzas de Benedicto XIII, de quien era amigo personal; cf. J. FAVIER, ob. cit., pp. 502-504.
} 
Todos los subcolectores debían dar cuenta de su gestión al colector general, tanto de los ingresos percibidos como de los gastos que también conllevaba su gestión. El libro que analizamos contiene bastantes liquidaciones de cuentas - hasta un total de $30^{26}$ - realizadas a lo largo de los dos años que duró dicha administración [tabla $\mathrm{C}$ del Anexo]; algunas incumben a un mismo subcolector en diferentes momentos o por ingresos de diferente tipo ${ }^{27}$. Como muchas otras pagas, un cierto número de estas liquidaciones fueron validadas por notarios barceloneses, lo cual confirma lo que ya sospechábamos: que Berenguer Ribalta, pese a los desplazamientos realizados a las distintas sedes diocesanas de la Corona de Aragón, centralizó buena parte de su gestión en la Ciudad Condal, como centro de operaciones ${ }^{28}$. Aún así, hay liquidaciones localizadas en Zaragoza, Valencia, Tortosa..., y no siempre con el subcolector de la misma diócesis: así, Jaume Navarri, subcolector de Segorbe, rindió cuentas de su oficio en Valencia. Algunas de estas liquidaciones se remontan a 1393 como mucho, y cubren periodos de diferente duración hasta el momento mismo en que se hizo el finiquito. En todas ellas aparecen indicadas algunas cantidades a "devolver" a la Cámara Apostólica, cantidades que en algunos casos resultan ser insignificantes y en otros bastante altas ${ }^{29}$.

El libro de B. Ribalta recoge, pues, todas esas liquidaciones así como entradas directas de numerario. Todas las cifras anotadas en el margen derecho de cada página están expresadas en libras/sueldos/dineros barceloneses, lo que implica numerosas operaciones de conversión de aquellas cantidades que inicialmente están consignadas en otras monedas, ya se trate de florines (de Aragón), de moneda jaquesa (para el caso de las diócesis aragonesas y de algunos pagos efectuados en las diócesis de Lleida y de Tortosa), o de moneda mallorquina, señalando en cada caso los correspondientes "fors" o tasas de conversión que se utilizaron.

Así pues, todas las anotaciones realizadas en moneda jaquesa y mallorquina son convertidas, a efectos contables, al patrón barcelonés

${ }^{26}$ Aparte de las cuentas liquidadas con anterioridad por el subcolector de Mallorca ante Guillem Carbonell por un total de 265 fl. 1 s. 8 d. (fol. $4 \mathrm{v}$ ).

${ }^{27}$ Repartido de la siguiente manera: hay 15 liquidaciones a cuenta de la recaudación de anatas y/o medias procuraciones, 8 liquidaciones de décimas, 2 de subsidios y el resto tiene carácter indeterminado o diverso.

${ }^{28}$ Más aún, debió de hacerlo en el convento de su orden religiosa. Al menos una vez se consigna una cantidad de florines, «quos mihi tradidit numerando Barchinone in camera mea» (fol. 28r).

${ }^{29}$ Para esto último puede servir de ejemplọ el caso de Guerau Oger, subcolector de Zaragoza quien rindió cuentas de su gestión por el periodo comprendido entre el 28 de enero de 1401 y el 18 de abril de 1402, la fecha de liquidación de sus cuentas, teniendo que devolver - por anatas, medias procuraciones y restas de muchos años- un total de 531 libras y media, contabilizado en moneda jaquesa, cuya conversión a moneda barcelonesa da poco más de 580 libras, a las que podrían añadirse otra pequeña suma $(17 \mathrm{lb}$.) anotada aparte por restas de medias procuraciones. Anteriormente ya lo habia hecho para el periodo anterior a la fecha indicada de 1401 (contando desde el 4 de septiembre de 1399), haciendo entrega en aquel entonces de 225 lib.jac. $(=247,5$ lb.b.). Así pues, dicho subcolector habría entregado a B. Ribalta, en diferentes momentos, unas 845 libras de suma. 
(libras/sueldos/dineros/óbolos barceloneses) ${ }^{30}$. Y lo mismo cabe decir por lo que se refiere a la moneda en circulación.

La colectoría estudiada muestra la variedad de monedas utilizadas en el ámbito catalanoaragonés según la zona ${ }^{31}$, siendo quizás lo más llamativo el uso de timbres (moneda comenzada a acuñar en tiempos de Juan I en la ceca de Perpiñán) y escudos franceses, cuya circulación se registra únicamente en las diócesis del norte del Principado (Elna, Urgell, Girona, Vic). Estas monedas se computaban a razón de 18 sueldos barceloneses (o a veces algo menos en el caso de los escudos).

Así, por ejemplo, en una entrada consignada en la diócesis de Urgell (fol. 10r) se indica haber recibido un total de 360 libras barcelonesas de la siguiente manera: 488 florines y medio +51 escudos +17 timbres +30 libras 2 sueldos 6 dineros de moneda menuda barcelonesa, todo lo cual, convertido al patrón barcelonés según el correspondiente "for", nos da la indicada cifra.

Equivalencias monetarias usadas en la colectoría de B. Ribalta:

\begin{tabular}{|l|l|}
\hline 1 florín & $\begin{array}{l}=15 \mathrm{~s} . \text { mallorquines } \\
=11 \mathrm{~s} . \text { barceloneses } \\
=10 \mathrm{~s} . / 10 \mathrm{~s} .1 \mathrm{~d} . / 10 \mathrm{~s} .1 \mathrm{~d} . \text { óbolo jaqueses }\end{array}$ \\
\hline 1 lb. jaquesa & $=1 \mathrm{lb} .2 \mathrm{~s}$. barceloneses \\
\hline 1 lb. mallorquina & $=14 \mathrm{~s} .8 \mathrm{~d}$. barceloneses \\
\hline
\end{tabular}

\subsection{Los ingresos}

Como ya se ha indicado más arriba, para cada diócesis se establecen cuatro apartados de ingresos siguiendo este mismo orden: "vacantes", procuraciones, décimas y "comunitates". En la presente colectoría no hay mención alguna a los "servicia comuna" (a diferencia de la estudiada por P. Bertran de unos años antes) y sólo algunas entradas correspondientes a derechos de expolio, que son contabilizadas aparte.

Ahora bien, cuando pasamos al examen más minucioso del contenido de cada apartado, enseguida salta a la vista la anotación de partidas en las cuales concurren conceptos impositivos diversos, no sólo del tipo indicado en

\footnotetext{
${ }^{30}$ Sin embargo, en las cuentas de G. Carbonell, copiadas al principio del libro de B. Ribalta, todas las cuantias y sumas están expresadas en florines, en lugar de libras.

${ }^{31}$ Podemos señalar el caso de Segorbe-Albarracín: mientras la diócesis de Segorbe funcionaba "ad monetam regalium" de Valencia, la de Albarracín lo hacía "ad monetam jaccensem"; cf. M. a CÁRCEL ORTí; V. PONS ÂLÓS, La diócesis de Segorbe-Albarracín a través de la décima de 14011404, "Acta Historica et Archaeologica Mediaevalia", 25 (2001), pp. 375-388.
} 
el enunciado de cada página ${ }^{32}$. Que estén contabilizadas en uno u otro apartado dependería del criterio del colector, quien debía fiarse (así lo indica la apostilla tantas veces utilizada: "ut ipse asseruit" u otras expresiones similares) de la declaración realizada por cada subcolector, los únicos que podían estar al caso de los pormenores de la colecta. Todo ello podría desvirtuar en cierta medida la clasificación que nos ofrece el registro. Aún así, es posible mantenerla tal cual a la hora de hacer la valoración de los diferentes tipos de ingresos, porque de otra manera entraríamos en un terreno sumamente resbaladizo que implicaría recomponer cada apartado por completo sin la seguridad de poder mejorar el resultado final. Al fin y al cabo, lo que realmente importaba al colector general no era el monto que podía derivarse de cada tipo de entrada, sino la suma de ingresos obtenida en cada diócesis.

Analizaremos en primer lugar los ingresos de carácter ordinario obtenidos en cada diócesis, dejando para más adelante la revisión de los ingresos extraordinarios:

\subsubsection{Ingresos ordinarios}

Desde un punto de vista formal, serían ordinarios todos aquellos ingresos que, en el correspondiente libro de cuentas, aparecen consignados bajo determinados epígrafes que se van repitiendo para cada diócesis:

\section{a) Vacantes (¿o anatas?)}

Las vacantes o fructus medii temporis eran tasas percibidas por los frutos de los beneficios que se encontraban vacantes por fallecimiento o traslado del titular, hasta que era nombrado un nuevo titular. Esto en teoría, pues en nuestra colectoría, a pesar del título ("vacantes"), hay consignados ingresos de otro tipo.

En efecto, si pasamos a leer atentamente cada uno de los asientos registrados en este apartado, nos encontramos que lo que en realidad aparece contabilizado son ingresos por anatas ${ }^{33}$. En rigor, las anatas o fructus primi anni aludían a la percepción de una parte de las rentas de un beneficio durante el primer año de su colación por parte del papa $^{34}$. Con todo, en algunos casos parece como si anatas y vacantes fueran una misma cosa y, de hecho, la utilización de un término u otro no parece responder a criterios muy estric-

\footnotetext{
${ }^{32}$ Por ejemplo, en el apartado de las "procuraciones" de Zaragoza de 1401-02 (fol. 69v) se anotan 400 florines desglosados de la siguiente manera: 200 florines de anatas, 100 florines de medias procuraciones y 100 florines de vacantes («fructibus medii temporis»); en el siguiente asiento, se anotan 300 florines, o sea, 100 florines de anatas y 200 florines de medias procuraciones.

${ }^{33}$ Así, por ejemplo, en el folio 9v, correspondiente a las "vacantes" de la diócesis de Urgell, la primera referencia anotada lo es « annatis beneficiorum dicte diocesis». Otras anotaciones son "pro annata, de annatis seu restis annatarum, de peccuniis annatarum...», según se van repitiendo en los demás asientos de cada diócesis.

${ }^{34} \mathrm{La}$ definición de Favier es clara al respecto: " annate est la perception sur le bénéficier nouvellement pourvu d'une part de sa première année de revenus»; cf. J. FAVIER, ob. cit., p. 205.
} 
$\operatorname{tos}^{35}$. De una forma u otra, la percepción de las anatas se asocia a los beneficios que quedaban vacantes, hasta tal punto que más bien habría que hablar, por lo menos en ciertos casos, de "anatas de vacantes" ${ }^{36}$.

Teóricamente, las anatas sólo podían ser percibidas una vez que ya había sido nombrado el titular del beneficio por la Santa Sede ${ }^{37}$. Así, una posible interpretación sería que se tratase de beneficios ya adjudicados, pero que podían permanecer un tiempo vacantes antes de que el nuevo titular tomase posesión efectiva del cargo ${ }^{38}$. Sea como fuere, vamos a rebautizar este apartado con el nombre de la exacción que más parece corresponderse con su contenido real.

Habría que recordar, por otra parte, que el cobro de las anatas se basaba en las tasas decimales, percibiéndose bien sobre la tasa de la décima o bien sobre la diferencia entre el valor del beneficio (renta bruta) y dicha tasa. El colector siempre escogía el montante mayor (que, en general, era equivalente a la mitad o más de las ganancias brutas), procurando, en todo caso, que la anata no fuera superior a la tasa de la décima ${ }^{39}$. Al respecto, se podía cobrar la tasa íntegramente, como así se indica, por ejemplo, en relación con la permuta realizada sobre la rectoría de la Selva del Camp, en la diócesis tarraconense ${ }^{40}$. Sin embargo, parece que era más frecuente establecer una "composición", fijando una cuota contributiva por debajo de la tasa. Podemos mostrar algunos ejemplos: así, en la diócesis de Lleida (fol. $59 \mathrm{v}$ ), se anota un beneficio tasado secundum totum valorem en $9 \mathrm{lb}$.j., por cuya anata, una vez hecha la composición, se pagaron 10 florines (serían unas $5 \mathrm{lb} . \mathrm{j}$.). En el caso de otra rectoría de la diócesis de Zaragoza (fol. 68v) que estaba tasada en $15 \mathrm{lb} . \mathrm{j}$., se hizo una composición por 24 florines (unas 12

${ }^{35}$ «ratione annate seu vaccantis ipsius ecclesie», se dice en el folio $24 \mathrm{v}$. Como ya advertía Favier, "les scribes de la Trésorerie écrivaient couramment «pro vacantibus» à propos d'annates"; cf. J. FAVIER, ob. cit., p. 292. La misma ambivalencia se pone de manifiesto en otras fuentes coetáneas o posteriores: " in omnibus vaccantibus et fructibus primarum annatarum», se indica en el libro de cuentas de Elna; cf. G. Mollat, Les comptes de Jean de Rivesaltes, p. 299; " per satisfacció de la annata o vagant deguda a la dita Cambra», se dice en un documento de 1427; ACB [Arxiu de la Catedral de Barcelona], vol. 408, documento suelto.

${ }^{36}$ En nuestra colectoría encontramos anotaciones del siguiente tipo: «de peccuniis annatarum sive beneficiorum vacantium» (fol. $24 \mathrm{v}$ ); «annatarum beneficiorum in dicta diocesis vacantium» (fol. 26v). La expresión "anatas de vacantes" está tomada de J.P. KIRSCH, Annates, en A. Baudrillart (dir.), Dictionnaire d'histoire et de géographie ecclésiastiques, t. III, Paris, 1924, p. 307.

${ }^{37}$ Así se hace explícito alguna vez en la fuente utilizada: «ratione annate sui dicti prioratus de quo fuerat auctoritate apostolica noviter provisus» (fol. 69r).

${ }^{38}$ En las cuentas de la diócesis de Elna, el primer apartado de ingresos se corresponde con las anatas y éstas se expresan de la siguiente manera: «recepte annalium ... de benefficịis collatis tam auctoritate apostolica quam ordinaria... / Et primo, de cameraria sancti Genesii de Fontanis, vacante per mortem fratris Petri Puyol, collata fratri Johanni Rech etc.», y en cada caso se va repitiendo el binomio "vacante/collata"; cf. G. MOLLAT, Les comptes de Jean de Rivesaltes, p. 309.

${ }^{39}$ Como decía G. Mollat, "dans le diòcese d'Elne le collecteur prit régulièrement la taxe parce qu'elle était plus avantageuse", como así se desprende de la siguiente declaración: «in dicto episcopatu bẹneficia sunt taxata ad antiquam taxam sive decimam que multo plus valet quam reșiduum cuiuslibet beneficii possit valere; quapropter in omnibus vaccantibus et fructibus primarum annatarum (...) fuit taxa cuiuslibet beneficil recepta»; cf. G. MOLLAT, Les comptes de Jean de Rivesaltes, p. 297 y 299.

${ }^{40}$ «solvit integre totam tatxam que est CX llr. » (fol. 58r). 
lb.j.), una rebaja consentida por considerar que era muy pobre. A propósito de esta declaración, sería interesante ver cuántos beneficios se encontraban en esa situación. Ahora bien, había composiciones que respondían a motivos de otra índole. Así, encontramos otra parroquia de la diócesis de Tarragona (Cambrils) que estaba tasada en $113 \mathrm{lb}$., pero como el titular de dicho beneficio - un canónigo de Lérida - estaba trabajando al servicio del Papa, se le rebajó el gravamen a $65 \mathrm{lb} .{ }^{41}$. ¿Se trataba simplemente de recompensar los servicios prestados? Sea como fuere, la percepción de las anatas se prestaba a este tipo de componendas, que se llevaban a cabo ante el subcolector de la diócesis o del propio Ribalta, a veces acompañados por otros eclesiásticos.

Veamos acto seguido las cifras de recaudación: en 1400-01 se ingresó un total de $1.593 \mathrm{lb} .14 \mathrm{~s}$., una cifra mucho más crecida en el subsiguiente ejercicio de 1401-02: $4.025 \mathrm{lb} .9 \mathrm{~s}$. (supone un incremento de más del 150\%). Buena parte de este incremento se podría achacar a la recaudación obtenida durante este segundo ejercicio en las diócesis de Lleida y Zaragoza, cuyos montantes ascienden a más de 700 y 900 libras, respectivamente [véase gráfico 1]. Teniendo en cuenta la recaudación de todo el bienio, destaca sobre todo Zaragoza, con un total de poco más de 1.281 libras. Ello contrasta con la bajísima recaudación que registran otras diócesis como Tarazona y Urgell [véase gráfico 1.1.]. La de Elna, que no aporta nada por este concepto, tendría que situarse aparte por las razones que expondremos más abajo.

\section{b) Procuraciones}

Tales procuraciones eran tasas percibidas como redención de las visitas anuales que debían realizar los obispos u otros cargos eclesiásticos (archidiáconos, deanes) a los parroquias de su jurisdicción. J. Trenchs dio a conocer las correspondientes tasas fijadas en tiempos de Benedicto XII en el ámbito de la Corona de Aragón (1336), pero ignoramos si aún estarían vigentes en la época de referencia ${ }^{42}$.

En todo caso, se trata de una renta absolutamente normalizada. Las colectas se contabilizan por bienios. Las pagas eran efectuadas en dos momentos del año: San Juan Bautista (junio) y Navidad (diciembre). No sabemos si sería por esta razón que se contabilizan sistemáticamente como "medias procuraciones" o si habría que adherirse a otro tipo de

\footnotetext{
${ }^{41}$ «dictus rector est domini nostri servitor, in cuius servitio libenter ac favorabiliter laborat» (fol. 58r.).

${ }^{42}$ Cf. J. TREnCHS, La Cámara Apostólica y el reino de Aragón, II, p. 88; cf. P. BERTRAN, La fiscalitat eclesiástica, p. 287.
} 
interpretación ${ }^{43}$. En todo caso, para poder percibir esta exacción era imprescindible contar con la correspondiente bula de reserva ${ }^{44}$.

En 1400-01 se ingresan 2.489 lb., y algo más en 1401-02: 2.725 lb. Una vez más, hay algunas diócesis que no registran ningún ingreso de este tipo, ya sea en ambos ejercicios o únicamente por lo que respecta al primer ejercicio. Y por encima de todas, destaca la recaudación obtenida por la diócesis de Urgell durante el primer ejercicio (635 lb.) y por la de Zaragoza, con casi 600 libras en el segundo ejercicio [véase gráfico 2]. Por lo que respecta al nivel de recaudación del bienio, son, precisamente, esas dos diócesis las que ocupan las posiciones más destacadas dentro del correspondiente ránquing, situándose en torno a las 1.000 libras de recaudación. [véase gráfico 2.1.]

\section{c) Décimas}

Como es sabido, era un impuesto extraordinario cuyo origen se remonta a finales del siglo XII (como forma de financiar las cruzadas). Como su nombre indica, debía percibirse la décima parte del valor en que estuviese tasado el beneficio ${ }^{45}$; dicho valor sería resultante de una estimación de la renta anual - renta bruta menos gastos- Esta tasación estaba regida por las normas adoptadas en el primer concilio de Lyon, tasación que pronto quedaría fijada - probablemente, como postula Morerod, ya lo estaría a principios del siglo XIV-, para no modificarse durante largo tiempo, con lo cual se produjo una fosilización de las tasas. Como a lo largo del siglo XIV no se procedió a una revisión de tales tasas, ni siquiera después de la Peste Negra, la décima se convirtió en un impuesto estereotipado, sin conexión con el valor real de los ingresos de los beneficios.

En la época de la colectoría analizada, la recaudación de décimas se había convertido casi en un impuesto ordinario, que se iba percibiendo anualmente sin solución de continuidad. De hecho, el volumen que estudiamos

\footnotetext{
${ }^{43} \mathrm{Al}$ parecer, las denominadas "medias procuraciones" aludían a la reserva parcial que hacía la Santa Sede de las visitas concernientes a los obispos, mientras que las de otros eclesiásticos quedarían reservadạs íntegramente a favor de la Cámara Apostólica, y así lo interpretaba P. Bertran en su análisis de la colectoría n. ${ }^{\circ} 122$; cf. P. BERTRAN, La fiscalitat eclesiástica, pp. 28788. Sin embargo, en el caso de Elna, según parece, tales procuraciones fueron cobradas en su integridad, sin dejar nada al prelado visitador, esto es, çon reserva total; cf. G. MOLLAT, Les comptes de Jean de Rivesaltes, p. 297. Y quizás lo mismo cabría inferir para el resto de la colectoría aragonesa.

${ }^{44} \mathrm{La}$ importancia de tal escritura se pone de manifiesto en el siguiente caso ocurrido en la diócesis de Viç: "Anno.primo quo ego sumpsi istud officium collectorie cessarunt procurationes in hac Vicencis diocesis ex eo quia per honorabilem dominum Jacobum de Rippis, quondam, predecessorem meum, fuit omissum mittere bullam sive literam reservationis dictarum procurationum quamvis ceteris omnibus subcollectoribus misisset. Et quia in visitatione subcollectorum quam feci repari negligentiam seu oblivionem dum fui Barchinone feci revolvi scripturas dicti predecessoris mei et perquiri dictam bullam quam inveni in domo extranea. Et ideo tunc refformavi pro anno venturo mittendo, scilicet, dictam literam preffato subcollectori» (fol. 14r).

${ }^{45}$ Por ejemplo, referente al obispo de Tortosa (por la décima de 1402-03), se indica: «dominus episcopus extimavit suum episcopatum ad»[58.700 s.] «pro quibus tenetur solvere in decima» [5.870 s.]; ACA, RP, MR, reg. 1886, s.f.
} 
registra partidas de diferentes décimas, esto es, además de la que se estaba colectando en aquel momento, se anotan las restas de otras anteriores. Todas las décimas tenían establecidas dos pagas: la de junio (san Juan Bautista) y la de noviembre (Todos los Santos). Pero, como se expondrá más adelante, hubo alteraciones en algunas pagas por circunstancias de diferente tipo. Habrá que ver, en todo caso, cómo se reparten las cantidades en relación con cada colecta.

En concreto, se registran entradas relativas a las siguientes décimas: - décima de 1393: concedida por Clemente VII a Juan I por tres años. Se comenzó a colectar en la festividad de Todos los Santos de aquel año. Sin embargo, a raíz de la muerte del rey (el fallecimiento se produjo el 19 de mayo de 1396), se dejó en suspenso la última paga, la que habría sido la sexta.

En el ejercicio de 1400-01, hay consignadas tres entradas de esta décima, aunque por cantidades poco importantes, puesto que se trata de restas concernientes a tan sólo tres obispados: Elna, Barcelona y Valencia.

-décima anual de 1396: alude a otra concesión de Clemente VII a favor de Juan I por el tiempo de un año. La percepción de esta décima se realizó durante el reinado de Martín I. La primera paga fue hecha en la fiesta de Todos los Santos de 1396 y la segunda, en San Juan del siguiente año.

De esta décima sólo hay registrada una pequeña entrada en el ejercicio de 1400-01 de la diócesis de Barcelona y otra entrada un poco más destacada de la diócesis de Urgell, ya en el segundo ejercicio (1401-02).

- décima trienal de 1397: concedida por Benedicto XIII al rey Martín I. Incluía seis pagas comprendidas entre Todos los Santos de 1397 y San Juan de 1400 .

El primer ejercicio de Berenguer Ribalta arroja un total de 1.488 libras (1.630 libras ya habían sido recolectadas por Guillem Carbonell, según se muestra en las correspondientes cuentas). La diócesis más destacada es la de Elna (329 lb.), que en las cuentas de Carbonell no figuraba. En el ejercicio de 1401-02, las entradas de esta décima se reducen significativamente, de manera que ya sólo suponen un total de 261 libras. Juntando todas las entradas pertenecientes a dicha décima en las tres cuentas contenidas en la colectoría objeto de estudio obtenemos los siguientes resultados por diócesis:

\begin{tabular}{|l|l|}
\hline Diócesis & Cuantía consignada \\
\hline Elna & 340 lb. 3 s. 6 d. \\
\hline Urgell & $339 \mathrm{lb} .2$ s. $8 \mathrm{~d}$. \\
\hline Girona & $360 \mathrm{lb} .4$ s. \\
\hline Vic & $487 \mathrm{lb} .2$ s. 8 d. \\
\hline Barcelona & 237 lb. 1 s. 6 d. \\
\hline Tarragona & $302 \mathrm{lb} .10 \mathrm{~s}$. \\
\hline
\end{tabular}




\begin{tabular}{|l|l|}
\hline Lleida & $255 \mathrm{lb} .13 \mathrm{s.} 2 \mathrm{~d}$. \\
\hline Tortosa & $167 \mathrm{lb} .13 \mathrm{~s} .7 \mathrm{~d}$. \\
\hline Segorbe & $28 \mathrm{lb} .6 \mathrm{~s} .1 \mathrm{~d}$. \\
\hline Zaragoza & $302 \mathrm{lb} .10 \mathrm{~s}$. \\
\hline Huesca & $55 \mathrm{lb}$. \\
\hline Tarazona & $126 \mathrm{lb} .16 \mathrm{~s} .10 \mathrm{~d}$. \\
\hline Mallorca & $154 \mathrm{lb} .2 \mathrm{~s} .10 \mathrm{~d}$. \\
\hline Total & $\mathbf{3 . 1 5 6} \mathrm{lb} .6 \mathrm{~s} .10 \mathrm{~d}$. \\
\hline
\end{tabular}

En suma, según estos resultados, durante el periodo abarcado por ambos ejercicios fueron satisfechas a la Cámara Apostólica algo más de 3.000 libras por esta décima, cuyo cobro finalizó justo antes de la colectoría encomendada a Guillem Carbonell, luego continuada por Berenguer Ribalta.

-décima septenal de 1401: fue concedida por Clemente VII a Juan I, y luego confirmada por Benedicto XIII al rey Martín. En cierta manera, sería considerada como continuación de la décima de 1393, lo que significaba prolongar el periodo de aquella décima trienal a 10 años. Tendría que haber comenzado en la fiesta de Todos los Santos de 1400, pero se postergó a San Juan de 1401, siendo ésta una paga duplicada, al menos por lo que respecta a la parte asignada a la Cámara Apostólica ${ }^{46}$.

Esta décima siguió recaudándose hasta 1407. Naturalmente, la colectoría objeto de estudio sólo recoge las primeras pagas (desde la primera paga duplicada de la fiesta de San Juan de 1401 hasta la que caía en la misma fecha de 1402), pero en razón de su actualidad, se trata de cantidades más importantes comparado con las entradas de las anteriores décimas.

En el ejercicio de 1400-01, se obtiene un total de unas 3.918 lb.; la cifra es aún más elevada en el ejercicio de 1401-02: $6.500 \mathrm{lb}$.

${ }^{46}$ «... in festo Sancti Johannis Baptiste proxime lapso, in quo termino pars Camere Apostolice fuit in duplo soluta per clerum, ex eo guia in prelapso termino Omnium Sanctorum fuerat solvi omissum» (fol. 16v); " ....in termino Sancti Johannis junii proxime lapsi, in quo pars Camere propter omissionem factam de dicta decima solvenda in prelapso termino Omnium Sanctorum dupliciter solvebatur» (fol. 19v); etc. 
Balance de la recaudación de décimas:

\begin{tabular}{|c|c|c|c|c|c|}
\hline & trienal 1393 & anual & & trienal 1397 & septenal 1401 \\
\hline $1400-1401$ & 69 lb. 14 s. 2 d. & $2 \mathrm{lb}$. & $8 \mathrm{~d}$ & $1.488 \mathrm{lb} . \quad 6 \mathrm{~d}$ & $3.918 \mathrm{lb} .15 \mathrm{~s} 10 \mathrm{~d}$ \\
\hline $1401-1402$ & & $66 \mathrm{lb}$ & & $261 \mathrm{lb} .7 \mathrm{~s} .3 \mathrm{~d}$. & $6.543 \mathrm{lb} .8 \mathrm{~s} \quad 8 \mathrm{~d}$ \\
\hline Total: & $69 \mathrm{lb} 14 \mathrm{~s} .2 \mathrm{~d}$. & $68 \mathrm{lb}$ & $8 \mathrm{~d}$. & 1.749 lb. 7 s. 9 d. & $10.462 \mathrm{lb} . \quad 4 \mathrm{~s} .6 \mathrm{~d}$ \\
\hline$\%$ & 0,6 & 0,6 & & 14,2 & 84,7 \\
\hline
\end{tabular}

En suma, en el ejercicio de 1400-01, se contabiliza una entrada global (por todas las décimas) de $5.478 \mathrm{lb}$. $11 \mathrm{s.} 2 \mathrm{~d}$.; y, en el de 1401-02, de 6.870 lb. 15 s. 11 d., lo que supone un $25 \%$ de incremento. Estas cantidades se refieren a la parte apropiada por el papado, que tan sólo era un tercio, ya que los dos tercios restantes iban a parar a las arcas de la monarquía.

En términos comparativos, destaca la diócesis de Valencia, con una recaudación situada por encima de las 1.100 libras en lo que atañe al segundo ejercicio de 1401-02 [véase gráfico 3]. Asimismo, la diócesis valenciana ocupa un lugar destacado en el correspondiente ránquing referido al bienio, con un total de 1.670 libras. Otras diócesis alcanzan niveles superiores a las 1.000 libras, concretamente las de Girona, Elna, Barcelona, Vic, Urgell y Zaragoza, por este mismo orden. [véase gráfico 3.1.]

\section{d) "comunitates"}

En este último apartado se anotan entradas de diferente índole, incluidas algunas que quizás deberían figurar en los anteriores apartados, pero que por tratarse de pagas atrasadas o por estar mezcladas con otros ingresos, hubo que consignarlas aparte. Así pues, este apartado constituye una especie de cajón de sastre: se incluyen medias procuraciones, restas de décimas, frutos de beneficios vacantes..., restas que incluso en algún caso se retrotraen a la época de la "indiferencia" ". De hecho, el concepto "fructus medii temporis" es el que más se repite. Ello nos remite a los beneficios vacantes ${ }^{48}$. Se tasaba sobre beneficios cuyo titular había fallecido, por lo cual se tenía en cuenta el periodo durante el cual dicho beneficio había estado vacante (sin que aún se hubiera producido el nombramiento de un sucesor, de ahí que se haga alusión al tiempo intermedio). Sólo en algunos casos concretos se hace explícito el tiempo que duró la vacante. Por ejemplo, cierto archidiaconato de Barcelona (fol. 57v) fue tasado por 12 días a 160 libras, siendo el fruto de 4 libras $(2,5 \%)$. En otros casos, el periodo tasado fue más largo: de 2 meses y

${ }^{47}$ A propósito de la liquidación de cuentas realizada con Bernat Despujol, subcolector de la décima de Vic, «ac comissarius comuniter deputatus ad colligendum, scilicet, bona ipsi Camera Apostolice debita de tempore indiferentie et domino regi per medium ex papali concessione», pues, efectivamente, dichos ingresos eran repartidos en mitades entre papado y monarquía (fol. $15 \mathrm{r})$.

${ }^{48}$ «de fructibus medii temporis aliquorum beneficiorum vaccantium» (fol. $75 \mathrm{r}$ ). 
10 días o bien de hasta 4 meses - en relación a ciertas preposituras de Valencia (fol. 66v) -; y en ambos casos se perciben cantidades mucho más elevadas: respectivamente, $125 \mathrm{lb} .1 \mathrm{~s} .5$ d. y $202 \mathrm{lb} .8$ s. 2 d. Así pues, parece que sería en este apartado final, y no en el primero, donde se contabilizaron las vacantes propiamente dichas.

Por otra parte, también se asientan algunas partidas de ingresos procedentes de subsidios de tiempo atrás, como el concedido por el clero de la provincia de Tarragona en noviembre de 1395, que fue tasado a razón de 2 sueldos por libra $(10 \%)^{49}$. El propio B. Ribalta estuvo al cargo de su colecta $^{50}$. En lo concerniente al libro contable que analizamos, nos consta que el subcolector de este subsidio en la diócesis de Girona rindió cuentas del mismo en enero de 1402, haciendo entrega de poco más de $34 \mathrm{lb}$. (53v). Se registran aún otras partidas relativas a subsidios de la provincia de Tarragona, como el concedido en el último concilio (1399) a razón de 12 dineros por libra, que prácticamente pasan desapercibidas, ya que son contabilizadas junto con otras cantidades.

Dentro del mismo apartado se consignan dos entradas referentes a una deuda recuperada por parte del subcolector de Valencia sobre los bienes que habían sido de una mujer del linaje Entença y esposa del militar Miquel Eximeniz de Vidosa, que antes lo fue del doncel García López de Cetina, por un total más o menos de $168 \mathrm{lb}$. Los motivos de la deuda, sin embargo, no quedan especificados. Quizás podría referirse a pagas pendientes por la armada que acudió a Aviñón a socorrer al Papa en $1398^{51}$.

Los ingresos que tenemos contabilizados en este apartado son muy irregulares. Frente a algunas diócesis que no tienen ninguna entrada consignada bajo este epígrafe, en las demás que sí tienen destaca el obispado de Valencia durante el ejercicio 1401-02 (370 libras). En la suma de ambos ejercicios, es la diócesis de Mallorca la que anota un mayor nivel de ingresos (536 libras), cifra que supera con creces a las obtenidas por esta misma diócesis en los demás apartados de ingresos. El hecho de no tener contacto directo con los subcolectores de esta diócesis quizás daría pie a una gestión menos escrupulosa de los ingresos procedentes de las islas.

\footnotetext{
${ }^{49}$ Correspondiente a este subsidio, consta la entrega de 1.000 florines a la Cámara Apostólica en octubre de 1396; cf. M. MILIÁN BoIX El fondo "Instrumenta Miscellanea" del Archivo Vaticano. Documentos referentes a España (853-1782), Roma, 1969, p. 263. También en el caso de Elna se alude, en relación a 1396, a un subsidio percibido a razón de 2 sueldos por libra; cf. G. MOLLAT, Les comptes de Jean de Rivesaltes, p. 297.

${ }^{50}$ Según un recibo regestado por J. BAUCELLS, El fons "Cisma d'Occident, p. 139. También fue colector del subsidio acordado por el clero de la provincia de Zaragoza en un concilio celebrado en dicha ciudad. En marzo de 1397 rindió cuentas de la correspondiente colecta, anotando unos ingresos de 22.524 florines 2 sueldos 1 dinero y una cantidad casi igual de gastos. Consta, además, que 13.000 florines fueron entregados a la monarquía para pagar el estipendio de dos galeras que el rey Martín pensaba enviar a Sicilia para socorrer a su hijo; cf. O. CUELLA, Bulario, I, doc. n. ${ }^{\circ}$ 716; J. FAVIER ob. cit., p. 427.

${ }^{51}$ En las cuentas de Guillem Carbonell, la mayor partida de gasto se refiere al pago del estipendio acordado con algunos contingentes de soldados que acudieron a Aviñón en 1398 para socorrer al Papa cuando éste estuvo asediado por las fuerzas del rey de Francia. Se trataba de una paga suplementaria a la que aquellos ya habían recibido con anterioridad. Todas las partidas relacionadas con este capitulo de gasto suman 354 florines, lo que supone más de las $3 / 4$ partes del gasto consignado en dichas cuentas.
} 
Valoración global de los ingresos: sumando las cantidades anotadas en cada apartado, obtenemos $9.996 \mathrm{lb}$. $17 \mathrm{~s}$. en el primer ejercicio y 14.352 lb. 19 s. 11 d. en el segundo. El diferencial se justifica por el incremento de cada tipo de ingreso, pero de algunos más que de otros (anatas $+152,6 \%$; décimas $+25,4 \%$; procuraciones $+9,5 \%$ ); incluso el capítulo "comunitates" también registra un total más elevado en el segundo ejercicio. Los datos están claros en lo que concierne a la principal fuente de ingresos: las décimas ocupan, con diferencia, la primera posición, tanto en el primero como en el segundo ejercicio. Los ingresos por anatas, que durante el primer ejercicio estaban situados por debajo de las procuraciones, pasan a ocupar el segundo lugar en el siguiente ejercicio, con algo más de la mitad de lo que se obtiene de las décimas [véase gráfico 4]. La distribución sería la siguiente:

\begin{tabular}{|l|l|l|l|l|l|l|l|l|}
\hline & [anatas] & $\%$ & Procuraciones & $\%$ & Décimas & $\%$ & otros & $\%$ \\
\hline $\begin{array}{l}1400- \\
1401\end{array}$ & $1.593 \mathrm{lb} .14 \mathrm{~s}$. & 16 & $2.489 \mathrm{lb} .6 \mathrm{~d}$. & 25 & $\begin{array}{l}5.478 \mathrm{lb} .11 \mathrm{s.} 2 \\
\text { d. }\end{array}$ & 55 & $\begin{array}{l}435 \mathrm{lb} .12 \mathrm{s.} 4 \\
\text { d. }\end{array}$ & 4 \\
\hline $\begin{array}{l}1401- \\
1402\end{array}$ & $4.025 \mathrm{lb} .9 \mathrm{~s}$. & 28 & $2.725 \mathrm{lb} .6 \mathrm{~s}$. & 19 & $\begin{array}{l}6.870 \mathrm{lb} .15 \mathrm{~s} .11 \\
\text { d. }\end{array}$ & 48 & $731 \mathrm{lb} .9 \mathrm{~s}$. & 5 \\
\hline
\end{tabular}

Una vez más, interesa fijarse más que nada en la valoración que se obtiene del correspondiente bienio. Como podemos ver a través del gráfico 4.1., las décimas representan más del $50 \%$ de la recaudación. Y tanto las anatas como las procuraciones obtienen porcentajes similares, superiores al $20 \%$, pero sin llegar a la cuarta parte del total.

En realidad, estos resultados no son muy diferentes de los expuestos para el periodo comprendido entre 1387-92 en la circunscripción de Aragón, cuando los ingresos por décima representaban el 55\%, frente al $35 \%$ de las anatas y el $7 \%$ de las procuraciones ${ }^{52}$.

Por diócesis, la situación se presenta muy variable [véase tabla D del Anexo]. De hecho, no todas las demarcaciones registran entradas en cada uno de los apartados tributarios consignados: destaca sobre todo el caso de Elna (sin entradas consignadas tanto por lo que respecta a las anatas como a las procuraciones, además de las "comunitates"); pero mientras que otras circunscripciones eclesiásticas tienen anotado el correspondiente titular, dejando el apartado en blanco, en el caso de Elna únicamente se tuvo en cuenta el apartado de las décimas ${ }^{53}$. Todo parece indicar, pues, que esta

\footnotetext{
${ }^{52}$ Datos publicados por J. FAVIER, ob. cit., p. 237 (presenta únicamente un cuadro de porcentajes, sin dar nịguna cifra). También el estudio de P. Bertran sobre el registro n. ${ }^{\circ} 122$ (1384-92) muestra la importancia de las décimas muy por encima de los demás ingresos.

${ }^{53}$ Ello quizás se explicaría en función de las cuentas manejadas por Joan de Ribesaltes, cuentas que fueron directamente presentadas por dicho colector (en realidad subcolector) a la Cámara Apostólica a finales de 1405. Dichas cuentas, dadas a conocer, al menos en parte, por el historiador francés G. Mollat, no anotan, como sị lo hace B. Ribalta, ingresos de las décimas. Sea como fuere, no es posible saber qué parte de ingresos - de los consignados por Ribesaltes hubieran podido pasar por las manos de Ribalta en el caso de no haber existido tal separación administrativa.
} 
diócesis, al menos por lo que respecta a la supervisión de los derechos apostólicos, había quedado segregada de la colectoría de Aragón, quizás en razón de su mayor proximidad a la capital aviñonense o debido a las desfavorables circunstancias que atravesaba la diócesis ${ }^{54}$.

Primero de todo, podemos comparar los resultados obtenidos en ambos ejercicios: en la mayoría de obispados (en todos menos en los dos indicados abajo), el montante de lo percibido por la Cámara apostólica es mayor en el ejercicio de 1401-02 que en el precedente, lo que también se da en la mayoría de las diócesis; sólo los obispados de Elna y Urgell (también Tortosa) aportan menos en el segundo periodo, aunque por diferenciales no muy importantes. En el caso de Tortosa, las cantidades resultantes guardan muy poca diferencia en ambos ejercicios. En aquellas diócesis donde aumentan los ingresos, la mayor diferencia porcentual se registra en Lleida, Valencia y Tarazona, tal y como se expone en la siguiente tabla de ingresos globales por diócesis [véase también gráfico 5]:

\begin{tabular}{|c|c|c|c|}
\hline & $1400-1401$ & 1401-1402 & $\begin{array}{l}\text { Variación } \\
\text { porcentual }\end{array}$ \\
\hline ELNa & $717 \mathrm{lb} .3 \mathrm{~s} .6 \mathrm{~d}$. & $528 \mathrm{lb} .10 \mathrm{~s}$. & $-35,8 \%$ \\
\hline URGELL & 1.113 lb. 14 s. 8 d. & 973 lb. 17 s. 4 d. & $-14,4 \%$ \\
\hline GIRONA & $1.000 \mathrm{lb} .7 \mathrm{~s}$. & 1.199 lb. 5 s. $5 \mathrm{~d}$. & $+19,9 \%$ \\
\hline VIC & $1.003 \mathrm{lb} .8 \mathrm{~s}$. & 1.131 lb. 9 s. $10 \mathrm{~d}$. & $+12,8 \%$ \\
\hline BARCELONA & $685 \mathrm{lb} .8 \mathrm{~s}$. & $1.083 \mathrm{lb} .3 \mathrm{~s}$. & $+58,1 \%$ \\
\hline TARRAGONA & 712 lb. 2 s. 8 d. & 1.100 lb. 14 s. 5 d. & $+54,5 \%$ \\
\hline LLEIDA & 577 lb. 6 s. 4 d. & 1.415 lb. 9 s. 4 d. & $+145,2 \%$ \\
\hline TORTOSA & 802 lb. 3 s. 11 d. & $793 \mathrm{lb} \quad 7 \mathrm{~d}$. & $-1,1 \%$ \\
\hline VALENCIA & 856 lb. 7 s. 2 d. & 2.075 lb. 17 s. 8 d. & $+142,4 \%$ \\
\hline SEGORBE & $110 \mathrm{lb}$ & $204 \mathrm{lb} .8 \mathrm{~s}$. & $+85,4 \%$ \\
\hline ZARAGOZA & $1.200 \mathrm{lb} .2 \mathrm{~s}$ & 2.202 lb. 13 s. 6 d. & $+83,5 \%$ \\
\hline HuEsCA & 444 lb. 8 s. & $522 \mathrm{lb} .8$ s. $10 \mathrm{~d}$. & $+17,6 \%$ \\
\hline TARAZONA & 140 lb. 1 s. 10 d. & $335 \mathrm{lb} .10 \mathrm{~s}$. & $+139,3 \%$ \\
\hline MALLORCA & 634 lb. 4 s. $11 \mathrm{~d}$. & $776 \mathrm{lb} .12 \mathrm{~s}$. & $+22,4 \%$ \\
\hline
\end{tabular}

\footnotetext{
${ }^{54} \mathrm{Al}$ respecto, las cuentas de Ribesaltes contienen una interesante declaración acerca de la disminución que habían experimentado los beneficios en dicha circunscripción por causas diversas: "Item est sciendum quod beneficia illius diocesis Elnensis sunt a decem annis citra in tantum diminuta propter mortalitates, guerras et inundationes aquarum, quod sunt multa que non sufficiunt ad divinum officium»; cf. G. MOLLAT, Les comptes de Jean de Rivesaltes, p. 302.
} 
El siguiente paso sería ver qué diócesis de la Corona de Aragón aportaban mayores ingresos a la Cámara apostólica, considerando el bienio en su conjunto. Así, las diócesis con un mayor potencial fiscal parecen ser dos: la de Zaragoza, con más de 3.400 libras, y la de Valencia, cuya recaudación se aproxima a las 3.000 libras [véase gráfico 5.1.]. Ello significa que 1/4 parte del total de la recaudación de la Corona de Aragón se obtenía en esas dos circunscripciones. La recaudación de las diócesis catalanas se sitúa en un término medio, ya que están comprendidas entre las cerca de 1.600 libras de Tortosa y las casi 2.200 libras de Girona. Otras diócesis periféricas, como Mallorca y Elna, aún obtienen niveles situados entre las 1.000 y las 1.500 libras. Situadas en los niveles inferiores encontramos las diócesis de Huesca, Tarazona y Segorbe, que ocupa el último lugar del ránquing. Hasta qué punto estos resultados serían un fiel baremo de la desigual riqueza que presentaban unas y otras diócesis creemos que es una cuestión demasiado compleja para poder ser abordada con los datos que tenemos más a mano.

Considerando las dos provincias eclesiásticas constituidas dentro de la Corona de Aragón (excluyendo, por tanto, las diócesis de Elna y de Mallorca), obtenemos los siguientes resultados:

\begin{tabular}{|l|l|l|l|}
\hline & prov. de Tarragona & prov. de Zaragoza & Porcentajes \\
\hline $1400-1401$ & $6.751 \mathrm{lb} .17$ s. 9 d. & 1.894 lb. 11 s. $10 \mathrm{~d}$. & $78 \% / 22 \%$ \\
\hline $1401-1402$ & 9.772 lb. 17 s. 7 d. & $3.265 \mathrm{lb} . \quad 4 \mathrm{~d}$. & $75 \% / 25 \%$ \\
\hline
\end{tabular}

Aparte del incremento que se registra entre los dos ejercicios (del orden de un $44 \%$ y un $72 \%$ en una y otra provincia), de tales cifras se infiere lo siguiente: la Cámara Apostólica recaudaba tres veces más en la provincia de Tarragona que en la de Zaragoza. Naturalmente, existe una desigualdad manifiesta en el número de diócesis que tenía cada provincia, pero sin dejar de obviar este hecho, lo cierto es que las diócesis más pobres serían las aragonesas, con la notable excepción de la metrópoli: la recaudación en la ciudad del Ebro alcanza un 63\% (1400-01) y un 67\% (1401-02) del total recaudado en la provincia. Por tanto, hay un notable desequilibrio entre la diócesis de Zaragoza y las que le estaban subordinadas. En la provincia tarraconense, la recaudación anotada a cada diócesis varia tanto de un ejercicio a otro que es difícil ver una polarización tan marcada a favor de una $\mathrm{u}$ otra diócesis.

¿Cuál sería, por otra parte, el peso recaudatorio de cada territorio de la Corona (Aragón, Cataluña, Valencia, Mallorca)? (para ello computamos la diócesis de Elna con Cataluña y la de Segorbe con el reino de Valencia). [véase también el mapa 2] 


\begin{tabular}{|l|l|l|l|l|}
\hline & Cataluña & Aragón & Valencia & Mallorca \\
\hline $1400-1401$ & $6.612 \mathrm{lb} .(66 \%)$ & $1.784 \mathrm{lb} .(18 \%)$ & $966 \mathrm{lb} .(10 \%)$ & $634 \mathrm{lb} .(6 \%)$ \\
\hline $1401-1402$ & $8.225 \mathrm{lb} .(57 \%)$ & $3.060 \mathrm{lb} .(21 \%)$ & $2.280 \mathrm{lb} .(16 \%)$ & $776 \mathrm{lb} .(5 \%)$ \\
\hline
\end{tabular}

En cifras absolutas, la contribución de los cuatro territorios aumentó entre uno y otro ejercicio, con un índice de incremento mayor por lo que respecta a Valencia $(+136 \%)$ y Aragón $(+71,5 \%)$, en contraste con los índices más moderados de Cataluña $(+24,4 \%)$ y Mallorca $(+22,4 \%)$.

Con todo, a partir de estos datos, queda patente que más de la mitad del producto que se transfería a la Cámara apostólica de la colectoría de la Corona de Aragón provenía de Cataluña, esto es, de las ocho diócesis catalanas. Aragón proporcionaba tan sólo 1/5 parte del total (una gran parte, como hemos visto, de Zaragoza); Valencia, algo menos; y en último lugar queda Mallorca en una situación más bien residual.

\subsubsection{Ingresos extraordinarios}

Debemos considerar aquí otras partidas de ingresos que no están incluidas en ninguno de los apartados considerados hasta el momento, al margen, pues, de lo que se contabiliza como "recepte comune":

Derechos de expolio. Como es sabido, tal derecho significaba la apropiación de los bienes muebles de los prelados y clérigos difuntos, bienes que antes tenían que ser inventariados y evaluados para luego proceder a su venta $^{55}$. Obviamente, cabe considerarla como una fuente de ingresos extraordinaria.

La colectoría que estudiamos contiene dos páginas en los que se hace mención de tales derechos. Así, en el folio 35r, incluido aún en el primer ejercicio, se anota la restitución, por parte del subcolector de Tarragona (Joan de Morelló), de diversos libros que pertenecieron a un fraile menor (Bartomeu de Virgili, obispo de Jerusalén ${ }^{56}$ ) que murió en Tarragona en 1397: se trataba de un misal, un psalterio, un breviario, un libro de sermones y otro titulado Flos sanctorum. No era una biblioteca extensa, pero al menos estaba bien provista de lo más indispensable en cuanto a libros litúrgicos (el psalterio suele aparecer con frecuencia en las librerías de los eclesiásticos, dado que era un texto imprescindible para la liturgia) y en cuanto también a la literatura de tipo ejemplificante. Con todo, no sabemos si lo que se contabiliza aquí sería la librería al completo del difunto o sólo una parte, quizás de los ejemplares

${ }^{55}$ Los inventarios de expolios aportan noticias relevantes de muebles, rentas y, especialmente, de las bibliotecas del alto clero; véanse los trabajos de D. WILLIMAN, J. MonFriN y M.H. JULLIEN DE POMMEROL, Les bibliothèques ecclésiastiques au temps de la paupauté d'Avignon, 2 vols., Paris, 1980-2001.

${ }^{56}$ Recordemos que, desde 1342 , la Orden franciscana tenía a su cargo, por orden papal, la custodia de los Santos Lugares. 
más valiosos o mejor conservados, pues el número reducido de libros expoliados contrasta con las bien dotadas bibliotecas que salen inventariadas a través de otras fuentes no fiscales, como se ve en el caso del obispo de Barcelona muerto en 1401, estudiado por J. Hernando.

Sea como fuere, de todos estos libros se hace una estimación de su posible valor: el más valorado, en torno a 4 florines, es el breviario (algo parecido valdría el psalterio: 3 o 4 florines; el Flos sanctorum, 3 florines o casi; el misal, 2 florines; y el libelo de sermones, tan sólo 2 sueldos). Sin embargo, no hay ninguna cantidad consignada: hasta que no fueran vendidos, la colectoría no podría sacar ningún provecho de estos bienes ${ }^{57}$.

En cambio, sí se anotan cantidades por lo que respecta a los derechos de expolio consignados en dos asientos incluidos al principio del ejercicio de 1401-02: de una parte, del expolio de otro eclesiástico muerto en Tarragona (de quién sólo se indica que era arzobispo de Neopatria), entregado por el citado Joan de Morelló, sin concretar qué tipos de bienes eran tasados; de otra parte, se recibe del subcolector de Tortosa el precio de venta de una Biblia que perteneció al rector de Gandesa, la cual fue vendida a un canónigo de Valencia. La cantidad consignada lo es restando el coste de envío y la paga del corredor que intervino en la transacción.

Ambos asientos suman poco más de 49 libras. En la contabilidad que manejamos aquí, el derecho de expolio representa, pues, una fuente de ingresos muy marginal. Se dice que el Cisma obstaculizó el ejercicio del ius spolii y que por este motivo esta exacción fue yendo a la baja, en contraste con el auge que había alcanzado en la etapa anterior. Contrasta, en todo caso, con la importancia que de nuevo llegó a tener en época moderna, según ha mostrado J.M. Carretero en sus trabajos.

Las rentas de la diócesis de Lérida (¿un caso de apropiación?). Ello constituye un apartado específico de los ingresos del segundo ejercicio. Por alguna razón se optó por consignar estos ingresos aparte, esto es, al principio del ejercicio y no en el apartado correspondiente a la diócesis de Lérida, en la que hay anotadas diversas entradas por vacantes, procuraciones y décimas, pero no por "comunitates", donde se hace constar un lacónico "nichil".

Oficialmente, dicha sede estuvo vacante entre 1399 y $1403^{58}$. A instancias de Francesc Climent (cubiculario de Benedicto XIII), los emolumentos procedentes de este obispado fueron ingresados íntegramente por la propia colectoría. Por tanto, debería considerarse como una vacante, aunque tal término no se haga constar en ningún momento, pero no de una vacante limitada a unos pocos días o meses, como en el caso de las vacantes que ya

\footnotetext{
${ }^{57} \mathrm{Si}$ no eran vendidos o utilizados para saldar deudas del difunto, iban a engrosar los tesoros de la Cámara Apostólica; véase al respecto Ch. SAMARAN, G. MOLLAT, La fiscalité pontificales p. 101. En el caso del misal, se dice que fue retenido por Francesc Climent, pero sin pagar el indicado precio.

${ }^{58}$ Entre Pere de Santcliment, que fue nombrado el 7.V.1399, pero no tomó posesión, y Joan Baufés, preconizado el 17.VIII.1403 (P.B. GAMS, Series episcoporum ecclesiae catholicae, Graz, 1957, p. 44; AAVV, Diccionario de Historia Eclesiástica de España, t. II, p. 1294).
} 
hemos visto anotadas en el apartado "comunitates" de algunas otras diócesis, sino a dos años.

Dichas rentas fueron administradas por Joan Senant, canónigo y sacristán de Lérida, durante un bienio que finalizaba el último día de abril de 1402 (por tanto, comenzó a contar a partir del 1 de mayo de 1400, cubriendo una buena parte del periodo encomendado a B. Ribalta). Se anotan seis asientos, la última ápoca fechada el 6 de agosto del año indicado. Algunas cantidades fueron consignadas en la taula de canvi de los hermanos Maçana (Jaume y Joan).

\begin{tabular}{|l|l|l|}
\hline Fecha & Suma recibida & Periodo de referencia \\
\hline $30 . I .1402$ & $1.446 \mathrm{lb} .10 \mathrm{~s}$. & \\
\hline $24 . ? .1402$ & $550 \mathrm{lb}$. & Del $2^{\circ}$ año finalizado el 30.IV.1402 \\
\hline 6.V.1402 & $825 \mathrm{lb}$. & 1. V.1401-30.IV.1402 \\
\hline 19.VI.1402 & $495 \mathrm{lb}$. & \\
\hline 25.VI.1402 & $286 \mathrm{lb}$. & Año finalizado el 30.IV.1402 \\
\hline (6.VIII.1402) & $550 \mathrm{lb}$ & Del año 1401 \\
\hline
\end{tabular}

En total, se contabilizan 4.152 libras y media, cifra que supera a cualquiera de las obtenidas en cada diócesis por todos los demás conceptos, constituyendo ni más ni menos que el 21,6\% del total de ingresos de este ejercicio.

Es posible que el nombramiento de un nuevo prelado en aquella sede se hubiera retardado deliberadamente con el fin, precisamente, de apropiarse de las rentas del obispado ${ }^{59}$. Al parecer, fue relativamente frecuente dejar sedes vacantes largo tiempo con el fin de poder sacar provecho de las rentas correspondientes $^{60}$. Estas mismas circunstancias también se habían dado en el obispado de Valencia, donde el papa dejó vacantes -intencionadamente- la mitra y otros beneficios durante más de dos años y medio (al parecer, entre diciembre de 1397 y agosto de 1400), para poder recibir los emolumentos a

\footnotetext{
${ }^{59}$ Ya Pedro el Ceremonioso había sacado gran provecho de las rentas de los beneficios que iban quedando vacantes durante el tiempo que duró la indiferencia; al respecto, véase J. VINCKE, Eine königliche Camera Apostolica "Römische Quartalschrift", XLI (1933), pp. 306-310; IDEM, Der König von Aragón und die Camera Aspotolica in den Anfängen des Grossen Schismas, "Gesammelte Aufsätze zur Kulturgeschichte Spaniens”, VII (1938), pp. 84-126.

${ }^{60}$ Así, se ha dicho que una manifestación de la voracidad de la curia pontificia era mantener beneficios vacantes durante un año entero o más, para asegurar a la curia la percepción de los frutos intercalares; cf. H. JEDIN (dir.), Manual de historia de la Iglesia, t. IV, Barcelona, 1973, p. 554 .
} 
ellos adscritos ${ }^{61}$. De hecho, en el cómputo precedente de Guillem Carbonell, la diócesis de Valencia está ausente (como también lo están las de Elna, Urgell y Tarazona), y en las cuentas de Ribalta tampoco aparece anotada ninguna entrada que pudiera retrotraerse a tal periodo vacante.

Así pues, contabilizando los ingresos de dichas rentas, la diócesis de Lérida pasa a ser la que mayores réditos proporcionó a la Cámara apostólica durante aquel año, aún más si se suma aquella cantidad con las 1.415 libras obtenidas a través de los demás expedientes ordinarios. A la vista de estos resultados, es indudable que sería mucho más provechoso apropiarse de las rentas de los beneficios vacantes en lugar de reclamar determinadas exacciones fiscales ${ }^{62}$.

$$
* * *
$$

De cara a un análisis completo de la contabilidad de B. Ribalta, debemos incorporar estos otros ítems de ingresos al cómputo final de dichas cuentas. La distribución de ingresos en cada ejercicio quedaría, pues, de la siguiente manera:

\begin{tabular}{|c|c|c|c|c|}
\hline & $1400-1401$ & $\%$ & $1401-1402$ & $\%$ \\
\hline Saldo anterior & $2.246 \mathrm{lb} .5 \mathrm{~s} .3 \mathrm{~d}^{63}$ & 18,3 & 602 lb. 17 s. 4 d. & 3,1 \\
\hline [Anatas] & $1.593 \mathrm{lb} .14 \mathrm{~s}$. & 13 & $4.025 \mathrm{lb} . \quad 9 \mathrm{~s}$. & 21 \\
\hline Procuraciones & $2.489 \mathrm{lb} . \quad 6 \mathrm{~d}$ & 20,3 & $2.715 \mathrm{lb} . \quad 6 \mathrm{~s}$. & 14,2 \\
\hline Décimas & 5.478 lb. 11 s. 2 d. & 44,7 & 6.870 lb. 15 s. $11 \mathrm{~d}$. & 36 \\
\hline "Comunitates" & $435 \mathrm{lb} .12$ s. 4 d. & 3,6 & $731 \mathrm{lb} .9 \mathrm{~s}$. & 3,8 \\
\hline Expolios & - & - & $49 \mathrm{lb} .2 \mathrm{~s} .6 \mathrm{~d}$. & 0,3 \\
\hline Rentas de Lleida & - & - & $4.152 \mathrm{lb} .10 \mathrm{~s}$ & 21,7 \\
\hline Totales & 12.243 lb. 3 s. 3 d. & & 19.147 lb. 9 s. 9 d. & \\
\hline
\end{tabular}

${ }^{61}$ A ello se refería V. CÁRCEL ORTÍ, Historia de las tres diócesis valencianas: Valencia, Segorbe-Castellón, Orihuela-Alicante, Valencia, 2001, p. 131. El nuevo obispo, Hug de Llupià,, llegó a la diócesis el 19 de agosto de 1400 procedente de Tortosa, pero su nombramiento se había prơducido el 28 de noviembre de 1397; cf. M. a M. CÁRC̣EL OrTí, Casa, Corte y Cancillería del obispo de Valencia Hug de Llupià (1398-1427), "Anuario de Estudios Medievales", 28 (1998), p. 641 .

${ }^{62}$ Posteriormente, una de las principales fuentes de ingresos de las colectorías fue el arrendamiento de los frutos de las sedes vacantes; véase J.M. CARRETERO, art. cit.

${ }^{63}$ Equivalente a 4.048 florines 1 sueldo 3 dineros. Efectivamente éste fue el saldo obtenido por lo administrado por G. Carbonell: $4.541 \mathrm{fl} .2 \mathrm{~s} .8 \mathrm{~d}$. de ingresos y $457 \mathrm{fl}$. $1 \mathrm{~s}$. $6 \mathrm{~d}$. de gastos. Pero una buena parte de dichos ingresos (concretamente 2.965 fl. $1 \mathrm{~s}$. $1 \mathrm{~d}$.) eran de la décima trienal. 
Los montos señalados nos indican un incremento, entre el ejercicio de $1400-01$ y $1401-02$, del $56 \%$ por lo que respecta a los ingresos (en cifras absolutas, algo más de 6.900 libras, incluyendo las poco más de 600 libras del saldo anterior).

Así pues, el segundo ejercicio de Berenguer Ribalta fue algo más fructífero para los intereses de la Cámara apostólica, de una parte, gracias al importante incremento experimentado por los ingresos ordinarios (anatas y demás), y, de otra, gracias a la apropiación de las rentas del obispado de Lleida.

\subsection{Los pagos}

Por lo que concierne a los gastos generados por la colectoría de Berenguer Ribalta pasaremos revista, en primer lugar, al apartado dedicado a los gastos comunes, los derivados de la propia gestión. manera:

Por lo que respecta a 1400-01 podemos extractarlo de la siguiente

- pagos hechos a notarios por la confección de escrituras o traslados, trabajos en los que destaca especialmente el notario barcelonés Pere Brives;

- compra de material de escritorio: papel, cera, cordel...;

- pagos a correos, a portadores de sumas de dinero y gastos de transporte de otras cosas, en particular del obsequio en especie que fue enviado por el subcolector de Mallorca a Barcelona, de donde tuvo que ser redireccionado hacia Aviñón; también se incluiría el precio de una mula utilizada en las visitas a las diócesis, que luego fue donada a la reina María, y que tuvo un coste de $42 \mathrm{lb} .7 \mathrm{~s}$.;

- pago de intereses por los cambios de moneda, tanto de francos como de florines (39 lb. 17 s. 10 d.);

- salario del causídico que trabajaba para la Cámara Apostólica (como tal figura en un principio Pere Torres, de Barcelona, reemplazado luego por Antoni Oliver, entre ambos: 16,5 lb.);

- gastos judiciales, en relación con la condena impuesta a la Cámara Apostólica por la corte del veguer de Barcelona en un pleito sostenido con los herederos de un ciudadano de Mallorca (237 lb. 12 s. 2 d.);

- gastos de representación, en relación con la embajada que hizo el noble Guerau de Cervelló ante el papa ${ }^{64}(137,5 \mathrm{lb}$.);

- pagos asignados a personas del entorno papal (Joan Munyós, familiar, y Ramon Bertran, castellano del palacio pontifical), sin precisar motivos, simplemente cumpliendo órdenes del vicecamarlengo (100 lb.).

A todo ello hay que añadir el estipendio asignado a Berenguer Ribalta y a sus servidores, computando 3 francos diarios que, a razón de 15 sueldos por franco, suman $823 \mathrm{lb}$. y media, lo que implica más o menos la remunera-

\footnotetext{
${ }^{64} \mathrm{Se}$ trata de Guerau Alemany Cervelló i de Queralt $(\dagger 1418)$, que fue camarlengo del rey Martín, en nombre del cual fue enviado como embajador al papa y al rey de Francia. Posteriormente, asistió como procurador al concilio convocado en Perpiñan y fue embajador en el de Pisa.
} 
ción de 365 días. Se trata de una cantidad muy elevada (en comparación, por ejemplo, con lo que sabemos que cobraban los subcolectores de décimas ${ }^{65}$ ), aunque no sabemos qué le quedaría neto a Ribalta después de pagar a sus servidores y al notario apostólico (Francesc Gener) así como los gastos de manutención por los animales que utilizó en sus viajes. Aún así, la parte de Ribalta no sería poca cosa. Sea como fuere, dicha cantidad representa más de la mitad de los gastos comunes.

Por lo que respecta a 1401-02, los gastos consignados son similares, ya que también incluyen remuneraciones a notarios, causídico, correos, material de escritorio, cambios de moneda... Aún se registran algunos pagos pendientes de la época que administró el colector Jaume de Ribes. Seguimos encontrando, de otra parte, diversos pagos realizados a favor de eclesiásticos o de otras personas por mandato del vicecamarlengo, en algunos casos por sumas de dinero importantes; por ej., las 75 libras que fueron entregadas al prior de un monasterio de Mallorca o las 132 libras recibidas por uno de los ardiacas de la iglesia de Gerona por el tiempo que estuvo realizando una embajada. También podríamos destacar las $54 \mathrm{lb}$. $17 \mathrm{~s}$. que habría costado un paño escarlata que se dio al papa, y que fue comprado a un mercader de Aviñón.

En este segundo ejercicio adquiere mayor protagonismo la figura del vicecamarlengo (ejercía como tal Pedro Ademar, abad de San Juan de la Peña), con cuya aprobación se despachan las libranzas de mayor cuantía, al margen, pues, de los gastos administrativos de carácter ordinario que implican cantidades pequeñas o francamente insignificantes.

También aquí debemos añadir el estipendio de Berenguer Ribalta, que se computa a la misma razón que antes, por lo que se anota una cantidad idéntica ( $823 \mathrm{lb}$. y media). El salario del colector general cubre más del $60 \%$ de los gastos comunes.

Los gastos comunes fueron algo más elevados en el primer ejercicio que en el segundo, como así se aprecia en el siguiente cuadro:

\section{Gastos comunes:}

\begin{tabular}{|l|c|c|}
\hline & $\mathbf{1 4 0 0 - 1 4 0 1}$ & $\mathbf{1 4 0 1 - 1 4 0 2}$ \\
\hline (sin estipendio del colector) & $606 \mathrm{lb} .19 \mathrm{~s} .9 \mathrm{~d}$. & $472 \mathrm{lb} .19 \mathrm{~s}$. \\
\hline (incluyendo estipendio) & $1.430 \mathrm{lb} .9 \mathrm{~s} .9 \mathrm{~d}$. & $1.296 \mathrm{lb} .9 \mathrm{~s}$. \\
\hline
\end{tabular}

Como ya he indicado al principio, la segunda parte de los gastos de cada ejercicio está reservada a las transferencias de dinero realizadas a

\footnotetext{
${ }^{65} \mathrm{O}$ en relación con el salario asignado a su predecesor, Guillem Carbonell, que cobró a razón de 15 sueldos barceloneses por día.
} 
Aviñón. Había dos formas de transferir el dinero: el envío de dinero en efectivo o por medio de cambios ${ }^{66}$.

En la contabilidad manejada aquí se anotan, pues, todos los cambios efectuados por Ribalta indicando de cada uno la fecha (de emisión), la suma de dinero cambiada en francos y el equivalente en moneda barcelonesa, con el correspondiente "for" de conversión. También se indica el mercader cambista que operaba en Aviñón y el factor o socio que tenía actuando en Barcelona, ciudad desde donde se hicieron todas las transferencias. Ahora bien, también se consignan algunas cantidades entregadas directamente, como los 2.600 francos que llevó Ribalta en persona cuando viajó a Aviñón en noviembre de 1401, y las llevadas por otras personas que fueron a dicha ciudad como embajadores del rey, como en el caso de Joan de Vallterra (feb.1402) y de Jaume de Prades (oct.-1402) [véase una relación pormenorizada de los distintos cambios efectuados en la tabla E del Anexo].

Un primer aspecto a destacar es la variedad de cambistas con los que Berenguer Ribalta contrató. Durante el primer ejercicio se citan once individuos (dos de ellos, los Alamani, debían de ser hermanos o parientes, ya que actuaban colegiadamente); y algunos menos en el segundo ejercicio: 9. Excepto dos, seguimos registrando a los mismos cambistas mencionados antes.

Según el estudio de J. Favier, los financieros y mercaderes que ayudaron a Benedicto XIII eran italianos en su mayoría (genoveses y florentinos, entre otros), lo que no excluye también alguno catalán ${ }^{67}$. Éste es, precisamente, el cuadro que se desprende de los datos que manejamos aquí, donde la mayoría de nombres referenciados son italianos, aunque sin especificar procedencias, pese a lo cual sabemos que Federigo Imperiale era genovés, Lorenzo Dinozzo era florentino, como también lo era Francesco da Prato, cuyo nombre completo sería Francesco di Marco Datini da Prato, el célebre mercader de todos conocido ${ }^{68}$; el único cambista catalán (así se indica

\footnotetext{
${ }^{66} \mathrm{En}$ ocasiones, se podía recurrir a letras de cambio (entendiendo por ello un documento privado, producido no por un notario sino por un particular, que contenía una orden de pago; véase R. CONDE, Tipologia de la documentació canviària medieval, "Lligall", 7. (1993), pp. 4363). Operaciones de este tipo están documentadas en algunas regestas confeccionadas sobre el fondo del Cisma de Occidente del archivo catedralicio de Barcelona: así, por ejemplo, el 10 de marzo de 1400, el propio Benedicto XIIII confesaba recibir en Aviñón de su cubiculario Francesc Climent 7.000 francos que Pere Maries, mercader residente en dicha plaza, tenía por letra de cambio enviada por Guillem Colom, mercader de Barcelona, con fecha del pasado 22 de diciembre; cf. J. BAUCELLS, El fons “'Cisma d'Occident, p. 163. Otro ejemplo lo tenemos en las cuentas precedentes de Guillem Carbonell, receptor de una letra de cambio enviada por el subcolector de la décima de Lleida respecto de 200 florines que le fueron entregados por un mercader residente en Barcelona (fol. 3r). Por la misma época, ciertos municipios, como Cervera, comenzaron a utilizar letras de cambio para sus transacciones financieras, cada vez con mayor profusión a lo largo de la primera mitad del siglo XV: cf. P. VERDÉS, "Per co que la vila no vage a perdició". La gestió del deute públic en un municipi català (Cervera, 1387-1516), Barcelona, 2004 , p. 137.

${ }^{67}$ El propio Favier se limitó a dar una lista de todos estos cambistas y sus socios (p. 501), si bien con algunos nombres de mercaderes (catalanes) italianizados. Del lado romano, véase L. PALERMO, La finanza pontificia e il banchiere "depositario" nel primo Quattrocento, en D. Strangio (curador), Studi in onore di Ciro Manca, Padova, 2000, pp. 349-78.

${ }^{68}$ Aviñón fue una de les sedes de las diferentes compañías que formaron parte del sistema datiniano, junto con Prato, Florencia, Pisa, Génova y Barcelona; véase I. ORIGO, The Merchant of Prato. Francesco di Marco Datini, Londres, 1957.
} 
expresamente en nuestra fuente) era Pere Maries. A él se refería Favier en relación con diversas operaciones realizadas entre 1389 y 1404. Todos estos mercaderes residían, pues, en Aviñón.

En la correspondiente estadística, podemos ver que hay algunos cambistas con quienes Ribalta efectuó un mayor número de transacciones: destaca, por lo que concierne al primer ejercicio, Andrea de Thiri (12 cambios); y, por lo que respecta al segundo ejercicio, Pere Maries (10 cambios). Así, este Maries, que ocupa el último lugar en el primer ejercicio, pasó a tener el máximo protagonismo durante el segundo ejercicio. De hecho, con algunos de los socios que dicho cambista tenía en Barcelona se llegó a un pacto (1402) por el cual se irían efectuando cambios de 500 francos cada mes: por ello, se anotan diversas pagas, desde enero hasta diciembre, evidentemente manteniendo siempre el mismo "for", que era de $15 \mathrm{~s} .9 \mathrm{~d}$. por franco. También la cantidad global relativa a dicho cambista destaca muy por encima de las sumas negociadas con los demás operadores.

\section{Síntesis de las transferencias realizadas a Aviñón (ordenado por número de cambios)}

\begin{tabular}{|c|l|c|c|}
\hline $\begin{array}{c}\mathbf{N}^{\mathbf{0}} \text { cambios } \\
(\mathbf{1 4 0 0 - 1 4 0 1 )}\end{array}$ & Cambista de Aviñón & $\begin{array}{l}\text { Cuantía } \\
\text { (en francos) }\end{array}$ & \\
\hline 12 & Andrea de Thiri ${ }^{69}$ & $4.700 \mathrm{fr}$. & $44,0 \%$ \\
\hline 6 & Andrea de Besivench & $962 \mathrm{fr}$. & $9,0 \%$ \\
\hline 4 & Miquele de Simon & $1.310 \mathrm{fr}$. & $12,3 \%$ \\
\hline 2 & Fabrini Tholosani & $1.200 \mathrm{fr}$. & $11,2 \%$ \\
\hline 2 & Francesco da Prato & $550 \mathrm{fr}$. & $5,2 \%$ \\
\hline 2 & Antonio y Urbano Alamani & $400 \mathrm{fr}$. & $3,7 \%$ \\
\hline 1 & Filipo Malgonelle & $450 \mathrm{fr}$. & $4,2 \%$ \\
\hline 1 & (no indica) & $400 \mathrm{fr}$. & $3,7 \%$ \\
\hline 1 & Federigo Imperiale & $350 \mathrm{fr}$. & $3,3 \%$ \\
\hline 1 & Domenico de Pazzi & $200 \mathrm{fr}$. & $1,9 \%$ \\
\hline 1 & Pere Maries & $150 \mathrm{fr}$. & $1,4 \%$ \\
\hline & & $\mathbf{1 0 . 6 7 2}$ fr. & \\
\hline
\end{tabular}

${ }^{69}$ Escrito Andrea de Thiri, traducido por Favier como André Thierry. En los regesta de la documentación del Archivo de la Catedral de Barcelona aparece transcrito como Andrea de Trevi. 


\begin{tabular}{|c|l|c|c|}
\hline $\begin{array}{c}\mathbf{N}^{\mathbf{0}} \text { cambios } \\
\mathbf{( 1 4 0 1 - 1 4 0 2 )}\end{array}$ & Cambista de Aviñón & $\begin{array}{l}\text { Cuantía } \\
\text { (en francos) }\end{array}$ & \\
\hline 10 & Pere Maries & $10.700 \mathrm{fr}$. & $53,8 \%$ \\
\hline 7 & Andrea de Thiri & $3.100 \mathrm{fr}$. & $15,6 \%$ \\
\hline 4 & Lorenzo de Dinozzo & $1.500 \mathrm{fr}$. & $7,5 \%$ \\
\hline 3 & Fabrini Tholosani & $1.100 \mathrm{fr}$. & $5,5 \%$ \\
\hline 2 & Filipo Malgonelle & $1.400 \mathrm{fr}$. & $7,0 \%$ \\
\hline 2 & Francesco da Prato & $1.000 \mathrm{fr}$ & $5,0 \%$ \\
\hline 2 & Antonio y Urbano Alamani & $400 \mathrm{fr}$. & $2,0 \%$ \\
\hline 1 & Enrico de Rovilasco & $700 \mathrm{fr}$. & $3,5 \%$ \\
\hline & & $\mathbf{1 9 . 9 0 0 ~ f r . ~}$ & \\
\hline
\end{tabular}

Entre los socios residentes en Barcelona, los había tanto italianos como catalanes: Jaume Biure - citado con anterioridad como intermediario en las transferencias realizadas desde Mallorca-, Pere de Bonahora, Joan Sesavaces (o ses Avasses), Pere Serra y los Maçana, entre otros. Los Maçana, a los cuales ya hemos hecho mención antes a propósito de su intervención en la administración de las rentas del obispado de Lérida, son los únicos cuya profesión era la de ser cambistas; otros aparecen citados como mercaderes. De otros, de los cuales no se indica profesión, cabría presumir que serían igualmente mercaderes.

\begin{tabular}{|l|l|}
\hline Cambistas & Socios barceloneses \\
\hline Andrea de Thiri & Nerio de Niccolò, mercader; Andrea de Pazzi, mercader \\
\hline Andrea de Besinench & Pere de Bonahora \\
\hline Miquele de Simon & Filipo de Lorino; F. Copó; F. Manuel \\
\hline Fabrini Tholosani & P. Tarquini, mercader; F. de Simon; Filipo Soldani \\
\hline Francesco da Prato & Simon Andree; otro Francesco da Prato \\
\hline Antonio y Urbano Alamani & F. Manuel \\
\hline Filipo Malgonelle & Filipozzo Soldani, mercader \\
\hline Lorenzo de Dinozzo & Rossell Soldani; F. de Simon; Andrea de Pazzi \\
\hline Federigo Imperiale & Pere de Galamany \\
\hline
\end{tabular}




\begin{tabular}{|l|l|}
\hline Domenico de Pazzi & Andrea de Pazzi, mercader \\
\hline Pere Maries & $\begin{array}{l}\text { Joan Sesavases / Pere Serra, mercaderes; } \\
\text { Jaume y Joan Maçana, cambistas; } \\
\text { Jaume Biure, draper }\end{array}$ \\
\hline Henricus de Rovilasco & Guillem de Bagat, mercader \\
\hline
\end{tabular}

En cuanto a los "fors" computados en cada operación de cambio, éstos varían constantemente. Durante 1400-01, se dibuja una horquilla comprendida entre un mínimo de 15 sueldos (por franco) y un máximo de 15 sueldos 8 dineros y 1 óbolo (por franco); durante 1401-02, esta horquilla está comprendida entre los 15 sueldos y los 15 sueldos 10 dineros. En el cuadro adjunto podemos apreciar la distribución numérica de cada tipo de for según el mes del año:

Distribución de "fors" a lo largo de cada ejercicio:

\begin{tabular}{|c|c|c|c|c|c|c|c|c|c|c|c|c|c|c|c|c|c|c|}
\hline 15 s. $10 \mathrm{~d}$. & & & & & & & & & 2 & & & & & & & & & \\
\hline 15 s. 9 d. & & & & & & & & & 1 & & & 1 & & 1 & & 1 & & 1 \\
\hline 15 s. 8 d. óbolo & & & 3 & & & & & & & 1 & & & & 1 & & & & \\
\hline 15 s. 8 d. & & 1 & 3 & 2 & & & & & & 1 & & & 3 & 2 & & & & 1 \\
\hline 15 s. 7 d. óbolo & & & & & & & & & & & & & & & & & & 2 \\
\hline 15 s. 7 d. & & 2 & & & & 2 & & & & & & 1 & & 2 & & & & 1 \\
\hline 15 s. 6 d. óbolo & 2 & & & & & & & & & & & & & & & & & \\
\hline 15 s. 6 d. & & & & & & 2 & & & & & & & & & & & & \\
\hline 15 s. 5 d. & & & & & & 5 & 2 & & & & & & & & & & & \\
\hline 15 s. 3 d. & & & & & & & 8 & & & & & & & & & & & \\
\hline 15 s. $1 \mathrm{~d}$. & & & & & & & & & & & & & & & 5 & & & \\
\hline $15 \mathrm{~s}$. & & & & & & & & 1 & & & & & & & 1 & 3 & & \\
\hline Mes: & M & $\mathbf{A}$ & M & $\mathbf{J}$ & $\mathbf{J}$ & $\mathbf{A}$ & $\mathbf{S}$ & 0 & $\mathbf{F}$ & $\mathbf{M}$ & $\mathbf{A}$ & M & $\mathbf{J}$ & $\mathbf{J}$ & $\mathbf{A}$ & $\mathbf{S}$ & o & $\mathbf{N}$ \\
\hline & & & & & 140 & & & & & & & & & 1402 & & & & \\
\hline
\end{tabular}

En total, se anotan, pues, hasta 11 "fors" diferentes, siendo el más usado el estipulado a razón de 15 s. 8 d. Sin embargo, si nos fijamos en las cantidades transferidas en función de uno u otro "for", advertimos que fue precisamente el que se pactó con los representantes del cambista Pere Maries ( $15 \mathrm{~s} .9$ d.) el que despachó una suma mayor (6.000 francos), seguido por los "fors" algo más bajos de $15 \mathrm{~s} .8 \mathrm{~d}$. y $15 \mathrm{~s} .7 \mathrm{~d}$. La mitad del montante de las cantidades cambiadas lo fueron respondiendo, pues, a estos tres "fors". 
Distribución de "fors" en las operaciones con los cambistas:

\begin{tabular}{|c|c|c|c|c|}
\hline \multirow{2}{*}{ For estipulado } & \multicolumn{3}{|c|}{$\mathrm{N}^{0}$ de cambios } & \multirow{2}{*}{$\begin{array}{l}\text { Sumas } \\
\text { cambiadas (\%) }\end{array}$} \\
\hline & $1400-1401$ & $1401-1402$ & Totales & \\
\hline $15 \mathrm{~s}$. & 1 & 4 & 5 & 1.600 fr. $(5,2)$ \\
\hline $15 \mathrm{~s} .1 \mathrm{~d}$. & - & 5 & 5 & 2.700 fr. $(8,8)$ \\
\hline 15 s. 3 d. & 8 & - & 8 & 2.468 fr. $(8,1)$ \\
\hline 15 s. 5 d. & 7 & - & 7 & 2.200 fr. $(7,2)$ \\
\hline 15 s. $6 \mathrm{~d}$ & 2 & - & 2 & 500 fr. $(1,6)$ \\
\hline 15 s. 6 d. óbolo & 2 & - & 2 & 403 fr. $(1,3)$ \\
\hline 15 s. 7 d. & 4 & 4 & 8 & 4.100 fr. $(13,4)$ \\
\hline 15 s. 7 d. óbolo & - & 2 & 2 & 400 fr. $(1,3)$ \\
\hline 15 s. 8 d. & 6 & 7 & 13 & 5.501 fr. (18) \\
\hline 15 s. 8 d. óbolo & 3 & 2 & 5 & 2.700 fr. $(8,8)$ \\
\hline 15 s. 9 d. & - & 5 & 5 & 6.000 fr. $(19,6)$ \\
\hline 15 s. $10 \mathrm{~d}$. & - & 2 & 2 & 2.000 fr. $(6,5)$ \\
\hline
\end{tabular}

El número de operaciones efectuadas entre el primer y el segundo ejercicio es bastante similar: 33 frente a 31 . Estos cambios se iniciaron en marzo de 1401, esto es, cuando ya habían transcurrido seis meses desde que Ribalta asumió el cargo de colector general, y prosiguieron, con desigual ritmo, hasta noviembre de 1402. Con la estancia de por medio en Aviñón (noviembre de 1401), las transferencias correspondientes al primer ejercicio alcanzan hasta el 1 de octubre de 1401, reanudándose - las del segundo ejercicio- a partir del 1 de febrero de 1402. En el gráfico correspondiente (n. ${ }^{\circ}$ 6) podemos apreciar las fluctuaciones de las capitales transferidos a Aviñón, con un máximo alcanzado en febrero de 1402 (más de $3.000 \mathrm{lb}$.). Fue, precisamente, durante el segundo año (1402) cuando se constata un mayor volumen de transferencias. En efecto, si durante el primer ejercicio contabilizamos una transferencia global de 10.672 francos, en el segundo esta cifra casi se duplica: 19.900 francos, más de la mitad adscrita, como hemos dicho, al cambista Pere Maries.

Las transferencias por una u otra vía a Aviñón suman, en moneda de cuenta barcelonesa, unas 10.210 libras el primer año y unas 16.775 libras el segundo año. Esto representa un $83 \%$ y un $87 \%$, respectivamente, de los ingresos obtenidos de la colecta. Éste fue, por tanto, el beneficio neto que habría obtenido la Cámara Apostólica de la colectoría de la Corona de Aragón, para ayudar a cubrir sus necesidades. Dicho a la inversa, entre un 13- 
$17 \%$ de lo ingresado durante aquel bienio no llegó a las arcas pontificias al ser gastado por el colector en su gestión administrativa ${ }^{70}$. Aún así, la parte transferida a Aviñón era importante. ¿Lo sería también para las arcas pontificias en su conjunto? Las dos cantidades indicadas equivaldrían más o menos a 13.613 y 22.366 florines de la Cámara ${ }^{71}$. Así pues, en los dos años administrados por Ribalta se transfirieron a la tesorería pontificia unos 35.979 florines, lo que está en sintonía con otros datos manejados por J. Favier ${ }^{72}$. En 1408, el colector de Aragón transfirió a la tesorería de Benedicto XIII 12.575 florines, una cifra bastante próxima a la que consignamos en $1400-01^{73}$. Esto indica que el nivel de ingresos de la demarcación aragonesa no experimentó, en términos medios, fluctuaciones importantes en los años inmediatamente posteriores. Con todo, el segundo ejercicio de B. Ribalta parece destacar por encima de lo normal, por más que se nutriera también de ingresos pendientes del primer ejercicio.

Según Favier, fue a partir de 1405 cuando la colectoría de Aragón pasó a tener un papel preeminente por la defección de otros territorios a la obediencia aviñonesa, sobre todo por la defección de Francia ${ }^{74}$. De hecho, dicha colectoría se convirtió en el principal sostén financiero de Benedicto XIII, llegando a quintuplicarse su importancia financiera. Entre 1404-08, la contribución aragonesa representaba, según el indicado autor, una cuarta parte de las entradas de dinero de la Tesorería ${ }^{75}$.

Obviamente, no podemos saber, a partir de la fuente que manejamos, en qué se gastó el dinero procedente de la Corona de Aragón o de qué forma fue utilizado por el fisco papal, aunque lo más probable es que hubiera servido para pagar, no sólo los gastos más ordinarios de la administración pontificia, sino también los derivados de la defensa del palacio de Aviñón, que aún continuaba asediado en los primeros años del siglo $\mathrm{XV}^{76}$.

\footnotetext{
${ }^{70}$ Efectivamente, la resta de ingresos del ejercicio de 1400-01 (en torno a $2.033 \mathrm{lb}$.) coincide con la suma de los gastos comunes (1.430 lb.) y del saldo transferido al siguiente ejercicio (602 $\mathrm{lb}$.); la misma coincidencia se observaría con respecto al ejercicio de 1401-02 si no fuera por un diferencial de unas $10 \mathrm{lb}$., probablemente debido a un error de cálculo derivado del hecho de haber anotado, como total de gasto, $18.082 \mathrm{lb}$. en lugar de las $18.072 \mathrm{lb}$, , que es la suma verdadera.

${ }^{71}$ Cálculo realizado a razón de 40 sueldos aviñoneses por libra barcelonesa y la equivalencia: 30 sueldos aviñoneses $=1$ florín de la Cámara.

${ }^{72} \mathrm{Tal}$ cifra viene a representar la mitad de los 73.660 florines que se contabilizan en los cuatro años comprendidos entre 1404-1408; cf. J. FAVIER, ob. cit. p. 428. Asimismo, en un solo mes (agosto de 1405) la corte de Benedicto XIII consignó haber ingresado 7.247 florines de la Camara, de los cuales 3.360 florines fueron recibidos por vía de cambio por parte de Pere Regacol, subcolector general de Aragón, a través de unos banqueros genoveses; cf. A. PÉREZ CASTILLO, El balanç econòmic de la Cúria de Benet XIII l'agost de 1405, en Jornades sobre el Cisma d'Óccident a Catalunya, les Illes i el País Valencia (Segona Part), Barcelona, 1988, pp. 531-545.

${ }^{73}$ Cf. J. FAVIER, ob. cit., p. 475.

${ }^{74}$ Antes, "la France avait éte avec l'Aragon la grande source des revenus de la Papauté avignonnaise" (p. 674).

${ }^{75}$ Cf. J. FAVIER, ob. cit., p. 428.

${ }^{76} \mathrm{Al}$ respecto, véase G. BUTAUD, Les deux sièges du palais apostolique d'Avignon (13981411) en Ch. RAYNAUD (dir.), Villes en guerre (XIV-XV sieccles), Aix-en-Provence, 2008, pp. 103-126. La mayor partida de gasto (354 florines $=194 \mathrm{lb}$. $14 \mathrm{~s}$.) de las cuentas precedentes de Guillem Carbonell se refiere al pago que aún estaba pendiente del estipendio que fue acordado
} 
Por último, sólo queda referirse a la liquidación de las cuentas. Ambos ejercicios tienen consignados saldos positivos (los ingresos superan a los gastos): en el primero, de unas 600 libras, y en el segundo, que representa el saldo final de la administración de esta colectoría, de $1.065 \mathrm{lb} .8 \mathrm{~s} .3 \mathrm{~d}$. Esta es la cantidad que Berenguer Ribalta debía entregar a la Cámara Apostólica para poder finiquitar su cuenta, como así se hizo.

\section{Las cuentas de B. Ribalta (cómputo global):}

\begin{tabular}{|l|c|c|c|}
\hline & \multicolumn{1}{|c|}{ Ingresos } & \multicolumn{1}{|c|}{ Gastos } & \multicolumn{1}{c|}{ Saldo } \\
\hline 1400-1401: & 12.243 lb. 3 s. 3 d. & 11.640 lb. 5 s. 11 d. & $(+) 602$ lb. 17 s. 4 d. \\
\hline 1401-1402: & 19.147 lb. 9 s. 9 d. & 18.082 lb. 1 s. 6 d. & $(+) 1.065$ lb. 8 s. 3 d. \\
\hline
\end{tabular}

Así, mientras el sobrante de 1400-01 se trasladó a los ingresos del siguiente ejercicio, el sobrante de éste fue transferido a Aviñón. B. Ribalta envió a la Cámara Apostólica por medio de Jorge Richi, socio de Jaume de Soler, mercader/draper de Aviñón, 1.363 francos 11 grossos, equivalente al indicado saldo ${ }^{77}$.

Nuestro Berenguer Ribalta siguió ejerciendo como colector de la Cámara Apostólica hasta su muerte, acaecida en marzo de 1405, cuando aún no hacía ni un año que había sido nombrado obispo de Tarazona ${ }^{78}$.

con algunos contingentes de soldados que acudieron a Aviñón en 1398 para socorrer al Papa en el momento de mayor peligro. También las cuentas analizadas por G. Mollat (Elna) anotan diferentes gastos relacionados con el asedio del Palacio de Avinón, hasta el momento de la evasión papal. Los gastos de carácter bélico (retribución de hombres de armas, provisiones destinadas a una galera...) continuaban siendo importantes (más del 30\%) en las cuentas realizadas por el tesorero del Papa en el mes de agosto de 1405; véase A. PÉREZ CASTILLO, art. Cit.

${ }^{77}$ Ello se hizo computando cada franco a razón de 15 sueldos, 7 dineros y 1 óbolo de moneda barcelonesa.

${ }^{78}$ Ello habría sido como recompensa a los servicios prestados al papa, según postulaba $\mathrm{N}$. JASPERT, Centro y periferia: los superiores de la orden del Santo Sepulcro y sus prioratos en la Corona catalano-aragonesa, en II Jornadas de Estudio: La Orden del Santo Sepulcro (Zaragoza, 23-26 de noviembre de 1995), Zaragoza, 1996, p. 138. ID., Stift und Stadt: das Heiliggrabpriorat von Santa Anna und das Regularkanonikerstift Santa Ëulälia del Camp im mittelalterlichen Barcelona (1145-1423), Berlin, 1996, p. 400. 


\section{CONCLUSIONES}

A partir del libro contable utilizado, hemos podido ver, ante todo, cómo se organizaba una colectoría sometida a la obediencia aviñonesa. Pero esta colectoría, que internamente estaba constituida por 14 diócesis, dos de las cuales eran capitales de provincia, distaba bastante de ser una entidad homogénea, ya que dichas circunscripciones eclesiásticas no eran del todo coincidentes con las fronteras políticas de los distintos reinos o territorios que configuraban la Corona de Aragón, y tampoco existía un único sistema monetario uniformizador para todo el conjunto.

Como se ha visto, Barcelona fue el centro de operaciones de la colectoría de Aragón. Berenguer Ribalta, siendo prior del convento barcelonés de Santa Ana, habría realizado buena parte de su labor en dicha ciudad, dejando a otros que actuaran en su nombre mientras estuvo viajando por las distintas sedes diocesanas o en el intermedio que fue a Aviñón; aún así, todos los itinerarios seguidos por los distintos territorios de la Corona de Aragón habrían tenido la Ciudad Condal como punto de retorno. No en balde, muchos de los notarios que firman ápocas eran barceloneses, aunque también los había de otras localidades visitadas. También eran de aquella ciudad la mayoría de mercaderes que se citan como intermediarios de los sucesivos pagos realizados, y cuya presencia se detecta un poco por todas partes. Por no hablar, por otro lado, de los cambios transferidos a Aviñón desde Barcelona, por medio de los socios barceloneses o domiciliados en la ciudad que actuaban en representación de los cambistas aviñonenses. También en el ámbito que nos ocupa, Barcelona desempeñaba un importante papel como centro financiero para toda el área catalanoaragonesa (e incluso más allá de las fronteras del reino $^{79}$ ). Pese a no ser cabeza de una archidiócesis (como Tarragona o Zaragoza), sino una simple diócesis, Barcelona sería la capital de la colectoría.

B. Ribalta estuvo asistido en su labor por otras personas que actuaron como procuradores, además de sus propios subordinados (en especial, el notario apostólico Francesc Gener) y del plantel de subcolectores, oficio en el que vemos desfilar eclesiásticos de diferente rango, pero en el que figuran sobre todo religiosos seculares (bastantes canónigos, además de simples presbíteros y rectores de parroquias), generalmente de la propia diócesis donde se realizaba la colecta. De hecho, cabe diferenciar entre tres tipos de subcolectores: de las anatas y procuraciones (derechos apostólicos propiamente dichos), de las décimas y de los subsidios. Al respecto, cabe señalar el caso particular de Elna, pues la colecta de los derechos apostólicos de este obispado estaba siendo gestionada al margen de la colectoría de Aragón.

\footnotetext{
${ }^{79}$ Según señalaba Favier, también iban a realizar operaciones de cambio en Barcelona algụnos colectores de Castilla: los de Burgos y a veces también los de Toledo, cuando estaban demasiado lejos de Sevilla; cf. J. FAVIER, ob. cit., p. 501.
} 
Aparte de esto, el análisis de la colectoría de B. Ribalta nos ha permitido ver cuáles eran los ingresos que la Cámara Apostólica de Aviñón percibía en los territorios de la Corona de Aragón, y la importancia -en cifras absolutas y porcentuales - de cada tipo de entrada.

Sin lugar a dudas, el principal ingreso de esta colectoría provenía de las décimas, las cuales reportaban más del doble o del triple de lo que se recaudaba de las demás exacciones (incluso contabilizados juntos, los ingresos de anatas y procuraciones apenas llegan a igualarse con el producto obtenido de las décimas), y aún debe tenerse en cuenta que la Cámara Apostólica sólo podía disponer de una tercera parte de aquel impuesto, puesto que las dos otras partes eran cedidas, invariablemente, a la monarquía. De hecho, este impuesto se extendía a todos los beneficios eclesiásticos, salvo los que gozaban de exenciones, mientras que otras tasas, como las anatas, sólo se aplicaban sobre determinados beneficios (a propósito de cambios de titular). Las restantes entradas tienen un carácter residual, como los expolios, que apenas aportan nada en la contabilidad analizada aquí. Claro que parte de lo que ingresaba la Colectoría eran atrasos o cantidades pendientes de tiempos atrás: lo hemos visto en el caso sobre todo de las décimas, pues hay registrados ingresos pertenecientes aún a las concesiones de 1393, 1396 y 1397. Naturalmente, la principal entrada se corresponde con la décima coetánea de 1400 , sobre todo en la contabilidad del segundo ejercicio. De esta décima, que en realidad era la continuación de la de 1393, se obtiene un total (entre los dos ejercicios) próximo a 10.500 libras. La suma de todas las décimas es de unas 12.350 libras, frente a las 5.600 libras de las anatas y las algo más de 5.000 libras de las procuraciones (sumando también los resultados obtenidos en ambos ejercicios), y esto sin tener en cuenta lo ingresado en la anterior administración de $\mathrm{G}$. Carbonell, donde el monto de las décimas era de $1.630 \mathrm{lb}$., cifra que representa el $65 \%$ del total de sus cuentas.

Como ingreso de carácter extraordinario, destaca la entrada proveniente de la administración de las rentas del obispado de Lleida, que representa más del $20 \%$ de los ingresos obtenidos en el segundo ejercicio. Frente al cúmulo de exacciones fiscales que gravitaban sobre los beneficios, parece que aún más rentable para las arcas pontificias sería la apropiación de las rentas de los obispados vacantes. Según parece, este modo de proceder se dio en más de una ocasión, afectando a otros obispados, a lo largo del pontificado de Benedicto XIII, siendo una forma de obtener mayores ingresos para las arcas aviñonesas.

A la vista de todos estos datos, es evidente que existen importantes diferencias con respecto a las colectorías del siglo XVI estudiadas por J.M. Carretero, ya que en ellas tanto las vacantes propiamente dichas como el derecho de expolio tenían suma relevancia, frente a la inexistencia o no consignación de otras fuentes de renta ${ }^{80}$.

\footnotetext{
${ }^{80}$ Asimismo, en la colectoría administrada en Castilla en la década de 1470, la principal fuente de ingresos habría sido la procedente de la concesión de indulgencias a determinadas iglesias, por lo menos en comparación con el monto aparentemente más ređucido de otros ingresos de carácter ordinario (censos y anatas); cf. J. FERNANDEZ ALONSO, Los enviados pontificios, p. 83.
} 
La colectoría de B. Ribalta habría ingresado 31.390 libras en el bienio analizado: en cifras redondas, unas 12.000 en el primer ejercicio, 19.000 en el segundo. La diferencia entre ambos montos se explica en parte por los ingresos del obispado de Lleida. Pasando por alto esta partida de carácter más extraordinaria, podemos situar la recaudación media de la Corona de Aragón entre las 13.000 y 14.000 libras. Aunque importantes, no se trata de cuantías espectaculares. Naturalmente, aquí únicamente tenemos en cuenta las fuentes de ingresos más o menos ordinarias, de manera que no sabemos si hubo recurso a otros expedientes, como los préstamos realizados al Papa en años posteriores $^{81}$.

Al margen de las cifras globales, hemos podido observar las desigualdades internas que presentaba la colectoría de Aragón. De las 14 diócesis que componían la colectoría de la Corona de Aragón, la más productiva para la Cámara Apostólica en términos financieros era la de Zaragoza, quizás por ser una de las más extensas y, por ello mismo, una de las que debía tener un mayor número de beneficios sujetos a gravamen. La situación pujante del obispado de Zaragoza de alguna manera se corresponde con el creciente papel protagonista que iba a desempeñar Aragón en el ámbito de la Corona, tanto desde el punto de vista económico como político (compromiso de Caspe), y tampoco sería ajeno al hecho de que hubiera sido precisamente un aragonés, Pedro de Luna, quién pasó a ocupar el solio pontificio. Como hemos visto en la evaluación por provincias eclesiásticas, la de Zaragoza (con sus diócesis sufragáneas) representaba la cuarta parte del conjunto de la recaudación de la Corona de Aragón.

A nivel más interno, se aprecia la gran diferencia existente entre la sede zaragozana y las restantes circunscripciones que le estaban subordinadas (Tarazona, Huesca y Segorbe), porque mientras aquélla ocupa el primer lugar del ranking de la Corona de Aragón, las otras tres se sitúan en las últimas posiciones. La de Segorbe era, con diferencia, la diócesis con menor rendimiento fiscal de toda la Corona de Aragón. En cambio, una situación tan contrastada no se observa en el seno de la provincia tarraconense; es más, en este caso, la capital de provincia (Tarragona) no era la que mayores ingresos reportaba a las arcas aviñonesas, puesto que parece que había otras diócesis (la de Valencia, por descontado) que tenían un mayor peso contributivo. Así mismo, el obispado de Barcelona se sitúa por debajo del de Tarragona en los dos ejercicios contables. Claro que hay que tomar estos resultados con ciertas reservas, puesto que, por una u otra circunstancia, algunas diócesis habrían rendido menos de lo que en principio cabría esperar de ellas (sería necesario realizar aquí un estudio pormenorizado de cada colecta diocesana, contabilizando el número de beneficios sujetos a contribución y su valoración, reseñando las posibles dificultades surgidas en la recaudación de los correspondientes tributos). Sea como fuere, lo recaudado en la provincia

\footnotetext{
${ }^{81}$ Se trataba de importantes cantidades: 500.000 florines $(275.000 \mathrm{lb}$.) en 1404 y 350.000 florines (192.500 lb.) en 1407; cf. J. BAUCELLS, El fons "Cisma d'Occident, pp. 242-243. Ello se enmarca en el nuevo período abierto tras la huída del Papa del palacio de Avinón: "ce fut dans les années 1403-1408 une veritable course au crédit”, decía J. FAVIER, ob. cit., pp. 670-71.
} 
eclesiástica de Tarragona era dos veces más de lo que se obtenía de la vecina provincia de Zaragoza.

Por territorios, no hay duda de que la mayor partida recaudatoria provenía de las diócesis catalanas; las aragonesas aportaban en su conjunto 1/5 parte, algo menos Valencia y Mallorca en torno al 5\%. En otras palabras, el peso de las diócesis catalanas seguía siendo netamente mayor que el representado por Aragón o por Valencia, y no digamos ya por Mallorca.

Los gastos son similares en uno y otro ejercicio. Entre los gastos comunes, destaca el estipendio cobrado por el colector, que incluiría el pago de dietas y del personal de servicio, y representa entre 57,5 y $63,5 \%$ de dichos gastos comunes en los respectivos ejercicios contabilizados. Aparte, también destacan algunos gastos judiciales (derivados de algunos pleitos) y de representación (embajadas), entre otros capítulos. Algunos pagos fueron realizados por mandato expreso del vicecamarlengo de Aviñón, a quién estaba supeditado el colector.

Como hemos visto, se anotan numerosos cambios de moneda barcelonesa a francos, y aparte de las transferencias realizadas desde Barcelona, también se anotan algunas cantidades en metálico llevadas a Aviñón por algunas personas, como el propio Ribalta, cuando se trasladó a dicha plaza en noviembre de 1401. Pese a los altibajos registrados, estas transferencias de dinero tendieron a incrementarse entre 1401 y 1402. Ribalta contrató con una docena de cambistas aviñoneses o, mejor dicho, con sus respectivos socios en Barcelona, entre los que figuran tanto catalanes como extranjeros (italianos). A pesar del gran número de operadores, Ribalta optó por dar preferencia al grupo de Pere Maries, con quién pactó la transferencia de pagas regulares a un "for" único de $15 \mathrm{~s}$. 9 d. por franco. Con ellos se hicieron cambios por valor de hasta 10.700 francos durante 1401-02, lo que representa más de la mitad del monto contabilizado en este ejercicio. Los "fors" utilizados también fueron variando en el transcurso del periodo analizado y dependiendo también de las transacciones realizadas con las diferentes personas con las cuales se hicieron tratos, pero al menos $1 / 5$ parte del capital manejado quedó estipulado a razón de $15 \mathrm{~s} .8 \mathrm{~d}$. por franco. Por término medio (considerando los dos ejercicios), se hicieron transferencias por una u otra vía por valor de 13.500 lb.b., lo que vendría a suponer, también por término medio, un $86 \%$ de los ingresos administrados por B. Ribalta durante su bienio. Aún en el momento de la liquidación de estas cuentas se anota un saldo de poco más de 1.000 libras que fueron transferidas a Aviñón mediante otro cambio, cantidad que debería ser añadida a aquella otra. Por tanto, no hay duda de que la mayor parte del numerario administrado fue a parar a las arcas pontificias, al margen de la resta consumida por la administración del propio colector, y en buena medida habrían ayudado a salvar al papa mientras estuvo asediado en su palacio-búnquer de Aviñón.

Los ingresos procedentes de la colectoría de Aragón podrían representar entre un 10-17\% de los ingresos pontificios (si tomamos en consideración los 130.000 florines que indicaba J. Favier para 1404-1405) o 
incluso más ${ }^{82}$. A causa de la defección de otros reinos, o más concretamente a partir de la segunda sustracción de la obediencia francesa (1407), la situación financiera del papa Luna se mantuvo únicamente gracias al aporte de la Corona de Aragón, cuya obediencia iba a perdurar aún durante bastantes años. Sin embargo, en opinión de J. Favier, las finanzas de Benedicto XIII dejaron de ser las de un papa a partir de cuando éste pasó a instalarse en Perpiñán para inaugurar un concilio con sus incondicionales $(1408-09)^{83}$.

Como es sabido, el fin del Cisma, a partir del concilio de Constanza (1414-18), dio paso a una nueva época caracterizada por el auge del conciliarismo, que supuso una limitación del poder de los pontífices y, lo que más interesa destacar aquí, una notable reducción del fiscalismo pontificio dentro de los distintos estados, al menos en aquellos en los que tal fiscalismo tuvo mayor incidencia, como parece ser el caso de la Corona de Aragón (sobre todo, supuso poner freno a la continua demanda de décimas) ${ }^{84}$. En palabras de J. Favier, se produjo la ruina del sistema aviñonense, que en 1429 había reducido los ingresos papales a la tercera parte con relación a 1378 . También el retorno de los papas a Roma supuso un giro de orientación de las finanzas pontificias, que pasaron a nutrirse más bien de las rentas procedentes de su patrimonio italiano (aumento de las rentas temporales frente a la disminución de las rentas espirituales). Todo parece coincidir, pues, con el declive de las colectorías, al menos tal y como éstas habían estado funcionando a lo largo del siglo XIV. Al respecto, la gestionada por B. Ribalta se corresponde con el final de la época de mayor esplendor del fiscalismo pontificio tal y como se vino practicando en Aviñón.

Fecha de recepción del artículo: diciembre 2008.

Fecha de aceptación y versión final: marzo 2009.

${ }^{82} \mathrm{Cf}$. J. FAVIER, ob. cit., p. 688. Como ya se ha indicado anteriormente, en otra parte de este artículo, se estima que la colecta de Aragón podría representar $1 / 4$ parte del total.

${ }^{83}$ Cf. J. FAVIER, ob. cit., p. 679.

${ }^{84}$ En el ámbito de la Corona de Aragón, se observa un mayor recurso a los subsidios, los cuales debían ser aprobados en el seno de concilios territoriales. En cambio tan sólo se registra una décima en el periodo comprendido entre el comienzo del reinado de Alfonso el Magnanimo segle XV (Regnats d'Alfons Vi Joan II), València, 1997, pp.193-326. 



\section{ANEXO}

I. MAPAS

II. GRÁFICOS

III. TABLAS 


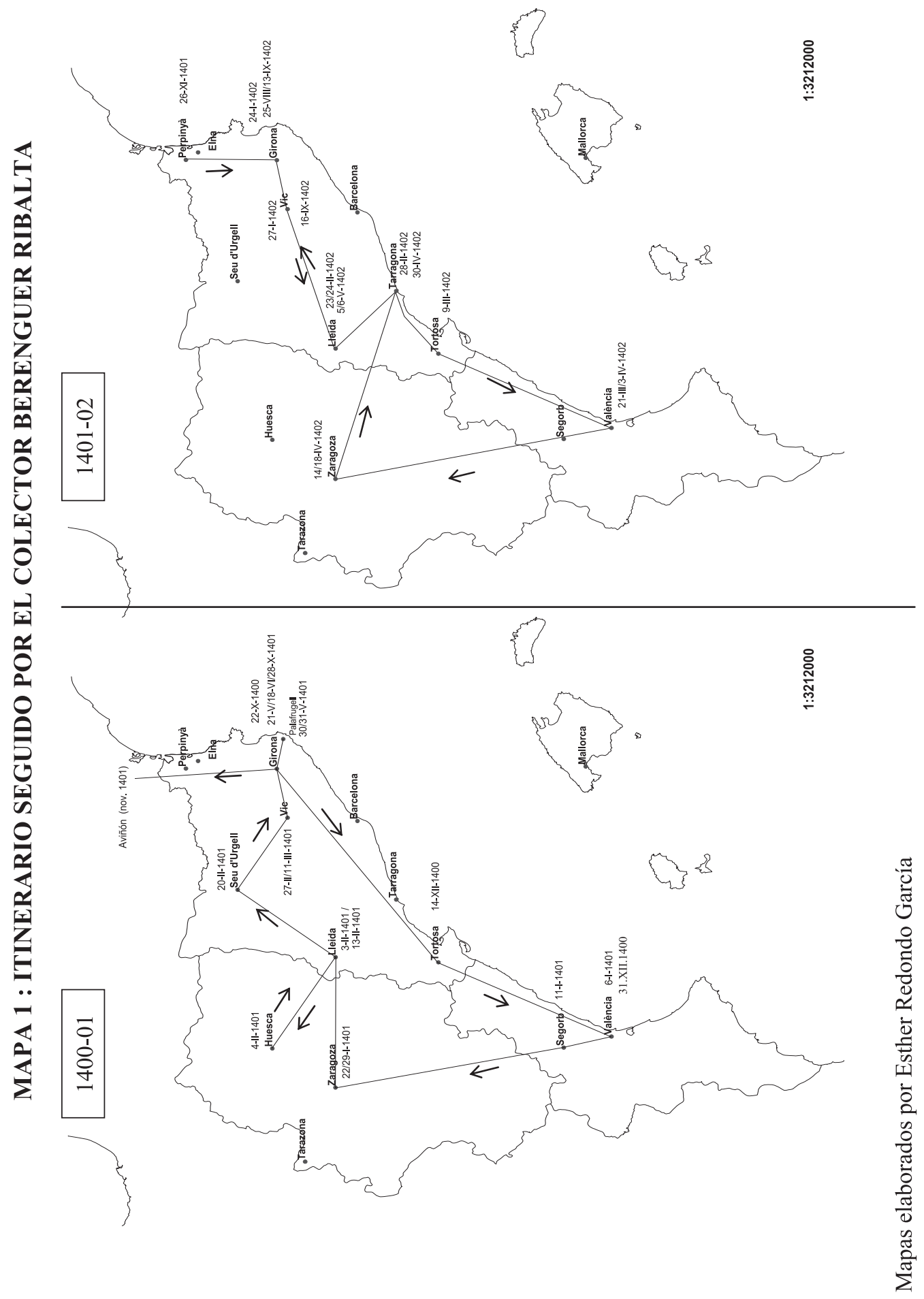




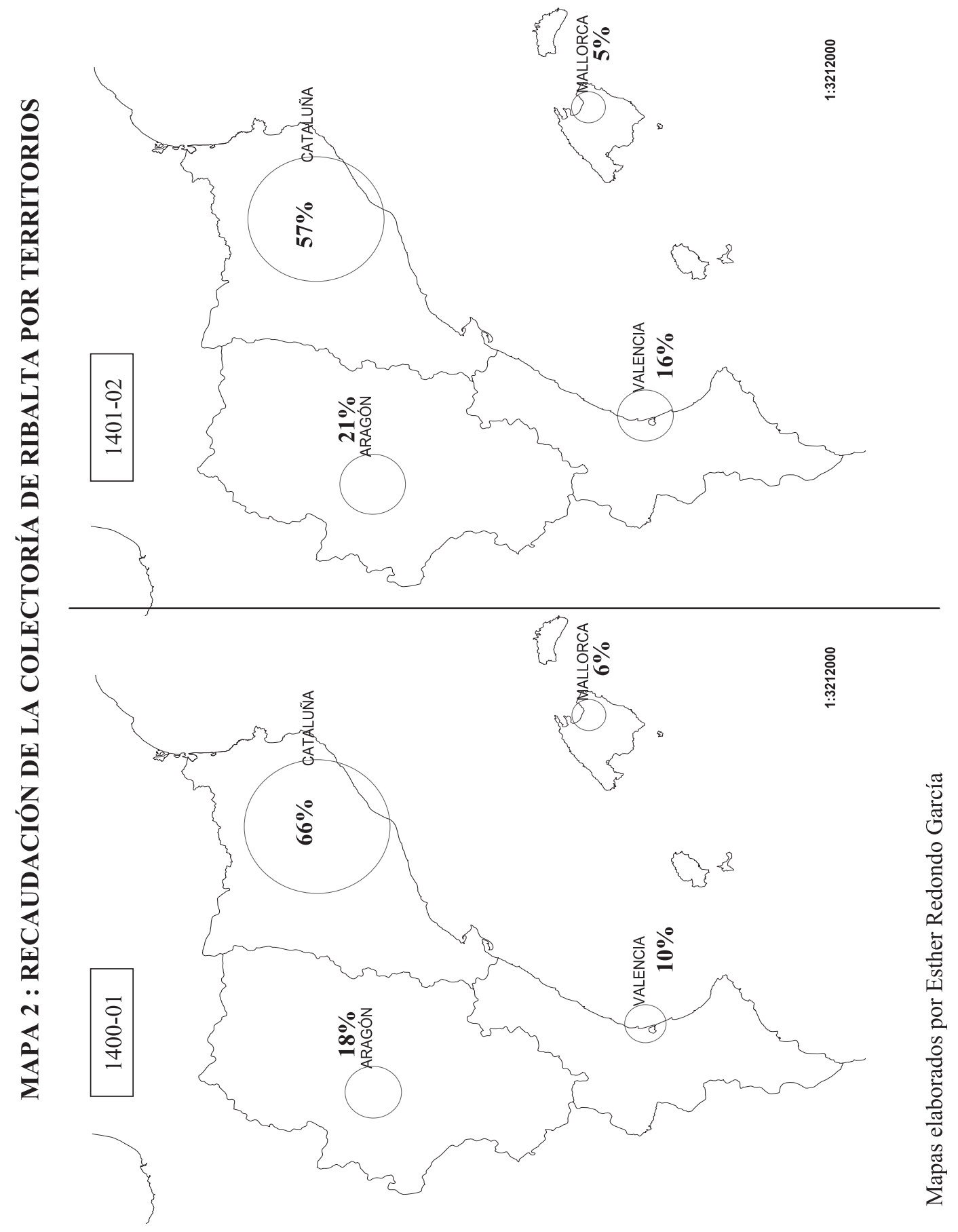



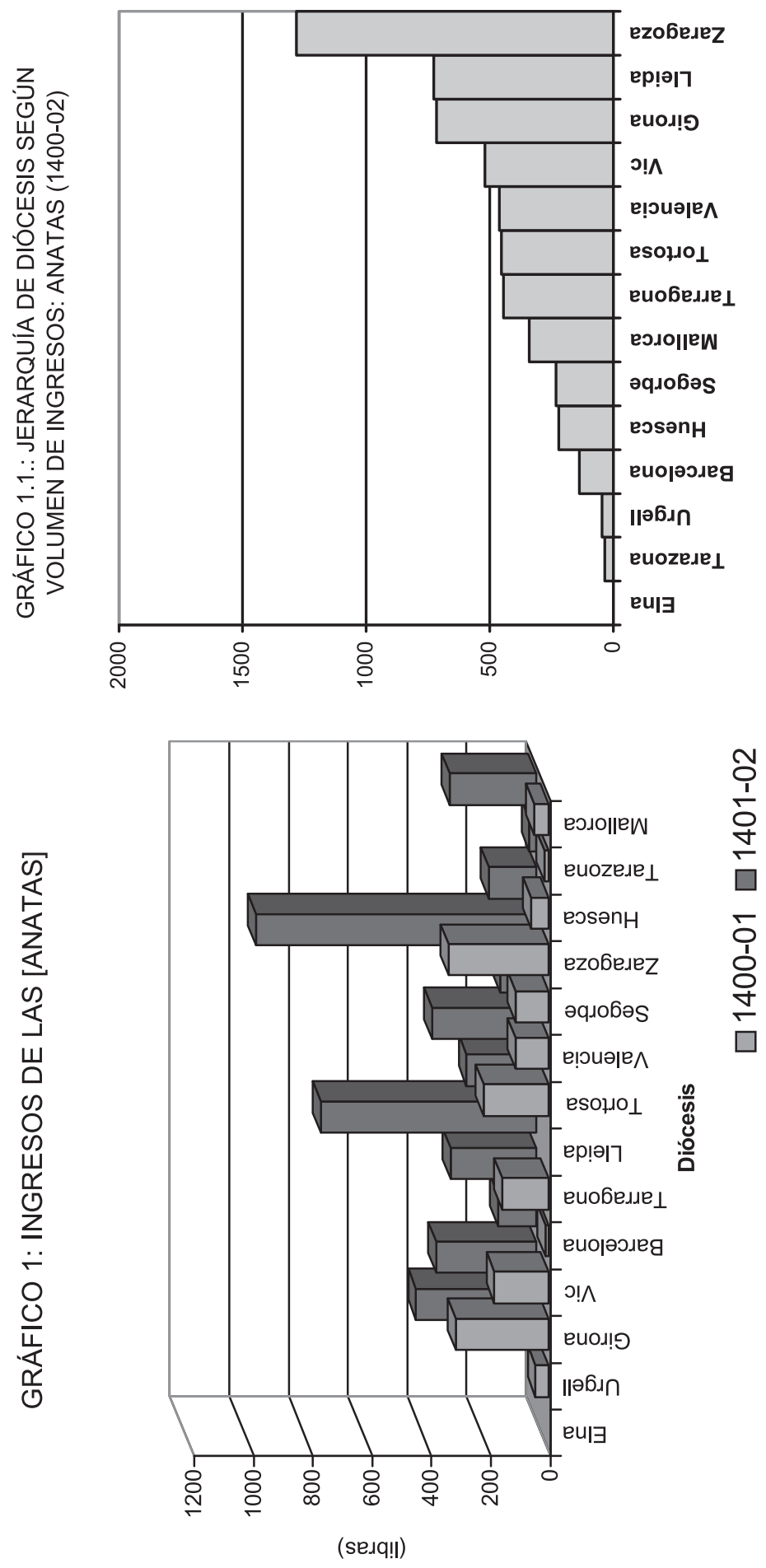

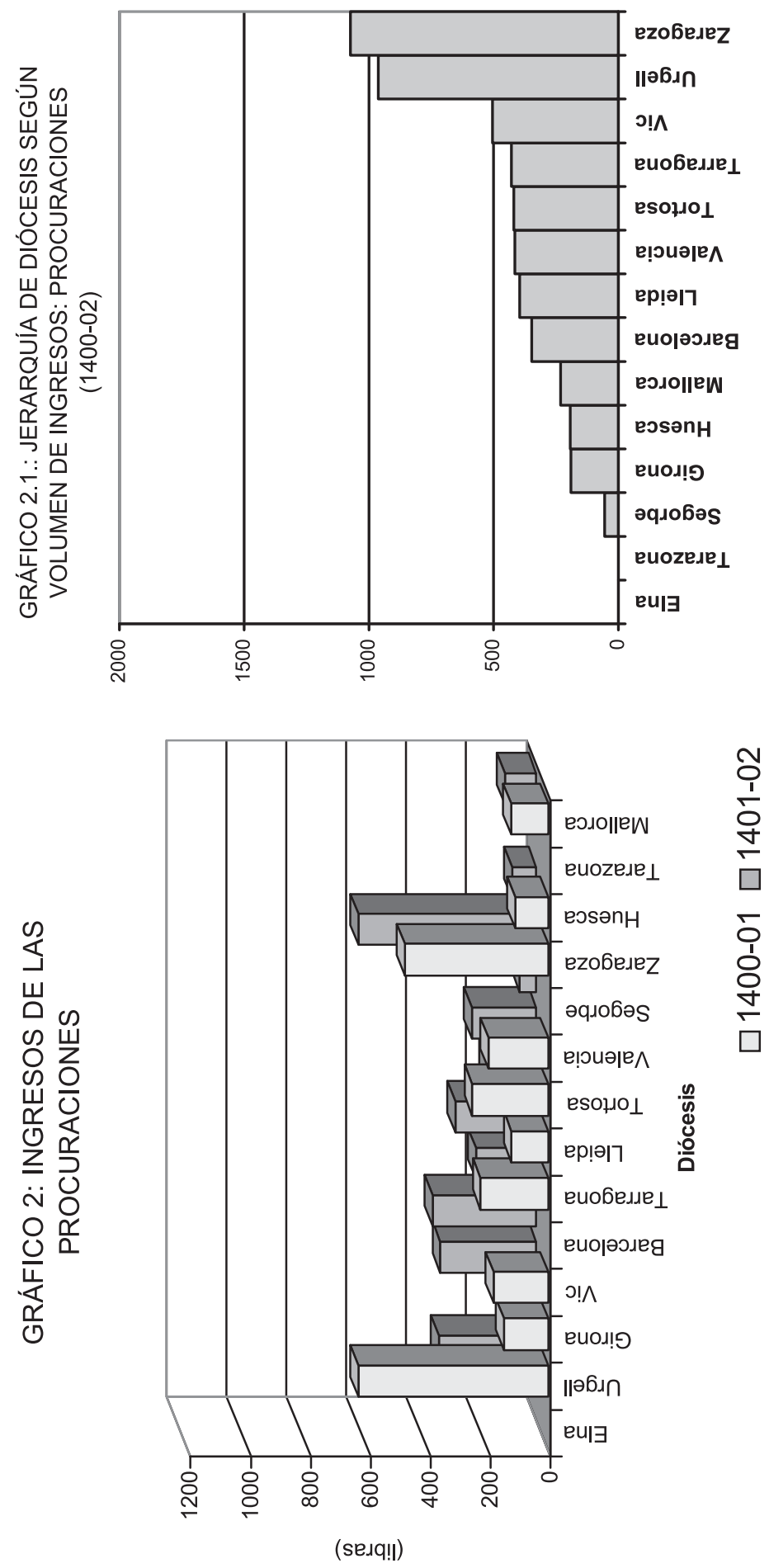

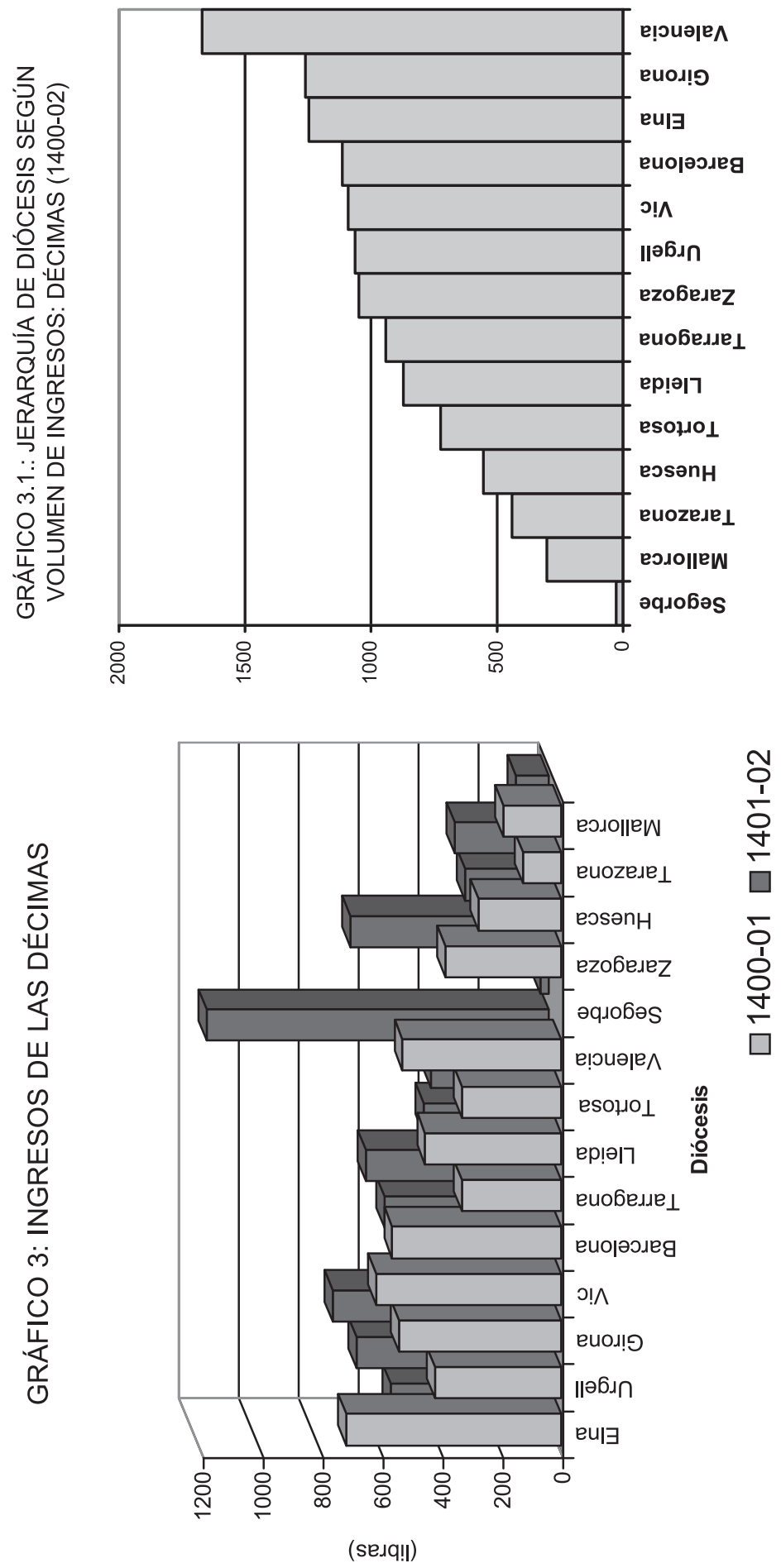

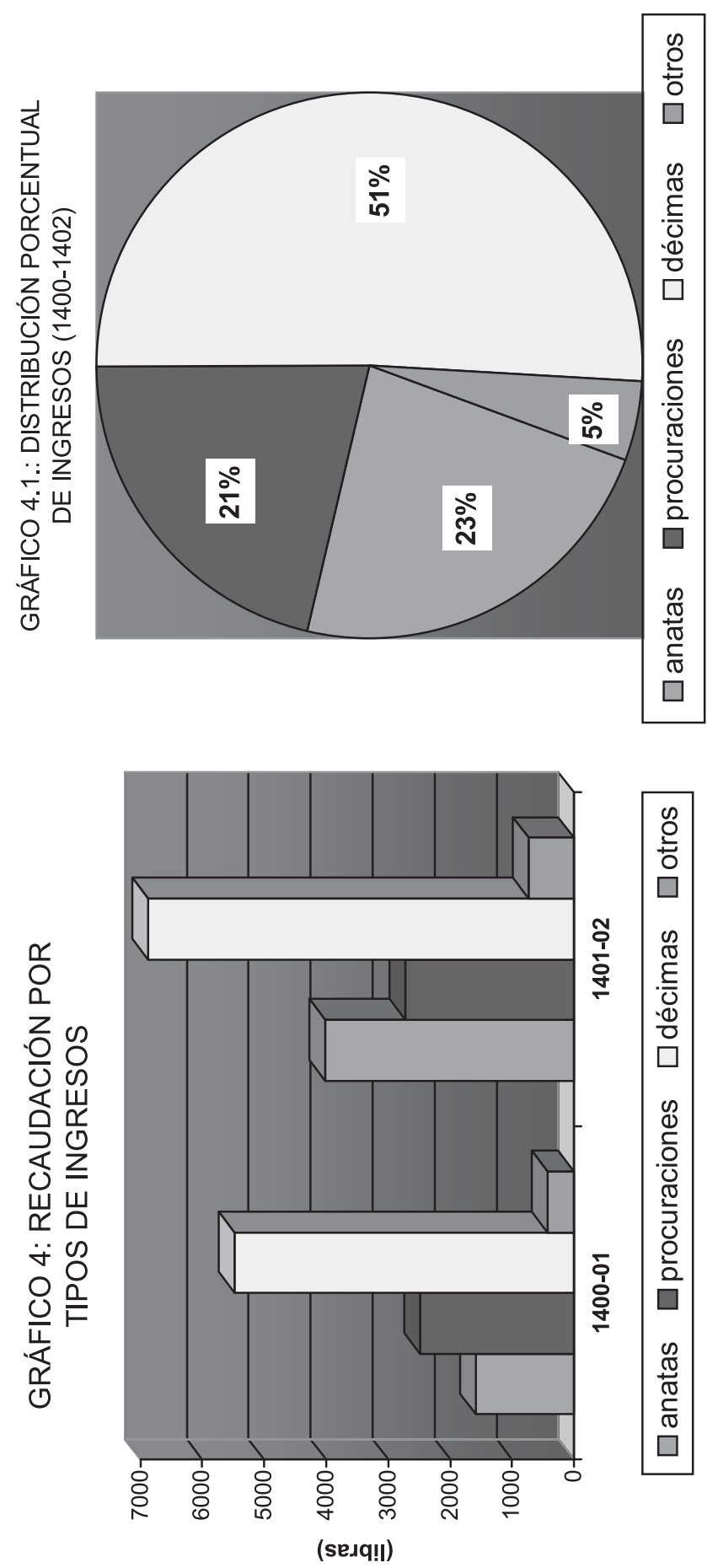


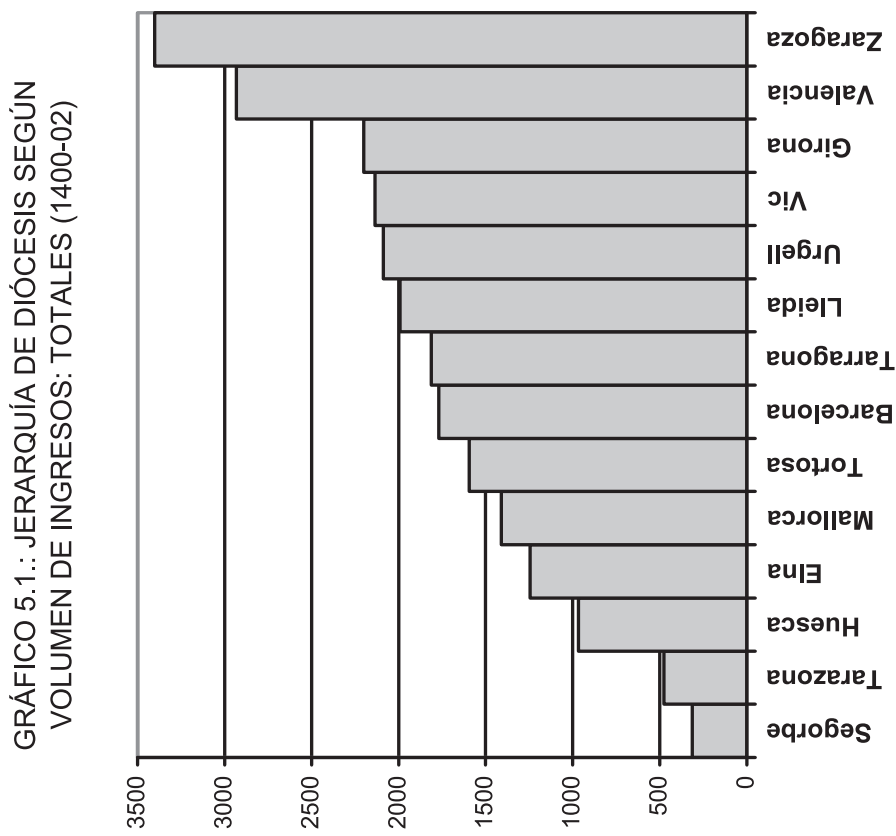

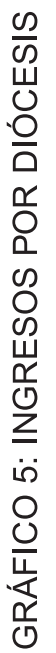

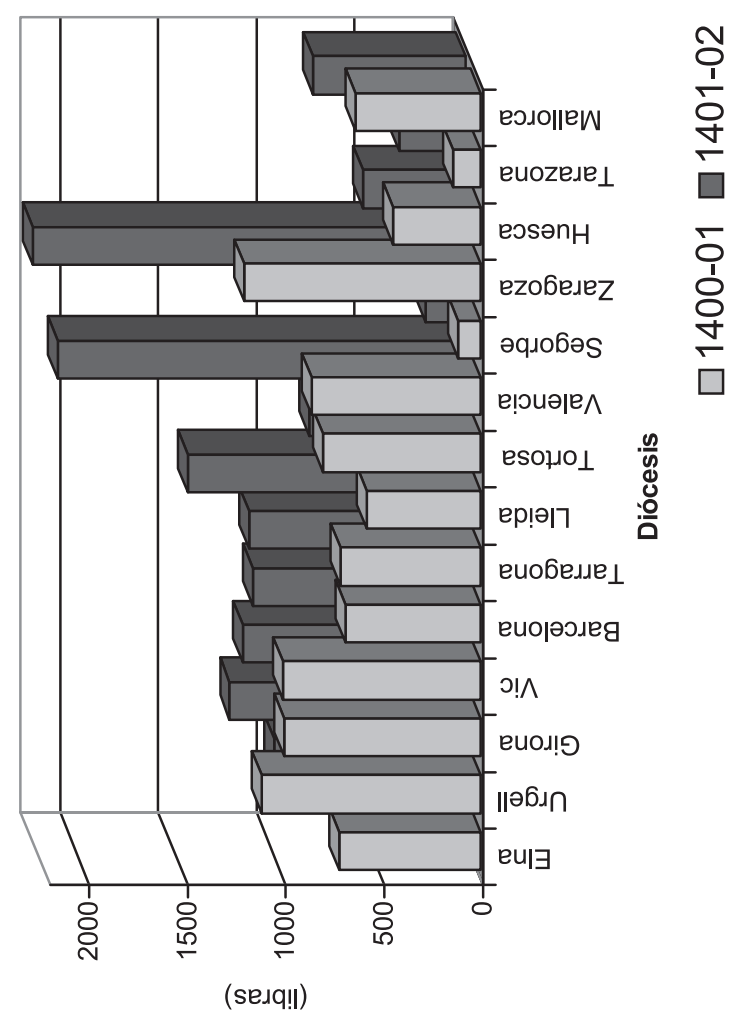




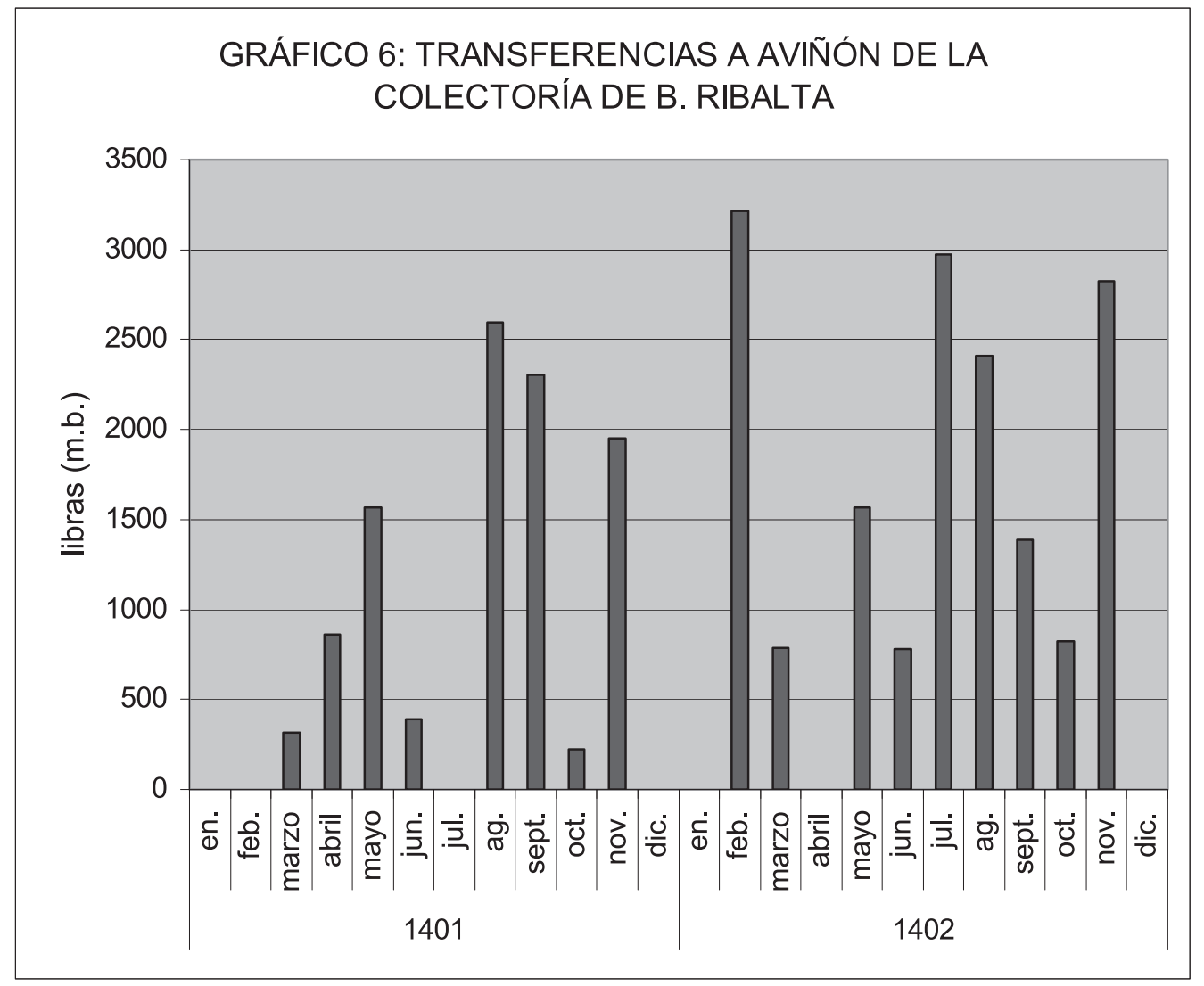




\section{ANEXO III}

\section{TABLAS}

\section{A. ITINERARIO SEGUIDO POR BERENGUER RIBALTA:}

\begin{tabular}{|c|l|l|}
\hline Fecha & Localidad & Folio \\
\hline 22.X.1400 & Girona & $(11 \mathrm{v})$ \\
14.XII.1400 & Tortosa & $(22 \mathrm{v})$ \\
31.XII.1400 & Valencia & $(25 \mathrm{r})$ \\
6.I.1401 & Íd. & $(24 \mathrm{v})$ \\
11.I.1401 & Segorbe & $(26 \mathrm{v})$ \\
22.I.1401 & Zaragoza & $(28 \mathrm{r})$ \\
29.I.1401 & Íd. & $(27 \mathrm{v})$ \\
3.II.1401 & Lleida & $(21 \mathrm{v})$ \\
4.II.1401 & Huesca & $(30 \mathrm{v})$ \\
13.II.1401 & Lleida & $(21 \mathrm{r})$ \\
20.II.1401 & Urgell & $(9 \mathrm{v}, 10 \mathrm{r})$ \\
27.II.1401 & Vic & $(13 \mathrm{v})$ \\
11.III.1401 & Íd. & $(14 \mathrm{v})$ \\
21.V.1401 & Girona & $(11 \mathrm{v}, 12 \mathrm{r})$ \\
30.V.1401 & Palafrugell & $(12 \mathrm{v})$ \\
31.V.1401 & Íd. & $(11 \mathrm{v})$ \\
18.VI.1401 & Girona & $(11 \mathrm{v})$ \\
13.X.1401 & Íd. & $(51 \mathrm{v})$ \\
28.X.1401 & Íd. & $(52 \mathrm{v})$ \\
10.XI.1401 & Aviñón & $(44 \mathrm{r}, 76 \mathrm{v})$ \\
\hline
\end{tabular}

\begin{tabular}{|c|l|l|}
\hline Fecha & Localidad & Folio \\
\hline 26.XI.1401 & Perpiñán & $(49 \mathrm{r})$ \\
24.I.1402 & Girona & $(51 \mathrm{v})$ \\
27.I.1402 & Vic & $(54 \mathrm{r}-\mathrm{v}, 55 \mathrm{r})$ \\
23.II.1402 & Lleida & $(60 \mathrm{v})$ \\
24.II.1402 & Íd. & $(47 \mathrm{v})$ \\
28.II.1402 & Tarragona & $(47 \mathrm{r})$ \\
9.III.1402 & Tortosa & $(62 \mathrm{r}-\mathrm{v}, 63 \mathrm{r})$ \\
21.III.1402 & Valencia & $(64 \mathrm{r})$ \\
29.III.1402 & Íd. & $(64 \mathrm{v}, 66 \mathrm{r})$ \\
31.III.1402 & Íd. & $(62 \mathrm{r}, 65 \mathrm{r})$ \\
3.IV.1402 & Id. & $(67 \mathrm{r}, 68 \mathrm{v})$ \\
14.IV.1402 & Zaragoza & $(72 \mathrm{v}, 73 \mathrm{r})$ \\
18.IV.1402 & Íd. & $(68 \mathrm{v}, 70 \mathrm{r})$ \\
30.IV.1402 & Tarragona & $(59 \mathrm{r})$ \\
5.V.1402 & Lleida & $(59 \mathrm{v})$ \\
6.V.1402 & Íd. & $(47 \mathrm{v})$ \\
25.VIII.1402 & Girona & $(52 \mathrm{r})$ \\
27.VIII.1402 & Íd. & $(53 \mathrm{r})$ \\
13.IX.1402 & Íd. & $(52 \mathrm{r}, 53 \mathrm{r})$ \\
16.IX.1402 & Vic & $(54 \mathrm{r})$ \\
\hline
\end{tabular}

\section{B. SUBCOLECTORES EN LA ÉPOCA DE LA COLECTORÍA GESTIO-}

NADA POR B. RIBALTA:

-Subcolectores de los derechos de la Cámara Apostólica (anatas y procuraciones):

-Elna: [Joan de Ribesaltes, sacristán de St. Joan de Perpiñán]

-Urgell: $\quad$ Francesc d'Aguilar, canónigo

-Girona: $\quad$ Pere Bernat de Canyelles, presbítero

-Vic: Arnau de Condamina, canónigo tesorero

-Barcelona: Bonanat de Segalers, rector de la parroquia de Sant Just

-Tarragona: Joan de Morelló, canónigo prior -Lleida: Jaume de Salines, presbítero Antoni Sartre, rector de Albalat 
-Tortosa: $\quad$ Berenguer Serrat, canónigo

-Valencia: $\quad$ Pere Peregrí, canónigo

-Segorbe: Jaume Navarri, rector de Terriente

-Zaragoza: Guerau Oger, prior de S. Pedro Viejo de Huesca (orden benedictina)

-Huesca: $\quad$ Martín de Odina, prior de Pertusa (diócesis de Lleida)

-Tarazona: $\quad$ Martín de Mengucho, canónigo

-Mallorca: $\quad$ Antoni d'Estany, rector de Alaior

-Subcolectores de décimas ${ }^{1}$ :

Décima de 1393:

-Elna: Joan Jaubert, ardiaca de Conflent

-Barcelona: Pere de Coll, canónigo y sacristán del monasterio de Santa

Maria de l'Estany (diócesis de Vic)

Décima de 1396:

-Vic: $\quad$ Arnau de Condamina, canónigo tesorero

-Barcelona: Joan de Santhilari, presbítero

Décima de 1397:

-Elna: $\quad$ Joan Jaubert, ardiaca de Conflent

-Urgell: $\quad$ Pere d'Aguilar, presbítero de Solsona

-Girona: $\quad$ Felip de Palau, rector del Hospital de la sede de Girona

-Vic: $\quad$ Bernat de Pujol, canónigo

-Barcelona: Bonanat de Segalers, rector de la parroquia de Sant Just de Barcelona

-Tarragona: Joan de Morelló, canónigo/prior de Tarragona

-Lleida: Jaume de Salines, presbítero

-Tortosa: Guillem Riera, rector de Nules

-Valencia: $\quad$ Francesc Martorell, rector de Énova

-Segorbe: $\quad$ Ramon Cabrit, presbítero

-Zaragoza: $\quad$ Antoni Caldes, rector de Pujol (diócesis de Valencia)

-Huesca: $\quad$ Martín de Odina, prior de Pertusa

-Tarazona: Martín de Mengucho, canónigo

-Mallorca: $\quad$ Pere Pellicer, presbítero

1 Por la presente, sólo tenemos en cuenta los nombres que aparecen citados en la fuente utilizada de referencia. No obstante, consultando los registros de décimas conservados en el ACA se obtienen nóminas más completas. 
Décima de 1400-07:

-Elna: $\quad$ Joan de Ribesaltes, sacristán de St. Joan de Perpiñán

-Urgell: $\quad$ Pere d'Aguilar, presbítero beneficiado en la iglesia de Solsona

-Girona: Bernat Descamps, canónigo

-Vic: $\quad$ Bernat de Pujol, canónigo

-Barcelona: Bernat Miret, presbítero (beneficiado en la parroquia de Sant Pere)

-Tarragona: Narcís Astruç, canónigo/ardiaca mayor de Tarragona

-Lleida: Joan Senant, canónigo/sacristán de Lérida

-Tortosa: $\quad$ Guillem Riera, rector de Nules

Vicent Segarra, canónigo

-Valencia: fra Pere Guerau, rector de la parroquia de Sant Bartomeu de Valencia

-Segorbe: Ramon Cabrit, presbítero

-Zaragoza: Jaime Berenguer, canónigo de Jaca

Antonio de Alpertil, canónigo/sacristán de Santa María la Mayor de Zaragoza

-Huesca: $\quad$ Martín de Odina, prior de Pertusa

-Tarazona: Martín de Mengucho, canónigo

-Mallorca: $\quad$ Francesc Negrell, canónigo

C. RENDICIONES DE CUENTAS DE SUBCOLECTORES (por orden cronológico):

\begin{tabular}{|c|c|c|c|c|}
\hline Fol. & Subcolector & $\begin{array}{l}\text { Concepto } \\
\text { tributario }\end{array}$ & $\begin{array}{l}\text { Periodo } \\
\text { cubierto }^{2}\end{array}$ & $\begin{array}{l}\text { Cuantía a } \\
\text { devolver (m.b.) }\end{array}$ \\
\hline 9r & $\begin{array}{l}\text { Joan Jaubert, } \\
\text { subcolector de } \\
\text { Elna }\end{array}$ & Décima de 1397 & {$[8 . X .1400]$} & 329 lb. 3 s. 6 d. \\
\hline $9 \mathrm{r}$ & Ídem & Décima de 1393 & $\begin{array}{l}\ldots \\
{[9 . X .1400]}\end{array}$ & $28 \mathrm{lb}$. \\
\hline $32 r$ & $\begin{array}{l}\text { Martín de } \\
\text { Mengucho, } \\
\text { subcolector de } \\
\text { Tarazona }\end{array}$ & Décima de 1397 & {$\left[\begin{array}{l}\ldots \\
{[9 . X .1400]}\end{array}\right.$} & $121 \mathrm{lb} .16$ s. $10 \mathrm{~d}$ \\
\hline $31 \mathrm{v}$ & Ídem & \begin{tabular}{|l|} 
Vacantes, \\
medias \\
procuraciones
\end{tabular} & [11.X.1400] & $13 \mathrm{lb} .5 \mathrm{~s}$ \\
\hline $18 \mathrm{v}$ & $\begin{array}{l}\text { Joan de } \\
\text { Morelló, } \\
\text { subcolector de }\end{array}$ & $\begin{array}{l}\text { Vacantes y } \\
\text { 'comunitates' }\end{array}$ & \begin{tabular}{|l|} 
1.III.1395 / \\
30.XI.1400
\end{tabular} & $56 \mathrm{lb} .6 \mathrm{~s}$. \\
\hline
\end{tabular}

\footnotetext{
${ }^{2}$ En negrita, la fecha en la que se hizo la rendición de cuentas.
} 


\begin{tabular}{|c|c|c|c|c|}
\hline & Tarragona & & & \\
\hline $22 \mathrm{v}$ & $\begin{array}{l}\text { Berenguer } \\
\text { Serrat, } \\
\text { subcolector de } \\
\text { Tortosa }\end{array}$ & $\begin{array}{l}\text { Anatas o } \\
\text { vacantes }\end{array}$ & \begin{tabular}{|l|} 
27.IV.1398/ \\
14.XII.1400
\end{tabular} & 79 lb. 19 s. 2 d. \\
\hline $23 r$ & Ídem & $\begin{array}{l}\text { Medias } \\
\text { procuraciones }\end{array}$ & $\begin{array}{l}\ldots / \\
14 . X I I .1400\end{array}$ & 89 lb. 14 s. 9 d. \\
\hline $28 \mathrm{r}$ & $\begin{array}{l}\text { Guerau Oger, } \\
\text { subcolector de } \\
\text { Zaragoza }\end{array}$ & $\begin{array}{l}\text { Restas de medias } \\
\text { procuraciones }\end{array}$ & \begin{tabular}{|l|} 
4.IX.1399/ \\
28.I.1401
\end{tabular} & 17 lb. $12 \mathrm{~s}$. \\
\hline $27 v$ & Ídem & $\begin{array}{l}\text { Anatas o } \\
\text { vacantes }\end{array}$ & \begin{tabular}{|l|} 
4.IX.1399 / \\
29.I.1401
\end{tabular} & 247 lb. 10 s. \\
\hline $21 v$ & \begin{tabular}{|l|} 
Jaume de \\
Salines, \\
subcolector de \\
Lérida
\end{tabular} & $\begin{array}{l}\text { Décima (de } \\
1397)\end{array}$ & \begin{tabular}{|l|} 
21.V.1398/ \\
3.II.1401
\end{tabular} & 68 lb. 13 s. 2 d. \\
\hline $21 r$ & Ídem & $\begin{array}{l}\text { Medias } \\
\text { procuraciones }\end{array}$ & \begin{tabular}{|l|} 
21.V.1398 / \\
13.II.1401
\end{tabular} & 68 lb. 13 s. 2 d. \\
\hline $15 r$ & $\begin{array}{l}\text { Bernat de Pujol, } \\
\text { subcolector/com } \\
\text { isario }\end{array}$ & Indet. & $\begin{array}{l}\ldots \\
{[11 . I I I .1401]}\end{array}$ & 20 lb. $12 \mathrm{~s}$. \\
\hline $14 \mathrm{v}$ & \begin{tabular}{|l} 
ídem, \\
subcolector de \\
Vic
\end{tabular} & Décima de 1397 & [11.III.1401] & 169 lb. 6 s. 8 d. \\
\hline $14 \mathrm{r}$ & \begin{tabular}{|l} 
Arnau de \\
Condamina, \\
subcolector de \\
Vic
\end{tabular} & $\begin{array}{l}\text { Anatas, censos, } \\
\text { décima de } 1396- \\
97 \text { y medias } \\
\text { procura-ciones... }\end{array}$ & \begin{tabular}{|l|} 
20.II.1395 / \\
15.V.1401
\end{tabular} & 64 lb. $13 \mathrm{~s}$. \\
\hline $17 \mathrm{v}$ & $\begin{array}{l}\text { Berenguer de } \\
\text { Maçons, } \\
\text { canónigo de } \\
\text { Barcelona } \\
\end{array}$ & $\begin{array}{l}\text { Subsidio del } \\
\text { concilio de } \\
\text { Tarragona } \\
(1398)\end{array}$ & {$[17 . V .1401]$} & 8 s. $8 \mathrm{~d}$. \\
\hline $29 v$ & \begin{tabular}{|l} 
Martín de \\
Odina, \\
subcolector de \\
Huesca
\end{tabular} & $\begin{array}{l}\text { Anatas, medias } \\
\text { procuraciones, } \\
\text { restas de } \\
\text { décimas... }\end{array}$ & \begin{tabular}{|l|} 
18.VI.1398/ \\
17.V.1401
\end{tabular} & 59 lb. $8 \mathrm{~s}$. \\
\hline $33 v$ & $\begin{array}{l}\text { P. Pellicer, } \\
\text { subcolector de } \\
\text { Mallorca }\end{array}$ & Décima de 1397 & $\begin{array}{l}\cdots \\
{[2 . V I I I .1401]}\end{array}$ & $\begin{array}{l}44 \mathrm{lb} .2 \mathrm{~s} .10 \mathrm{~d} \text {. } \\
\text { óbolo }\end{array}$ \\
\hline $50 v$ & $\begin{array}{l}\text { P. d'Aguilar, } \\
\text { subcolector de } \\
\text { Urgel }\end{array}$ & $\begin{array}{l}\text { Restas de la } \\
\text { décima de } 1397\end{array}$ & [27.IX.1401] & 119 lb. 2 s. 8 d. \\
\hline $51 \mathrm{v}$ & $\begin{array}{l}\text { P. Bernat de } \\
\text { Canyelles, } \\
\text { subcolector de }\end{array}$ & $\begin{array}{l}\text { Anatas o } \\
\text { vacantes }\end{array}$ & $\begin{array}{l}\text { 1.V.1398/ } \\
\text { 28.IX.1401 }\end{array}$ & 96 lb. $3 \mathrm{~s}$. \\
\hline
\end{tabular}




\begin{tabular}{|c|c|c|c|c|}
\hline & Gerona & & & \\
\hline $52 \mathrm{r}$ & Ídem & $\begin{array}{l}\text { Medias } \\
\text { procuraciones }\end{array}$ & \begin{tabular}{|l|}
$1397-1399$ \\
[28.IX.1401]
\end{tabular} & 40 lb. 1 s. 11 d. \\
\hline $63 r$ & $\begin{array}{l}\text { G. Riera, } \\
\text { subcolector de } \\
\text { Tortosa }\end{array}$ & Décima de 1397 & [3.X.1401] & 2 lb. 13 s. 7 d. \\
\hline $53 v$ & $\begin{array}{l}\text { Bernat de } \\
\text { Camps, } \\
\text { subcolector de } \\
\text { subsidio }\end{array}$ & $\begin{array}{l}\text { Subsidio de } \\
1395\end{array}$ & $\begin{array}{l}\ldots \\
\text { [24.I.1402] }\end{array}$ & 34 lb. 5 s. 6 d. \\
\hline $64 v$ & $\begin{array}{l}\text { P. Peregrí, } \\
\text { subcolector de } \\
\text { Valencia }\end{array}$ & $\begin{array}{l}\text { Medias } \\
\text { procuraciones }\end{array}$ & \begin{tabular}{|l|} 
20.V.1398/ \\
29.III.1402
\end{tabular} & 97 lb. 6 s. 6 d. \\
\hline $66 r$ & Ídem & $\begin{array}{l}\text { Anatas, censos, } \\
\text { vacantes }\end{array}$ & \begin{tabular}{|l|} 
20.V.1398 / \\
29.III.1402
\end{tabular} & 101 lb. 2 s. 5 d. \\
\hline $67 \mathrm{r}$ & $\begin{array}{l}\text { Jaume Navarri, } \\
\text { subcolector de } \\
\text { Segorbe }\end{array}$ & $\begin{array}{l}\text { Anatas, medias } \\
\text { procuraciones y } \\
\text { décimas }\end{array}$ & $\begin{array}{l}\text { 6.III.1393 / } \\
\text { 3.IV.1402 }\end{array}$ & $121 \mathrm{lb} .18 \mathrm{~s}$. \\
\hline $68 v$ & $\begin{array}{l}\text { Guerau Oger, } \\
\text { subcolector de } \\
\text { Zaragoza }\end{array}$ & \begin{tabular}{|l|} 
Anatas, medias \\
procuraciones y \\
restas... \\
\end{tabular} & \begin{tabular}{|l|} 
28.I.1401/ \\
18.IV.1402
\end{tabular} & 580 lb. 14 s. 6 d. \\
\hline $60 \mathrm{r}$ & \begin{tabular}{|l|} 
Antoni Sartre, \\
subcolector de \\
Lleida \\
\end{tabular} & $\begin{array}{l}\text { No indica } \\
\text { [anatas] }\end{array}$ & .../5.V.1402 & 177 lb. 19 s. 4 d. \\
\hline $70 v$ & $\begin{array}{l}\text { Martín de } \\
\text { Odina, } \\
\text { subcolector de } \\
\text { Huesca }\end{array}$ & $\begin{array}{l}\text { Anatas, medias } \\
\text { procuraciones, } \\
\text { censos y décima }\end{array}$ & $\begin{array}{l}\text { 17.V.1401/ } \\
\text { 18.IV.1402 } \\
\text { [10.VI.1402] }\end{array}$ & 105 lb. 14 s. $10 \mathrm{~d}$ \\
\hline $58 \mathrm{r}$ & $\begin{array}{l}\text { Joan de } \\
\text { Morelló, } \\
\text { subcolector de } \\
\text { Tarragona }\end{array}$ & Anatas & \begin{tabular}{|l|} 
25.XI.1400 / \\
1.VII.1402
\end{tabular} & 50 lb. 6 s. 6 d. \\
\hline $58 \mathrm{v}$ & Ídem & \begin{tabular}{|l|} 
Medias \\
procuraciones
\end{tabular} & $\begin{array}{l}\text { 25.XI.1400/ } \\
\text { 1.VII.1402 }\end{array}$ & 83 lb. 7 s. 11 d. \\
\hline
\end{tabular}

\section{DISTRIBUCIÓN INTERNA DE INGRESOS POR DIOCESIS} (cifras expresadas en libras/sueldos/dineros barc.):

\begin{tabular}{|l|l|l|l|l|l|}
\hline Diócesis & Ejercicio & [anatas] & $\begin{array}{l}\text { Procura- } \\
\text { ciones }\end{array}$ & décimas & $\begin{array}{l}\text { "comuni } \\
\text {-tates" }\end{array}$ \\
\hline \multirow{2}{*}{ Elna } & $1400-01$ & - & - & 717.3 .6 & - \\
\cline { 2 - 6 } & $1401-02$ & - & - & 528.10 & - \\
\hline \multirow{2}{*}{ Urgell } & $1400-01$ & 42 & 635 & 419.1 .6 & 17.13 .2 \\
\cline { 2 - 6 }
\end{tabular}




\begin{tabular}{|c|c|c|c|c|c|}
\hline & 1401-02 & 3.10 & 326.18 & 643.9 .4 & - \\
\hline \multirow[t]{2}{*}{ Girona } & $1400-01$ & 310.1 & 150 & 540.6 & - \\
\hline & $1401-02$ & 404.16 & 40.1 .11 & 720.2 . & 34.5 .6 \\
\hline \multirow[t]{2}{*}{ Vic } & $1400-01$ & 181.13 .4 & 184 & 617.2 .8 & 20.12 \\
\hline & $1401-02$ & 337.16 .10 & 320.13 & 473 & - \\
\hline \multirow[t]{2}{*}{ Barcelona } & 1400-01 & 10 & - & 563.6 .4 & 112.1 .8 \\
\hline & $1401-02$ & 127.10 & 346.13 & 550 & 59 \\
\hline \multirow[t]{2}{*}{ Tarragona } & $1400-01$ & 155.6 & 226.16 .8 & 330 & - \\
\hline & $1401-02$ & 288.11 .6 & 201.12 .11 & 610.10 & - \\
\hline \multirow[t]{2}{*}{ Lleida } & $1400-01$ & - & 123.13 .2 & 453.13 .2 & - \\
\hline & $1401-02$ & 725.15 .4 & 271.14 & 418 & - \\
\hline \multirow[t]{2}{*}{ Tortosa } & $1400-01$ & 217.9.2 & 254.14 .9 & 330 & - \\
\hline & $1401-02$ & 234.17 & 165 & 393.3.7 & - \\
\hline \multirow[t]{2}{*}{ Valencia } & $1400-01$ & 111 & 200 & 529 & 16.7 .2 \\
\hline & 1401-02 & 349.10 & 214.16 .6 & 1141.1 & 370.10 .2 \\
\hline \multirow[t]{2}{*}{ Segorbe } & $1400-01$ & 110 & - & - & - \\
\hline & $1401-02$ & 121.18 & 55 & 27.10 & - \\
\hline \multirow{2}{*}{ Zaragoza } & $1400-01$ & 335.10 & 479.12 & 385 & - \\
\hline & $1401-02$ & 945.18 .6 & 594 & 662.15 & - \\
\hline \multirow[t]{2}{*}{ Huesca } & $1400-01$ & 59.8 & 110 & 275 & - \\
\hline & $1401-02$ & 160.13 .10 & 82.10 & 279.5 & - \\
\hline \multirow[t]{2}{*}{ Tarazona } & $1400-01$ & 13.5 & - & 26.16 .10 & - \\
\hline & $1401-02$ & 22 & - & 313.10 & - \\
\hline \multirow[t]{2}{*}{ Mallorca } & $1400-01$ & 48.1 .6 & 125.3.11 & 192.1 .2 & 268.18 .4 \\
\hline & $1401-02$ & 292.9 & 106.6 .8 & 110 & 267.13 .4 \\
\hline
\end{tabular}

\section{E. RELACIÓN PORMENORIZADA DE CAMBIOS REALIZADOS EN AVIÑÓN:}

\begin{tabular}{|c|c|c|c|c|c|}
\hline Fecha & $\begin{array}{l}\text { Cambista } \\
\text { de Aviñón }\end{array}$ & $\begin{array}{l}\text { Socio en } \\
\text { Barcelona }\end{array}$ & $\begin{array}{l}\text { Transfe } \\
\text {-rencia }\end{array}$ & $\begin{array}{l}\text { For } x \\
\text { franco }\end{array}$ & Moneda barc. \\
\hline $\begin{array}{l}24-\mathrm{III} \\
-1401\end{array}$ & $\begin{array}{l}\text { Andrea de } \\
\text { Besivench }\end{array}$ & $\begin{array}{l}\text { P. de } \\
\text { Bonahora }\end{array}$ & $103 \mathrm{fr}$. & $\begin{array}{l}15 \mathrm{~s} .6 \mathrm{~d} \text {. } \\
\text { óbolo }\end{array}$ & $80 \mathrm{lb}$. \\
\hline íd. & $\begin{array}{l}\text { Andrea de } \\
\text { Thiri, } \\
\text { mercader }\end{array}$ & $\begin{array}{l}\text { Nerio de } \\
\text { Nicholò }\end{array}$ & $300 \mathrm{fr}$. & íd. & 233 lb. 2 s. 6 d. \\
\hline 11-IV & id. & íd. & $300 \mathrm{fr}$. & 15 s. $7 \mathrm{~d}$. & 232 lb. $15 \mathrm{~s}$. \\
\hline 11-V & \multicolumn{4}{|c|}{703 fr. $^{3}$} & 546 lb. 18 s. 3 d. \\
\hline 18-IV & $\begin{array}{l}\text { F. de Prato, } \\
\text { mercader }\end{array}$ & $\begin{array}{l}\text { otro F. de } \\
\text { Prato }\end{array}$ & $300 \mathrm{fr}$. & 15 s. $7 \mathrm{~d}$. & 233 lb. 15 s. \\
\hline
\end{tabular}

${ }^{3}$ El documento correspondiente a la transferencia de dicha cantidad se encuentra regestado en M. RoviRA, Catàleg dels pergamins municipals..., pp. 88-89 (doc. n..$^{\circ} 891$ ). 


\begin{tabular}{|c|c|c|c|c|c|}
\hline íd. & $\begin{array}{l}\text { Andrea de } \\
\text { Thiri }\end{array}$ & $\begin{array}{l}\text { Nerio de } \\
\text { Nicholò }\end{array}$ & $500 \mathrm{fr}$ & 15 s. $8 \mathrm{~d}$. & 391 lb. 13 s. 4 d. \\
\hline $14-\mathrm{V}$ & Íd. & íd. & 500 fr. & íd. & 391 lb. 13 s. 4 d. \\
\hline íd. & $\begin{array}{l}\text { Andrea de } \\
\text { Besivench }\end{array}$ & $\begin{array}{l}\text { P. de } \\
\text { Bonahora }\end{array}$ & $101 \mathrm{fr}$. & 15 s. $8 \mathrm{~d}$. & 79 lb. 6 s. 6 d. \\
\hline íd. & $\begin{array}{l}\text { Miquele de } \\
\text { Simon, } \\
\text { mercader }\end{array}$ & $\begin{array}{l}\text { Filipo de } \\
\text { Lorino }\end{array}$ & 200 fr. & íd. & 157 lb. 1 s. 8 d. \\
\hline $16-\mathrm{V}$ & $\begin{array}{l}\text { Fabrini } \\
\text { Tholosani, } \\
\text { mercader }\end{array}$ & $\begin{array}{l}\text { Filipo } \\
\text { Soldani }\end{array}$ & 500 fr. & $\begin{array}{l}15 \text { s. } 8 \mathrm{~d} \text {. } \\
\text { óbolo }\end{array}$ & 392 lb. 14 s. 2 d. \\
\hline $\begin{array}{l}11-V I \\
-1401 \\
\end{array}$ & \multicolumn{4}{|c|}{$2.101 \mathrm{fr}$. } & $1.646 \mathrm{lb} .4 \mathrm{~s}$. \\
\hline $25-\mathrm{V}$ & $\begin{array}{l}\text { Andrea de } \\
\text { Besivench }\end{array}$ & $\begin{array}{l}\text { P. de } \\
\text { Bonahora }\end{array}$ & $200 \mathrm{fr}$. & $\begin{array}{l}15 \mathrm{~s} .8 \mathrm{~d} \text {. } \\
\text { óbolo }\end{array}$ & 157 lb. 1 s. 8 d. \\
\hline íd. & $\begin{array}{l}\text { Andrea de } \\
\text { Thiri }\end{array}$ & $\begin{array}{l}\text { Nerio de } \\
\text { Nicholò }\end{array}$ & 500 fr. & íd. & 392 lb. 14 s. 2 d. \\
\hline 9-VI & $\begin{array}{l}\text { Miquele de } \\
\text { Simon }\end{array}$ & F. Copó & $200 \mathrm{fr}$. & 15 s. $8 \mathrm{~d}$. & 156 lb. 13 s. 4 d. \\
\hline $10-\mathrm{VI}$ & $\begin{array}{l}\text { Andrea de } \\
\text { Thiri }\end{array}$ & $\begin{array}{l}\text { Nerio de } \\
\text { Nicholò }\end{array}$ & 300 fr. & íd. & $235 \mathrm{lb}$. \\
\hline 21-VI & \multicolumn{4}{|c|}{$1.200 \mathrm{fr}$. } & 941 lb. 9 s. 2 d. \\
\hline 17-VIII & $\begin{array}{l}\text { Fabrini } \\
\text { Tholosani }\end{array}$ & $\begin{array}{l}\text { Filiposo } \\
\text { Soldani }\end{array}$ & $700 \mathrm{fr}$. & $15 \mathrm{s.} 7 \mathrm{~d}$. & 545 lb. 8 s. 4 d. \\
\hline íd. & $\begin{array}{l}\text { Andrea de } \\
\text { Thiri }\end{array}$ & $\begin{array}{l}\text { Nerio de } \\
\text { Nicholò }\end{array}$ & 500 fr. & íd. & 389 lb. 11 s. 8 d. \\
\hline 20-VIII & $\begin{array}{l}\text { Miquele de } \\
\text { Simon }\end{array}$ & $\begin{array}{l}\text { Filipo de } \\
\text { Lorino }\end{array}$ & $250 \mathrm{fr}$. & 15 s. 6 d. & 193 lb. $15 \mathrm{~s}$. \\
\hline íd. & F. de Prato & $\begin{array}{l}\text { Simoni } \\
\text { Andree }\end{array}$ & 250 fr. & íd. & $194 \mathrm{lb} .6 \mathrm{~s}^{4}$ \\
\hline 25-VIII & $\begin{array}{l}\text { Antonio y } \\
\text { Urbano } \\
\text { Alamani, } \\
\text { mercaderes }\end{array}$ & F. Manuel & $300 \mathrm{fr}$. & 15 s. $5 \mathrm{~d}$. & $231 \mathrm{lb} .5 \mathrm{~s}$. \\
\hline íd. & $\begin{array}{l}\text { Andrea de } \\
\text { Thiri }\end{array}$ & $\begin{array}{l}\text { Nerio de } \\
\text { Nicholò }\end{array}$ & $500 \mathrm{fr}$. & íd. & 385 lb. 8 s. 4 d. \\
\hline íd. & Íd. & $\begin{array}{l}\text { Andrea de } \\
\text { Pachi, } \\
\text { mercader }\end{array}$ & 200 fr. & íd. & 154 lb. 3 s. 4 d. \\
\hline íd. & $\begin{array}{l}\text { Dominicus } \\
\text { de Pachi, } \\
\text { mercader }\end{array}$ & íd. & $200 \mathrm{fr}$ & Íd. & 154 lb. 3 s. 4 d. \\
\hline íd. & $\begin{array}{l}\text { Filipus } \\
\text { Malgonelle }\end{array}$ & $\begin{array}{l}\text { Filiposso } \\
\text { Soldani, } \\
\text { mercader }\end{array}$ & 450 fr. & Íd. & 346 lb. 17 s. 6 d. \\
\hline
\end{tabular}

\footnotetext{
${ }^{4}$ Dicha cantidad tiene añadida 1 florín ex pacto.
} 


\begin{tabular}{|c|c|c|c|c|c|}
\hline 15-IX & \multicolumn{4}{|c|}{$3.350 \mathrm{fr}$. } & \multirow{2}{*}{$\begin{array}{l}\mathbf{2 . 5 9 4} \text { lb. } 18 \text { s. } \mathbf{6} \text { d. } \\
115 \text { lb. } 12 \text { s. } 6 \text { d. }\end{array}$} \\
\hline $5-\mathrm{IX}$ & $\begin{array}{l}\text { Andrea } \\
\text { Besivench, } \\
\text { mercader }\end{array}$ & $\begin{array}{l}\text { P. de } \\
\text { Bonahora }\end{array}$ & $150 \mathrm{fr}$. & 15 s. 5 d. & \\
\hline 6-IX & $\begin{array}{l}\text { no indica } \\
\text { (en blanco) }\end{array}$ & $\begin{array}{l}\text { Filiposso } \\
\text { Soldani }\end{array}$ & 400 fr. & íd. & 308 lb. 6 s. 8 d. \\
\hline 12-IX & Pere Maries & $\begin{array}{l}\text { Jaume } \\
\text { Biure, } \\
\text { draper }\end{array}$ & $150 \mathrm{fr}$. & 15 s. 3 d. & 114 lb. 7 s. 6 d. \\
\hline íd. & $\begin{array}{l}\text { Andrea de } \\
\text { Besivench }\end{array}$ & $\begin{array}{l}\text { P. de } \\
\text { Bonahora }\end{array}$ & $200 \mathrm{fr}$. & íd. & 152 lb. $10 \mathrm{~s}$. \\
\hline íd. & $\begin{array}{l}\text { Andrea de } \\
\text { Thiri }\end{array}$ & $\begin{array}{l}\text { Nerio de } \\
\text { Nicholò }\end{array}$ & $300 \mathrm{fr}$. & íd. & 228 lb. $15 \mathrm{~s}$. \\
\hline 13-IX & $\begin{array}{l}\text { Antonio y } \\
\text { Urbano } \\
\text { Alamani, } \\
\text { mercaderes }\end{array}$ & F. Manuel & $100 \mathrm{fr}$. & íd. & 76 lb. $5 \mathrm{~s}$. \\
\hline $\begin{array}{l}3-X \\
-1401 \\
\end{array}$ & & & $1.300 \mathrm{fr}$ & & 995 lb. 6 s. 8 d. \\
\hline 21-IX & $\begin{array}{l}\text { Andrea de } \\
\text { Thiri }\end{array}$ & $\begin{array}{l}\text { Nerio de } \\
\text { Nicholò }\end{array}$ & $500 \mathrm{fr}$. & 15 s. 3 d. & 381 lb. $5 \mathrm{~s}$. \\
\hline 27-IX & $\begin{array}{l}\text { Miquele de } \\
\text { Simon, } \\
\text { mercader }\end{array}$ & F. Manuel & $660 \mathrm{fr}$. & íd. & $503 \mathrm{lb} .5 \mathrm{~s}$. \\
\hline íd. & $\begin{array}{l}\text { Fredericus } \\
\text { Imperiali, } \\
\text { mercader }\end{array}$ & $\begin{array}{l}\text { P. de } \\
\text { Galamany }\end{array}$ & $350 \mathrm{fr}$. & íd. & 266 lb. 17 s. 6 d. \\
\hline íd. & $\begin{array}{l}\text { Andrea de } \\
\text { Besivench, } \\
\text { mercader }\end{array}$ & $\begin{array}{l}\text { P. de } \\
\text { Bonahora }\end{array}$ & $208 \mathrm{fr}$. & íd. & $158 \mathrm{lb} .12 \mathrm{~s}$. \\
\hline $1-\mathrm{X}$ & $\begin{array}{l}\text { Andrea de } \\
\text { Thiri }\end{array}$ & $\begin{array}{l}\text { Nerio de } \\
\text { Nicholò, } \\
\text { mercader }\end{array}$ & $300 \mathrm{fr}$. & $15 \mathrm{~s}$. & $225 \mathrm{lb}$. \\
\hline \multirow[t]{2}{*}{$\begin{array}{l}10-X I \\
-1401\end{array}$} & \multicolumn{4}{|c|}{$2.018 \mathrm{fr}$. } & 1.534 lb. 19 s. 6 d. \\
\hline & entrega en & efectivo $=$ & $2.600 \mathrm{fr}$ & $15 \mathrm{~s}$. & $1.950 \mathrm{lb}$. \\
\hline
\end{tabular}

\begin{tabular}{|l|l|l|l|l|l|}
\hline Fecha & $\begin{array}{l}\text { Cambista } \\
\text { de Aviñón }\end{array}$ & $\begin{array}{l}\text { Socio en } \\
\text { Barcelona }\end{array}$ & $\begin{array}{l}\text { Transfe } \\
\text {-rencia }\end{array}$ & $\begin{array}{l}\text { For x } \\
\text { franco }\end{array}$ & Moneda barc. \\
\hline $\begin{array}{l}\text { 1-II } \\
-1402\end{array}$ & $\begin{array}{l}\text { P. Maries, } \\
\text { mercader }\end{array}$ & $\begin{array}{l}\text { Joan } \\
\text { Sesavaces y } \\
\text { Pere Serra, } \\
\text { mercaderes }\end{array}$ & 1.000 fr. & $15 \mathrm{s.} 10 \mathrm{~d}$. & $791 \mathrm{lb} .13 \mathrm{~s} .4 \mathrm{~d}$. \\
\hline íd. & $\begin{array}{l}\text { [llevados } \\
\text { por Joan de } \\
\text { Vallterra] }\end{array}$ & 500 esc. & $\begin{array}{l}18 \mathrm{~s} . \mathrm{x} \\
\text { escudo }\end{array}$ & $450 \mathrm{lb}$. \\
\hline
\end{tabular}




\begin{tabular}{|c|c|c|c|c|c|}
\hline 8 -II & Pere Maries & $\begin{array}{l}\text { Joan } \\
\text { Sesavaces y } \\
\text { Pere Serra }\end{array}$ & 1.000 fr. & 15 s. 10 d. & 791 lb. 13 s. 4 d. \\
\hline & id. & íd. & $1.500 \mathrm{fr}$. & 15 s. 9 d. & $1.181 \mathrm{lb} .5 \mathrm{~s}$. \\
\hline $\begin{array}{l}31-\text { III } \\
-1402 \\
\end{array}$ & \multicolumn{4}{|c|}{$\begin{array}{l}4.066 \mathrm{fr} \text {. } \\
10 \text { gros. }\end{array}$} & $3.214 \mathrm{lb} .11 \mathrm{s.} 8 \mathrm{~d}$. \\
\hline 8 -III & $\begin{array}{l}\text { Andrea de } \\
\text { Thiri }\end{array}$ & $\begin{array}{l}\text { Nerio de } \\
\text { Nicholò }\end{array}$ & $500 \mathrm{fr}$. & 15 s. 8 d. & 391 lb. 13 s. 4 d. \\
\hline íd. & $\begin{array}{l}\text { Fabrini } \\
\text { Tholosani }\end{array}$ & $\begin{array}{l}\text { P. Tarquini, } \\
\text { mercader }\end{array}$ & $500 \mathrm{fr}$. & $\begin{array}{l}15 \mathrm{~s} .8 \mathrm{~d} . \\
\text { óbolo } \\
\end{array}$ & 382 lb. 14 s. 2 d. \\
\hline $\begin{array}{l}22-V \\
-1402\end{array}$ & \multicolumn{4}{|c|}{$1.000 \mathrm{fr}}$. & 784 lb. 7 s. 6 d. \\
\hline \multirow[t]{2}{*}{$22-\mathrm{V}$} & $\begin{array}{l}\text { Filipus } \\
\text { Malgonelle }\end{array}$ & $\begin{array}{l}\text { Filiposso } \\
\text { Soldani }\end{array}$ & $500 \mathrm{fr}$. & 15 s. 7 d. & 389 lb. 11 s. 8 d. \\
\hline & Pere Maries & $\begin{array}{l}\text { Joan } \\
\text { Sesavaces y } \\
\text { Pere Serra }\end{array}$ & $1.500 \mathrm{fr}$. & 15 s. 9 d. & $1.181 \mathrm{lb} .5 \mathrm{~s}$. \\
\hline $\begin{array}{l}30-V I \\
-1402 \\
\end{array}$ & \multicolumn{4}{|c|}{$2.000 \mathrm{fr}$. } & 1.570 lb. 16 s. $8 \mathrm{~d}$. \\
\hline $24-\mathrm{VI}$ & $\begin{array}{l}\text { Andrea de } \\
\text { Thiri, } \\
\text { mercader }\end{array}$ & $\begin{array}{l}\text { Nerio de } \\
\text { Nicholò }\end{array}$ & $400 \mathrm{fr}$. & 15 s. 8 d. & 313 lb. 6 s. 8 d. \\
\hline íd. & F. de Prato & $\begin{array}{l}\text { Simon } \\
\text { Andree }\end{array}$ & $400 \mathrm{fr}$. & íd. & 313 lb. 6 s. 8 d. \\
\hline íd. & $\begin{array}{l}\text { Lorenzo de } \\
\text { Dynoço }\end{array}$ & $\begin{array}{l}\text { Rossell } \\
\text { Soldani }\end{array}$ & $200 \mathrm{fr}$. & íd. & 156 lb. 13 s. 4 d. \\
\hline $1-\mathrm{VII}$ & $\begin{array}{l}\text { Andrea de } \\
\text { Thiri }\end{array}$ & $\begin{array}{l}\text { Nerio de } \\
\text { Nicholò }\end{array}$ & $500 \mathrm{fr}$. & íd. & 391 lb. 13 s. 4 d. \\
\hline 5 -VII & $\begin{array}{l}\text { Henricus de } \\
\text { Rovilasco }\end{array}$ & $\begin{array}{l}\text { G. de Bagat, } \\
\text { mercader }\end{array}$ & $700 \mathrm{fr}$. & íd. & 548 lb. 6 s. 8 d. \\
\hline $15-\mathrm{VII}$ & P. Maries & $\begin{array}{l}\text { Jaume y } \\
\text { Joan } \\
\text { Maçana, } \\
\text { cambistas }\end{array}$ & $1.000 \mathrm{fr}$. & $\begin{array}{l}15 \mathrm{~s} .8 \mathrm{~d} . \\
\text { óbolo }\end{array}$ & 785 lb. 8 s. 4 d. \\
\hline $24-\mathrm{VII}$ & F. de Prato & $\begin{array}{l}\text { Simon } \\
\text { Andree }\end{array}$ & $600 \mathrm{fr}$. & 15 s. 7 d. & 467 lb. $10 \mathrm{~s}$. \\
\hline \multirow[t]{2}{*}{ íd. } & $\begin{array}{l}\text { Andrea de } \\
\text { Thiri }\end{array}$ & $\begin{array}{l}\text { Nerio de } \\
\text { Nicholò }\end{array}$ & $500 \mathrm{fr}$. & íd. & 389 lb. 11 s. 8 d. \\
\hline & $\begin{array}{l}{[\text { Pere }} \\
\text { Maries }]\end{array}$ & $\begin{array}{l}\text { Joan } \\
\text { Sesavaces y } \\
\text { Pere Serra] }\end{array}$ & $500 \mathrm{fr}$. & 15 s. 9 d. & 393 lb. $15 \mathrm{~s}$. \\
\hline $\begin{array}{l}\text { 8-VIII- } \\
1402 \\
\end{array}$ & \multicolumn{4}{|c|}{$4.800 \mathrm{fr}}$. & $3.759 \mathrm{lb} .11 \mathrm{s.} 8 \mathrm{~d}$. \\
\hline 25-VIII & Pere Maries & $\begin{array}{l}\text { Jaume y } \\
\text { Joan } \\
\text { Maçana, } \\
\text { cambistas }\end{array}$ & $700 \mathrm{fr}$. & 15 s. 1 d. & 527 lb. 18 s. 4 d. \\
\hline
\end{tabular}




\begin{tabular}{|c|c|c|c|c|c|}
\hline íd. & $\begin{array}{l}\text { Andrea de } \\
\text { Thiri }\end{array}$ & $\begin{array}{l}\text { Nerio de } \\
\text { Nicholò }\end{array}$ & $300 \mathrm{fr}$. & íd. & 226 lb. $5 \mathrm{~s}$. \\
\hline 30-VIII & $\begin{array}{l}\text { Fabrini } \\
\text { Tholosani }\end{array}$ & F. de Simon & $300 \mathrm{fr}$. & íd. & 226 lb. 5 s. \\
\hline íd. & $\begin{array}{l}\text { Lorenzo de } \\
\text { Dynosso }\end{array}$ & íd. & $500 \mathrm{fr}$. & íd. & 377 lb. 1 s. 8 d. \\
\hline íd. & $\begin{array}{l}\text { Filipus de } \\
\text { Malgonelle }\end{array}$ & $\begin{array}{l}\text { Filipus } \\
\text { Soldani }\end{array}$ & $900 \mathrm{fr}$. & íd. & 678 lb. $15 \mathrm{~s}$. \\
\hline 31-VIII & $\begin{array}{l}\text { Lorenzo [de } \\
\text { Dynosso] }\end{array}$ & $\begin{array}{l}\text { Andrea de } \\
\text { Pachi }\end{array}$ & $500 \mathrm{fr}$. & $15 \mathrm{~s}$. & $375 \mathrm{lb}$. \\
\hline 2-IX & $\begin{array}{l}\text { Fabrini } \\
\text { Tholosani }\end{array}$ & $\begin{array}{l}\text { Tomás } \\
\text { Taquini }\end{array}$ & $300 \mathrm{fr}$. & íd. & $225 \mathrm{lb}$. \\
\hline íd. & $\begin{array}{l}\text { Lorenzo de } \\
\text { Dynoço }\end{array}$ & $\begin{array}{l}\text { Andrea de } \\
\text { Pachi }\end{array}$ & $300 \mathrm{fr}$. & íd. & $225 \mathrm{lb}$. \\
\hline 5-IX & $\begin{array}{l}\text { Andrea de } \\
\text { Thiri }\end{array}$ & $\begin{array}{l}\text { Nerio de } \\
\text { Nicholò }\end{array}$ & $200 \mathrm{fr}$. & íd. & $150 \mathrm{lb}$. \\
\hline & $\begin{array}{l}\text { Pere } \\
\text { Maries }]\end{array}$ & $\begin{array}{l}{[\text { Joan }} \\
\text { Sesavaces y } \\
\text { Pere Serra] }\end{array}$ & $1.000 \mathrm{fr}$. & 15 s. 9 d. & 787 lb. $10 \mathrm{~s}$. \\
\hline $\begin{array}{l}10-X \\
-1402 \\
\end{array}$ & \multicolumn{4}{|c|}{$5.000 \mathrm{fr}$. } & $2.798 \mathrm{lb} .15 \mathrm{~s}$ \\
\hline íd. & $\begin{array}{l}\text { [llevados } \\
\text { por Jaume } \\
\text { de Prades] }\end{array}$ & & $\begin{array}{l}1.500 \\
\text { florines }\end{array}$ & & $825 \mathrm{lb}$. \\
\hline $14-\mathrm{XI}$ & $\begin{array}{l}\text { Andrea de } \\
\text { Thiri }\end{array}$ & $\begin{array}{l}\text { Nerio de } \\
\text { Nicholò }\end{array}$ & $700 \mathrm{fr}$. & 15 s. 7 d. & 545 lb. 8 s. 4 d. \\
\hline íd. & $\begin{array}{l}\text { Antonio y } \\
\text { Urbani } \\
\text { Alamani }\end{array}$ & F. Manelli & $100 \mathrm{fr}$. & $\begin{array}{l}15 \mathrm{~s} .7 \mathrm{~d} . \\
\text { óbolo }\end{array}$ & 78 lb. 2 s. 6 d. \\
\hline $23-\mathrm{XI}$ & íds. & íd. & $300 \mathrm{fr}$. & íd. & 234 lb. 7 s. 6 d. \\
\hline \multirow[t]{2}{*}{ 28-XI } & $\begin{array}{l}\text { Pere Maries, } \\
\text { mercader } \\
\text { catalán }\end{array}$ & $\begin{array}{l}\text { Joanet } \\
\text { Sesavaces y } \\
\text { Pere Serra, } \\
\text { mercaderes } \\
\end{array}$ & $1.000 \mathrm{fr}$. & 15 s. $8 \mathrm{~d}$. & 783 lb. 6 s. 8 d. \\
\hline & Î́d. & íds. & $1.500 \mathrm{fr}$. & $15 \mathrm{s.} 9 \mathrm{~d}$ & $1.181 \mathrm{lb} .5 \mathrm{~s}$. \\
\hline $\begin{array}{l}13-X I I \\
-1402 \\
\end{array}$ & & & $3.600 \mathrm{fr}$. & & $2.822 \mathrm{lb} .10 \mathrm{~s}$ \\
\hline $\begin{array}{l}8-\mathrm{V}- \\
1403^{5}\end{array}$ & Pere Maries & $\begin{array}{l}\text { Joan } \\
\text { Sesavaces y } \\
\text { Pere Serra }\end{array}$ & $3.000 \mathrm{fr}$. & $\begin{array}{l}15 \mathrm{~s} .10 \mathrm{~d} . \\
\text { óbolo }\end{array}$ & $2.381 \mathrm{lb} .5 \mathrm{~s}$. \\
\hline
\end{tabular}

${ }^{5} \mathrm{Tal}$ transferencia, realizada con posterioridad al cierre de la colectoría estudiada, se encuentra en M. RoviRA, Catàleg dels pergamins municipals..., pp. 139-140 (doc. n. ${ }^{\circ}$ 958). La correspondiente letra de cambio fue emitida en Aviñón el 27.IV.1403. 